\title{
Walter Andreesen
}

\section{Untersuchungen zur Translation von Substantiven} zu Adjektiven im Altrussischen

Verlag Otto Sagner München - Berlin - Washington D.C.

Digitalisiert im Rahmen der Kooperation mit dem DFG-Projekt „Digi20“

der Bayerischen Staatsbibliothek, München. OCR-Bearbeitung und Erstellung des eBooks durch den Verlag Otto Sagner:

http://verlag.kubon-sagner.de

( $)$ bei Verlag Otto Sagner. Eine Verwertung oder Weitergabe der Texte und Abbildungen, insbesondere durch Vervielfältigung, ist ohne vorherige schriftliche Genehmigung des Verlages unzulässig.

«Verlag Otto Sagner» ist ein Imprint der Kubon \& Sagner GmbH. 


\title{
SLAVISTISCHE BEITRÄGE
}

\author{
BEGRÜNDET VON ALOIS SCHMAUS
}

HERAUSGEGEBEN VON HENRIK BIRNBAUM UND JOHANNES HOLTHUSEN

REDAKTION: PETER REHDER

Band 60 


\section{WALTER ANDREESEN}

\section{UNTERSUCHUNGEN ZUR TRANSLATION VON SUBSTANTIVEN ZU ADJEKTIVEN IM ALTRUSSISCHEN}

\section{VERLAG OTTO SAGNER - MÜNCHEN 1972}




\section{Esyorlis ho \\ Gisots stblioti:at}

irionction

ISBN 3876900697

Copyright by Verlag Otto Sagner, München 1972

Abtellung der Firma Kubon und Sagner, München

Druck: Alexander GroBmann

8 Múnchen 19, YsenburgstraBe $7^{I}$ 
Inhal tsverzelchnis

Abkürzungsverzelchnts

S. 6

vorbemerkung

S. 7

A. Allgemeiner Teil

S. 9

$I$ - Ziel der Arbeit $(\S 1$ - 6)

S. 9

II - Zur Translationslehre Tesnieres ( $\$ 7$ - 14)

S. 17

III- Adjektive als Determinanten ( $\S 15$ - 16)

S. 25

IV - Zum Problem der Beziehungen zwischen Syntax, Wortbildung und Morphologie ( $\S 17$ - 22)

S. 29

$v$ - Die konkurrierenden adjektivbildenden Translative und Möglichkelten elner Differenzierung $(\S 23-30)$

S. 39

B. Spezieller Teil

S. 51

I - Translation $0>A$ mit rein syntaktischer Funktion $(\S 31-57)$

S. 51

II - Translation $O>A$ mit zusätzlicher Beziehungsbedeutung ( $\$ 58-64)$

S. 89

III- Translation $0>A$ mit Bedeutungswandel zum reinen Eigenschaftsbegriff ( $\$ 65$ - 69)

S. 99

IV - Die Suffixe - bn- und -bsk- ( $(70-75)$

S. 105

$v$ - Translation $0>A$ bel zusammengesetzten Adjektiven ( $\$ 76-81$ )

S. 114

VI - Grammatische Fixierung des Transferendums $(\S 82-84)$

S. 121

VII- Semantische Fixierung des Transferendums $(\S 85-87$ )

S. 131

Schlubbemerkung

S. 141

Literaturverze1chnis

S. 143 
Abkurzungsverzeichnis der benutzten Quelien

Hyp. Ipat'erskaja letopis'. Polnoe sobranie russkich letopisej, Bd. II. Nachdr. Moskva 1962

Ch. Varianten der gleichen Chronik: Chlðbnikovskif spisok P. (Ch.) und Pogodinskij spisok (P.)

I. Text des Igorliedes in: Slovar'-spravolnik "slova o polku Igoreve". Moskva, Leningrad 1965

Izb. Izbornik I076 goda. Moskva 1965

L. Lavrent'evskaja lětopis'. Polnoe sobranie russkich letopisej, Bd. I. Nachdr. Moskva 1962

A. Varianten der gleichen Chronik: Rukopis' b. Moskovgkoj

R. Duchovnoj Akademij (A.), Kadzivilovskij spisok (R.),

T. Troickij spisok (T.)

L.L. Povest' vremennych let. Podgotorka teksta D. S.

lichaceva. Moskva, Leningrad 1950

Pat. Das Paterikon des Kiever Hühlenklosters. Nach der Ausgabe von D. Abramovid neu herauggegeben von Dmitrij Tschižewskij. München 1964

Sr. Sreznevskij, J. J.: Materialy dija slovarja drevnerusskago jazyka, Bd. I-III. Nachdruck der Ausgabe Sanktpeterburg 1893-1912. Moskva 1958 


\section{Vorbemerkung}

Auf eine längere Elnleltung ist in dieser Arbeit bewußt verzichtet worden. Stattdessen wird eine Gliederung in einen allgemeinen und speziellen Teil vorgenommen. Dabei ist der allgemeine Teil nicht etwa als ein Einleitungsersatz mit mehr oder weniger unverbindlichem Inhalt anzusehen, vielmehr bestimmten Gegenstand und Ergebnisse der Untersuchung die Wahl der Methode. Ursprüglich war vorgesehen, die Konkurrenz der sogenannten Possessivadjektive mit dem Genitivus bzw. Dativus possessionis zu untersuchen. Sehr bald stellte sich heraus, das 1. schon der Begriff "Possessivadjektive", so wie er insbesondere in den russischen Grammatiken gebraucht wird, nicht haltbar ist und 2. der Kreis der"Konkurrenten" erheblich erweltert werden muste, wollte man von der usprüglichen Vorstellung konkurrierender "possessiver" Fugungen abgehen. Es musten also alle Fügungen untersucht werden, in denen zwei Substanzen zueinander in Beziehung stehen, wobei die Frage der Mittel, wie diese Beziehungen hergestellt werden und ihre Konkurrenz im Vordergrund stehen. Die Frage nach dem determinierenden Adjektiv und dessen Bildung bedingte gleichzeltig die Frage nach dem Determinatum. Was Wortbildun! und Syntax im klassischen Sinne umfassen, konnte also nicht getrennt werden. Dies bedingte einerseits eine ge wisse Einengung in der Auswahl aus einer groBen Fulle an Material, andererseits eine stärkere Betonung methodischer Aspekte. Die "Eléments de syntaxe structurale" von Tesnière waren die entscheidende Hilfe. Für die Arbeit gilt der Satz André Martinets.: "On doit donc renoncer à presenter, dans un seul et meme ouvrage, l'ensemble des doctrines qui ont cours parmi les linguistes contemporains." Aus diesem Grunde wird auch darauf verzichtet, sämtliche Autoren, die zum gleichen Thema ähnliches zu sagen hatten, ausfuhrlich zu zitieren. Entscheidend war der praktische wert fur die vorliegende Arbelt.

Fragen der Genese wurden weitgehend ausgeklammert. Die Suffixe sind aus technischen Grünen - wie allgemein ublich - in ihrer historischen Gestalt angefuhrt. 
Dae Materlal der Arbelt stammt aue der Laurentiue-Chronik, der Hypatius-Chronik, dem Izbornik von 1076, dem Kiever Paterikon und schließlich aus den Materialy Sreznevakijo. Die genannten Sprachdenkmiler sowie die Belegatelien aus den Materialy kann man als einer im wesentlichen elnheltilchen Sprache zugehörig betrachten, wonn man davon ausgeht, das die altrussische Schriftsprache ein von Kirchenslarischen stark beeinflubtes konservatives System war, welches Aussagen uber die gesprochene russische Sprache erschwert.

Ubersetzungen sind nur dort gegeben, wo sio der Hervorhebung dienen oder Unterschiede zur deutschen Sprache sichtbar machen sol1en.

Die angefuhrten Belege wurden $z$. $T$. gebessert bzw. Abkurzungen aufgelöst, sofern dies Im Hinblick auf den Leser zweckdienlich schien.

Das Literaturverzelchnis enthäl nur solche Arbelten, die tatskchlich fur die vorliegende Arbeit benutzt wurden. 


\section{A. Allgemeiner Toll}

I - Ziel der Arbeit

\$1. "Genitiv und Adjektiv" ist der Titel eines im Jahr 1908 erschienenen Beitrago von J. Wackernagel ${ }^{1}$. Seltdem hat man - ich immer wieder dieses Themas angenonmen. Bei den olavischen Forschern finden sich des öfteren Hinwelse auf das Phänomen der Konkurrenz von Genitiv und Adjektiv in den allgemein bekannten Handbüchern von Miklosich, Vaillant, Vondrak, Sachmatov und Isakenko. Es wird wohl kaum eine historische Grammatik des Kussischen geben, die nicht zumindest am Rande auf dieses Problem einginge.

Gerade in den slavischen Sprachen ist die Konkurrenz zwischen Genitiv und den - wie man sie bisher zu nennen pflegte "Possessivadjektiven" besonders auffállig. In der Tat hat man sich dieses Themas in seiner Gesamtheit nicht angenommen, stellt es doch eine Fulle von schwierigen methodischen Problemen. Im Laufe des letzten Jahrzehntes sind dre1 Aufsatze von Zverkovskaja erschienen ${ }^{2}$, in ihnen befaBt sich die Autorin aber aussohlieblich mit der Konkurrenz von einigen Suffixen im Altrussischen untereinander, nichtsuffixale Konkurrenten werden ausgeschlossen. Ganz ahnlich geschieht dies in der auf

1Hackernagel, Jacobs Genitiv und Adjektiv. In: Mblanges de linquistique offerts à F. de Saussure. Paris 1908 .

${ }^{2}$ Zverkovokaja, N. P.: Prilagatel'nye s ouffiksami -ov- 1 -ovbn- $v$ drevnerusskom jazyke. In: Iotorikeskaja grammatika 1 leksikologija russkogo jazyka. Moskva 1962. Dieselbe: Parallel'noe obrazovanie prilagatel'nych s suffiksami -bn- 1 -bsk- $v$ drevnerusskom jazyke. In: Issledovanija po lstoriteskoj leksikologil drevnerusskogo jazyka. Moskva 1964. Dieselbes Parallel'nye prilagatel'nye suffiksami -ov- 1 -bn-. In: Leksikologija 1 slovoobrazovanie drevnerusskogo jazyka. Moskva 1966. 
diesem Geblet besten Arbeit von Brodowska-Honowska "Slowotworstwo przymiotnika w Jqzyku staro-cerkiemoslowlahskim" 3. Sowohl bel Zverkovskaja als auch bel BrodowskaHonowska werden Fragen der Genese mitbehandelt, was nicht zu neuen Gesichtspunkten fuhrt, sondern lm wesentlichen eine Wiederholung der Erkenntnisse darstellt, die ihren Niederschlag in den entsprechenden Handbuchern von BrugmannDelbrick, Hirt, Meillet, Miklosich, Vaillant und Vondrak finden. Erwähnt werden mus hier ferner der Aufsatz von R. Veterka "Ke konkurencl adnominklniho genitivu a adjektivu v staroslovinsting". 4 Dieser Aufsatz befaBt sich speziell mit dem Problem der Konkurrenz von Genitiv und Adjektiv Im Altkirchenslavischen. Elnige Ergebnisse dieses Aufsatzes waren indessen schon vorher bekannt. So weib man, daB zum Ausdruck der adnominalen Beziehungen in den slavischen Sprachen das Adjektiv weit häufiger gebraucht wird als der Genitiv. Es versteht sich auch, daß von substantivierten Adjektiven naturlich nicht nochmals Adjektive mittels Suffix gebildet werden, sondern dann eben der Genitiv gebraucht werden muB. Ebenso ist der Genitiv in sogenanter quantitativer Bedeutung kein Konkurrent der Adjektive. Man wird sich also in einer Untersuchung auf die Fälle stutzen, wo adnominaler Genitiv und Adjektiv - beide Begriffe werden hier im traditionellen Sinne gebraucht - wirklich Konkurrenten sein können.

\$2. Zudem muß man berücksichtigen, daß der Kreis der Konkurrenten weit mehr umfaBt als nur Genitiv und Adjektiv. Man denke nur an den zum Beispiel im Altkirchenslavischen häufig gebrauchten adnominalen Dativ. Wie groB dieser Krels sein kann, sisht man besonders deutlich an der slavischen Uber-

3Brodowska-Honowska, Maria: Slowotwbrstwo przymiotnika w Jezyku staro-cerkiewno-slowlahskim. Wroclaw 1960.

4

In: Sbornfk prac1 filosofické fakulty Brnłnské university 6 (1937), S. 25 ff. 
setzungsilteratur. Wo das Griechische belspielswelse Komposita verwendet, erscheinen in der tbersetzung sehr oft adjektivische Fügungen und gerade dies kann das Zelchen für eine gute, den slavischen Sprachen gemäBe Ubersetzung sein. Das Slavische zeigt ja bekanntlich im Gegensatz zu anderen Sprachen eine grobe Vorliebe für den Gebrauch des Adjektive gegenuiber dem Genitiv oder der Komposition. DaB sich sowohl im Altkirchenslavischen als auch im Altrussischen eine Fulle von dem Griechischen nachgebildeten Komposita findet, ist nur ein Beweis dafúr, daß in diesen fälien - melstens handelt es sich um Termini der Gelehrtensprache bzw. der Theologen wie богословьць, образоломитель, законодавьць - die Ubersetzer sich nicht von der griechischen Vorlage befreien konnten. Kurt Schumann weist in seiner Arbeit "Die griechischen Lehnbildungen und Lehnbedeutungen im Altbulgarischen" 5 mit Recht darauf hin, daß es das Zeichen einer guten tibersetzung ist, griechische wie auch deutsche Komposita aufzulösen und durch syntaktische Verbindungen (Adjektiv + Substantiv) zu ersetzen bzw. mit Hilfe von Suffixen Ableitungen aus einem der Kompositionselemente zu bilden: "Nach diesem Gesichtspunkt sind die dem Deutschen nachgebildeten Formen tsch, paromifn 'Dampfmuhle', rychlovlak und skr. brzovoz 'Schnellzug' unslavische Bildungen, sie werden als fremd und unschön empfunden. Dem slavischen Sprachgeist entsprechen dagegen tsch. parni mlfn, rychlik, skr. parni mlin, brzi voz, poln. pocigg pobpleszny, russ. parovaja mel'nica." 6

\$3. Wackernagel bezieht sich in seinem bereits erwähnten Aufsatz in erster Linie auf das Griechische und Lateinische. Er hält die adjektivischen Konstruktionen für die älteren, das Vordringen des adnominalen Genitivs fur einen "Fortschritt": "Yenn man sich der umständlichen Bildung eines Adjektivs immer mehr entschlägt, wo ein einfaches Verhältnis

5schumann, Kurt: Die griechischen Lehnbildungen und Lehnbedeutungen im Altbulgarlschen. Berlin 1958.

6 ebenda, S. 6 . 
zweler Substant1v-Begriffe auszudrücken 1st". 7 Wackernagel meint, os sel ein Charakteristikun der slavischen Sprachen, das ihnen dieser "Fortschritt" fremd sei und sie in der Bildung "possessiver Adjektive viellelcht uber das ursprunglich Gegebene hinausgegangen" selen. Eine solche geradezu teleologische Betrachtungsweise wird man nicht akzeptieren können. Eine Sprache als System unterliegt keiner wertung. Im Gegensatz zu Wackernagel und Delbrück hált Hirt den adnominalen Genitiv fur blter als das attributive Adjektiv. Nach Hirts Auffassung liegt in Formen wie lat. Marci puer, faenus argent1, fines agri, belli fluctus u. a. ein Kasus indefinitus vor. Die Fügungen entsprächen in gewissem Sinne einer Zusammensetzung. An diese Formen auf -1-träten "Determinativen wie etwa "-len, "-11", was schlieblich zu Bildungen fuhrte, "die dann hinten flektiert werden", $z$. B. pueri-les anni, seni-1is aetas u. dgl.

Im Verlaufe dieser Arbeit wird zu zeigen sein, daB die Vielfalt der Müglichkeiten, das Verhältnis zweier Substantiv-Begriffe auszudricken, nicht Ausdruck der Unfähigke1t zur Vereinheitlichung von im System gleichberechtigt nebeneinanderstehenden Einheiten bedeuten muB, sondern auch eine gewisse Differenzierung zum Ausdruck bringen kann. Natürlich bestehen bel einer großen Fulle von ähnlichen sprachlichen Einheiten Uberschneldungen in der Funktion, d. h. wenn verschiedene adjektivbildende Suffixe gebraucht werden, so kann dies einerseits Differenzierung bedeuten. Diese Differenzierung muB aber nicht immer durchgefuhrt sein. Sie ist meistens nicht absolut scharf durchgefuhrt, so daB wir andererseits wieder dem Phanomen des Synkretismus bzw. der Neutralisation gegenuberstehen.

Wie die Geschichte der russischen Sprache bewelst, hat ja der Genitiv erheblich an Bedeutung gewonnen, was Jedoch noch nicht fur die Periode des Altrussischen bis etwa zum 16. Jahrhundert

7 Hackernagel, a.a.0., s. 146 .

${ }^{8}$ Hirt, Hermann: Indogermanische Grammatik, Bd. VI, Heidelberg 1934, S. 109 f. 
hin gilt. Bis zu welchem Grade fremdsprachlicher EinfluB verantwortlich gemacht werden kann, mubte noch genauer geklärt werden. Jedenfalls ist auch der Gebrauch bestimmter Adjektive, vor allem der sogenannten "Possessivadjektive", die man der Volkssprache zurechnet, im modernen Russisch ein Mittel der Differenzierung. In dem meisterhaften Roman von A. Tolstoj "Petr I" beispielsweise dienen bestimmte suffixal gebildete Adjektive, nămlich die auf -ov-, -in-, -j- vor allem, die als zur Volkssprache gehörig betrachtet werden, neben anderen sprachlichen Mitteln, etwa denen der Lexik, zur differenzierenden Darstellung bestimmter gesellschaftilcher Schichten, d. h. sprachliche Mittel werden bewuBt in ihrer Oppositionefunktion gebraucht. Diese gleichen sogenannten "Possessivadjektive" werden im Altrussischen in der hochliterarischen Sprache verwendet, d. h. sie dienen nicht zur Charakterisierung einer Opposition "Volkssprache : Literatursprache".

Es hätte wenig Sinn, in dieser Arbeit auf Fragen der Genese einzugehen. Was man im wesentlichen dariber weib, enthalten die anfangs bereits erwähnten Arbeiten, insbesondere die Vondraks. Die alten Sprachstudien, zumindest der slavischen Sprachen, aber nicht dieser allein, zeigen jedoch ein Bild, das der These Hirts nicht entspricht. Der sogenannte adnominale Genitiv spielt dort eine auBerordentlich geringe Rolle. Zudem erhebt sich die Frage, inwieweit der Gebrauch dieses Genitivs sowle der Komposition im Slavischen direkt vom Griechlschen her beeinfluBt sind.

\$ 4. Das Problem "Genitiv und Adjektiv" ist von einer anderen Seite ebenfalls behandelt worden, und zwar unter dem Aspekt des Ausdrucks der Possessivität (russ. "prinadleznost" ). Hier ist Insbesondere der Aufsatz von Makarova "Родительның падед принадлехности в русском язнке XI - XYII вв ." 9 zu nennen. Dieser Beitrag ist ein Auszug aus einer Habilitationsschrift, die selbst nicht beschafft werden konnte.

9akarova, S. Ja.: Koditel'nyj padez prinadlexnoet1 v russkom jazyke XI-XVII vv. In: Trudy instituta jazykoznanija, Bd.III, Moskva 1954. 
Der Aufsatz onthalt Fakten liber den Gobrauch dee Genitive und Hinvelse auf die Konkurrenz mit den sogenannten Possessivadjektiven. Was hier interessiert, nämlich die Differenzierung der Mittel fur den Ausdruck der "prinadleznost", wird nur sehr schemenhaft erkennbar. Indirekt erfuhrt nan aus einem Aufsatz ron Vidnás in Scando-Slavica IV, der sich auf die Arbeit ron Makarova bezieht, daB eine befriedigende Differenzierung nicht durchgefuhrt worden sei. Rudolf zimek setzt sich kritisch mit dem Begriff "Possessivitat" In seiner Abhandlung "K cháplenl posesirnosti" 10 auseinander. Auf diesen Aufsatz werden wir noch eingehen.

Allen genannten Darstellungen ist zweierlel gemeinsams 1. Es werden nicht alle sprachlichen Konkurrenten, mit deren Hilfe zwei Substantiv-Begriffe in Beziehung zueinander gesetzt werden können, berucksichtigt. 2. Es fehlt eine einheitliche Terminologie, mit deren Hilfe die Konkurrenten als Einheit gesehen und ihre Differenzierung durchgefuhrt werden kann.

\$5. Im folgenden soll dargelegt werden, wie etwa im Altrussischen diese Konkurrenten aussehen können. Die Varianten der Laurentius-Chronik und der Hypatius-Chronik fuhren uns dies bereits sehr deutlich vor Augen. Vgl.:

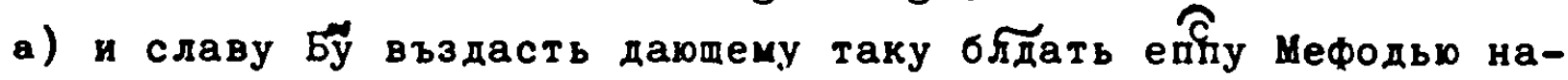
стольнику Анъдронику L. 28

In der Laurentiushandschrift steht also ein adnominaler Dativ. Die entsprechende Textstelle der Abschrift der Moskauer Gelstlichen Akademie (A) sowie die Radzivilovskij-Abschrift (R) haben hier настольнику Андроникову, benutzen also das Suffix-ov-, die Trolckij-Abschrift schlieblich hat das Suffix -J-: Андроничр

b) Die Laurentiushandschrift hat den Genitiv, zwei andere Abschriften benutzen Praposition + Genitiv:

мух царства вашего L. 49

R. A.: ... из царства... )

${ }^{10}$ In: Rusko-Zoskb studie. Praha 1960. 
c) In einem Satz der gleichen Handschrift stehen die Suffixe -in-, -ov-, -j- in absolut gleicher Funktion nebeneinander: градъ хе бъ Киевъ идехе есть нынь Дворъ Гордятинъ и Нихифоровъ а дворъ княхь бяше в городь идехе есть нНн дворъ Воротиславлъ и Чюдин L. (R., A.) 55

Weiter betrachten wir die adjektivischen Ableitungen von otbcs und totb. Letztere Form ist im Altrussischen nicht mehr belegt, jedoch weisen die suffixalen Ableitungen auf sie hin, ferner lebt sie zumindest im Slovakischen noch, wie Machek darlegt ${ }^{11}$. Wir gehen also dabei von zwei signifikanten fur ein Signifikat aus. Vgl :

отии городокъ (Новг. I.л.)Sr. II, 757

и мухи отни (Лавр. л.) Sr. II, 827

во отцево мьто (Lог. гр. I340 r.) Sr. II, 828

по отчи преданіо (Псков. I. Л.) Sr. II, 830

излохение отчию (Никон. Панд.) Sr. II, 832

отечьнви сирти (Переясл. л.) Sr. II, 832

очkow тебе славоу (Мин. I097 г.) Sr. II, 832

Hier lst klar ersichtlich, welche fulle von Suffixen miteinander konkurrieren können. Als Konkurrent muß ferner auch der Genitiv betrachtet werden: Bb oua mbcro L. 132 .

\$6. Man hat bisher zwischen Syntagmen vom Typ "Substantiv \& Adjektiv" und "Substantiv + Substantiv Im Genitiv, Dativ o. dg1." unterschieden. Auf begrifficher Ebene geschieht nichts anderes, als daB, wie Hirt es für den Genitiv formuliert hat, zwe 1 Substantiva in Beziehung zueinander gesetzt werden. "Bei dem ganzen Problem", schreibt Hirt, "ergeben sich nun zwei Fragen: 1. Besteht ein Unterschied zwischen Adjektiv und Genitiv?, 2. Welche Ausdrucksweise ist die urspringliche?n 12

11npodle Kotto 2.437 uxiva se v jedne msl. val ot, 1 plsnich je na pr. od vaseho ota..." In: Vaclav Machek: Etymologickf slovnlk jazyka Zesklho a slovenskbho, Praha 1957, S. 345

(2. Auf1. 1968, S. 422)

12 H1rt, a.a.0, S. 109 
Dor zwolten Frage worden wir hier nicht nachgehen können, dies lot Sache des Indogermanisten. Die erste Frage mibte ungestaltet fur die Problematik dieser arbeit lautens LaBt sich etwas uber die Konkurrenz der Mittel aussagen, ait deren Hilfe zwel Substantiva begrifflich in Beziehung zueinander gesetzt werden?

Methodisch lst dieses Problem nicht ganz einfach zu lösen, insofern zunächst einmal eine einheitliche Terminologie gefunden werden muB, die Erscheinungen umfaBt, welche sowohl in den Bereich der traditionelien Wortbildung wie der syntax fallen. Hier bietet sich die in den "Elements de syntaxe structurale" von L. Tesnière dargelegte Translationslehre geradezu an. Für eine Untersuchung "Zur Problematik der Suffixbedeutung adjektivbildender Suffixe im Kussichen" 13 auf der Grundlage der modernen russischen Sprache ist sie bereits von H. Wissemann herangezogen worden. Sie hat dabel die Möglichkeit einer praktischen Anwendbarkeit bewiesen. Hier soli untersucht werden, ob es möglich ist, irgebnisse aus dem Sprachpotential des Altrussischen zu ziehen. Ein absolut in sich stimmiges System von oppositionelien kinheiten kann kaum mit befriedigender Exaktheit aufgestelit werden. Oppositionelle Einheiten in Gestalt von formantien sind naturlich vorhanden, aber ihr Ausschlieblichkeitscharakter in bezug auf ihre Ableitungsbasis bzw. den Stamm läbt sich in don meisten Fällen kaum beweisen, vielleicht in Einzelfällen, nicht aber als ein Bündel von Relationen, wobei die Grenzen absolut festliegen. Der semantische Wert der Basis mubte ja berucksichtigt werden - denn in bezug worauf sollte denn der Oppositionscharakter der Formantien festgestellt werden? -, in der Semantik spielen aber u. a. stilistische Nuancen eine Holle, die strukturell kaum zu fassen sind. In dieser Arbeit wird sich zeigen, dab sehr häufig oben nur Synkretismus von sprachlichen Einheiten vorliegt. Zudem ist ja nur ein Teil des sehr umfangreichen Sprachpotentials des Altrussischen untersucht worden. So wird es die Aufgabe sein, in dieser Arbeit in methodischer Hinsicht einen KompromiB zwischen der traditionellen Grammatik und der Translationslehre Tesnières zu schließen.

13 In: Slavistische Studien zum vI. Intern. SlavistenkongreB in Prag 1968, Munchen 1968, S. 280-298. 
II - Zur Translationslehre Tesnières

§7. Tesnières Buch "Élements de syntaxe structuralen 14 hätte eher den Titel "Allgemeine Sprachwissenschaft" verdient als vieles andere, was sonst unter derglelchen Titeln zu erscheinen pflegt. Das umfangrelche Werk gliedert sich in drel grobe Te1le: 1. La connexion, 2. La jonction, 3. La translation. Das Kapitel über die jonction kann hier unberúcksichtigt bleiben, aus der Translationslehre soll erlautert werden, was fur das Verständnis dieser Arbeit notwendig ist. Dabel ist es unumgänglich, grundlegende Elemente von Tesnières Konnexionslehre zu berühren, da die Translation organisch mit der Konnexion verbunden ist. Gegenstand der Konnexionslehre ist der Satz. Gegenstand der Translationslehre dessen Telle, elnzelne Syntagmen. Die "Syntax" Tesnières umfaBt traditionelie Teile der Grammatik wie Morphologie und Wortbildungslehre. Dies kommt insbesondere auch bei der Differenzierung zwischen "mots vides" und "mots pleins" zum Alisdruck" . Die mots pleins haben semantische Funktion, zu ihnen fehören Verb. Substantiv. Adjektiv und Adverb. Die mots vides bezelchnet Tesnière als outils grammaticaux, zu innen gehört belspielsweise der Artikel, aber alich das 'de' In 'le livre d'Alfred'. Die mots vides werden als grammatische Hilfsmittel charakterisiert. Sie können keine selbständipen Knoten Im Konnexionsschema bilden, d.h. sie sind keine selbständigen Glieder im strukturalen Plan des Satzes und werden daher auch als mots subsidiatres gegeniber den Vollwörtern als mots constitutifs bezeichnet. Schlieblich macht Tesnière noch die Unterscheldung zwischen mots variables und mots invariables. Vollwörter sind im allgemeinen variabel. insofern z. B. ein Substantiv - dies wäre jetzt Gegenstand der Translationslehre - In ein Adjektiv verwandelt (= transferiert) werden kann. Das pronomen 'de' dagegen, welches grundsatzlich - man vergleiche nur verschiedene Sprachen-die gleiche Funktio und hier ergeben sich Berührungspunkte mit Martinet, wie ein

\footnotetext{
14tesnière, Lucien: Elements de syntaxe structurale. Paris 1959 ${ }^{15}$ Zum folgenden vgl. Tesnière, a.a.0.. s. 11-13.
} 
Suffix ausüben kann, ist nicht variabel. Damit charakterisiert Teenière drei Ebenens 1. Die semantische Ebene (mots pleins mots rides), 2. die strukturale bbene (mots constitutife mots eubsidialres), 3. die morphologische Ebene (mots variables - mots invariables). Des öfteren spricht Tesniere auch von "616ments vides", eine Unterscheidung ist nicht scharf durchgefuhrt, und in der Tat wird man sich den Begriff "mot vide" kaw zu eigen machen. Ubersetzen wir 'le livre d' Alfred' in das Kussische, so könnte diese Fügung mit 'Alfredova' kniga' oder 'kniga Alfreda' wiedergegeben werden. DaB hier das französische Pronomen 'de' und das russische Suffix -ovbzw. die Genitivendung die gleiche Funktion haben, gehört durchaus zu den grundlegenden Erkenntnissen der noch zu erläuternden Translationslehro Tesnidres, aber gerade deshalb wird man den Begriff "mot vide" nicht kritiklos ubernehmen, da die traditionelle Bezelchnung "Wort" sowohl fur das, was man bisher darunter verstand, gebraucht wird, wie für Elemente, die man als Morpheme zu bezelchnen hätte.

\$8. Die Konnexion lst fur Tesnière formaler Ausdruck des Denkens - "indispensable à l'expession de la pensé". Sie wird graphisch durch Konnexionslinien dargestellt, welche die Abhängigkeitsverhältnisse der Wörter untereinander veranschaulichen. So entsteht eine Hierarchie der Konnexionen, wobei das Verb grundsätzlich immer an der Spitze steht. Dies mag Tesnidro' scher Dogmatismus sein, indessen lst seine Konsequenz nach dieser Entscheidung a priori bewundernswert und ron praktischem Nutzen. Schlieblich steht er hier keineswegs allein, Erich Drach etwa ruckt bel seiner Gliederung des Satzes in Vorfeld, Mite und Nachfeld das "Geschehen" (= Personalform des Verbs) In die - konstant bleibende - Mitte. 16 In der Transformationsgrammatik etwa werden schlieblich auch nominale Fugungen aur Satzstrukturen mit prädikativem Kern zuruckgeruhrt.

Die Konnexion wird durch ein Stemma graphisch dargestellt. Die gesprochene Kette ist eindimensional, das Stemma zweidimensio-

${ }^{16}$ Drach, Erich: Grundgedanken der deutschen Satzlehre, Frankfurt a.M., 1940, S. 17 
nal. Es besteht zumindest aus einem ubergeordneten und einer untergeordneten Glied, "r6gissant" und "subordonnt". Jedes Regens kann mehrere subordonnes haben, nicht aber umgekehrt. Regens und subordonné bilden das, was Tesnière "noeud" (Knoten) nennt. Er unterscheidet "noeud verbal" and "noeud substantival". "Le noeud formb par le rogissant qui commande tous le subordonnes de la phrase est le noeud des noeuds ou noeud centrai [...] II s'identifie avec la phrase." 17 Der zentrale Knoten wird in der Regel von einem Verb als Regens gebildet. Nehmen wir ein Beispiel aus dem Altrussischen, den Satz Ольга искаше добров мдрти Бхоии L. 62 Im Konnexionsstemma stellt er sich uns dar:

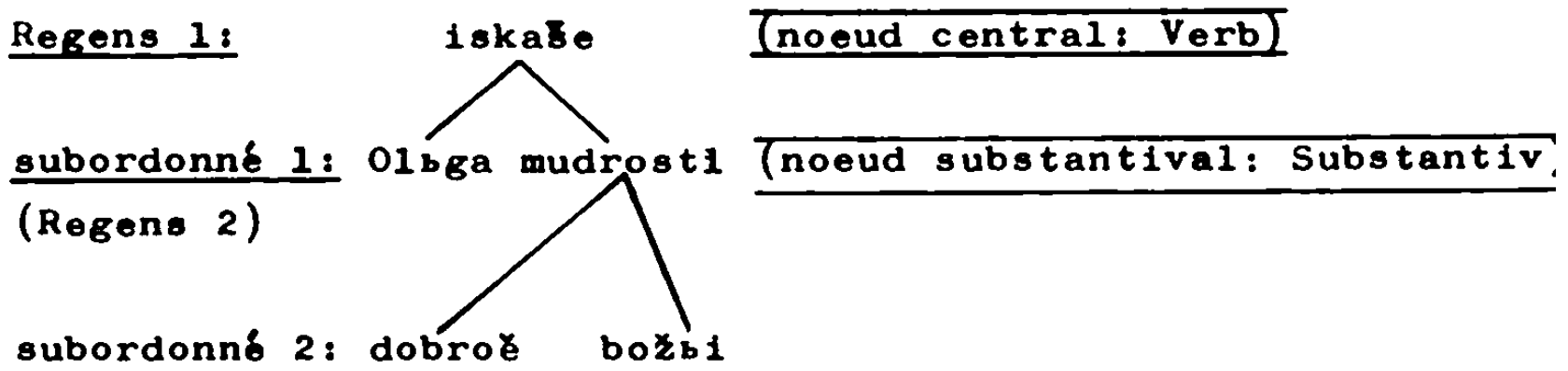

Wir sehen, daß das Subjekt Ольra zum subordonne des Prädikats geworden ist, ebenso wie das objekt, das nun wiederum Regens fur die beiden Adjektiva доброб und Бохьи innerhalb eines "nominalen Knotens" geworden ist. Das Substantiv Gorb ist durcl Subordination, welche durch das Suffix-bj-sichtbar wird, zum Adjektiv geworden, es hat sich ein kitegorialer Wechsel vollzogen.

89. Dieses einfache Beispiel fuhrt uns bereits vor Augen, was Tesnière unter $T r$ a 1 a $i$ o versteht: Die Lberfuhrung eines Vollwortes in eine andere grammatische Kategorie. Fur die bereits unter $\S 7$ angeführten Vollwörter benutz or folgende Zeichen: $I=$ Verb, $0=$ Substantiv, A = Adjektiv, $E$ = Adverb. Die kategoriale Veränderung eines Vollwortes ist Folge der Notwendigkeit der variablen Funktion der Wörter bei der Konnexion. Die Bildung syntaktischer Strukturen ist damit aufs engste mit der Translationslehre verbunden. Im Gegensatz zu den häufigsten Translationsformen hat die Konnexion kein

17 a.a.0., unter "noeud". 
kußeres sichtbares Zeichen. Tesnière gibt den Ubergang von einer Wortklasse zur anderen durch symbolhafte Zelchen wieder, $z$. B. wird die Translation eines Substantivs zu einem Adjektiv folGendermaßen charakterisiert: $0>A$. Nehmen wir ein Beispiel: Bb отца mbсто L. 132. Отьца = Gentiv von orbub lst hier nicht mehr im Sinne der Transiationslehre Substantiv (0), sondern Adjektiv (A), Insofern orbLa dem Substantiv rbcro untergeordnet ist, genau wie ein durch Suffix gebildetes Adjektiv. Wir hatten ja bereits weiter oben gesehen, dab ein отцево мысто gleichermaßen möglich ist. In einem Fall wird die Translation (kategoriale Veränderung) durch ein Suffix, im anderen durch ein Genitivmorphem vollzogen. Tesnière nennt die Ausdrucksmittel der Translation Translative. Diese können sehr vielgestaltig sein. Dem franz. 'de' bel der Translation o) A kann ein russisches Suffix-ov-oder ein Genttivmorphem entsprechen. Andererselts muB die Translation nicht unbedingt gekennzeichnet sein, hier spricht Tesnière von einem translatif zero, es handelt sich dabei im allgemeinen um Asyndeta wie etwa nарь колокол oder franz. Tour Eiffel. Transferierte Adjektive können grundskitzlich aus Verben ( $>A$ ), Substantiven $(O>A)$ und Adverbien (E > A) gebildet sein. Gegenstand unserer Untersuchung werden transferierte Adjektive des Typus $O>A$ sein. Diese gehören zu den weitaus haufigsten Formen trinsferierter Adjektive. Zu der Translation $I>A$ belspielsweise gehören natürlich viele partizipien, vgl. Бохию благодать раздрахающим Izb. 470 (раздрахающии < раздражати : A I). Die Translation

E $>$ Ast im Altrussischen kaum von Bedeutung.

$\S$ 10. Wenn Tesnière sagt: "Le translatif ne connecte donc pas"18, so mag dies erstaunen, denn nur um neue syntaktische verbindungen zu ermöglichen, ist Translation notwendig. Für Tesnière jedoch sind Translation und Konnexton gewissermaBen zwei Vorgänge, wobel die Translation vor der Konnexion erfolgt. "Il y a donc lieu de distinguer[...] les deux operations. La première est le changement de catbgorie qui constitue la transiation. Elle commande la seconde. La seconde est le changement de fonction qui en rosulte, et qui commande à son tour toutes les

18 
possibilitbs structurales." 19 Allerdings vollzieht sich die Veränderung eines Wortes ja nur im Hinblick auf die veranderte Stellung Im Konnexionsschema. Insofern wird man dem Mittel der Translation auch eine indirekte syntaktische Funktion zusprechen missen. Man darf jedoch die begriffilche Beziehung nicht mit der syntaktischen gleichsetzen. In der Fiigung $\mathrm{Cb}$ главы ирвв L. 94 werden die Semanteme цар- und глав- веgrifflich zueinander in Beziehung gesetzt mittels des Suffixes -ev-. Dieses Suffix entspricht in diesem Falle in seiner Funktion einem Genitiv. Martinet mubte hier von einem funktionalen Monem sprechen, Insofern als das russische Suffix dem französischen 'de' entsprechen wiirde. Dieses 'de' aber wäre ein Monem, das lediglich dazu dient, die Funktion eines anderen Monems anzuzeigens In ' 11 a donnb le livre à Jean' zeigt 'à' die Beziehung zwischen einem Erfahrungselement und der Erfahrung $1 \mathrm{~m}$ Ganzen an. 20 Man kann jedoch bei der Terminologie Tesnières bleiben und sagen, daß das Substantiv durch Translation für seine veränderte Stellung als Adjektiv im Konnexionsschema vorbereitet wird. In der Fugung 'la maison de Pierre' taucht 'de Pierre' innerhalb eines "nucleus" (Kern) im Konnexia schema als Ganzes auf:

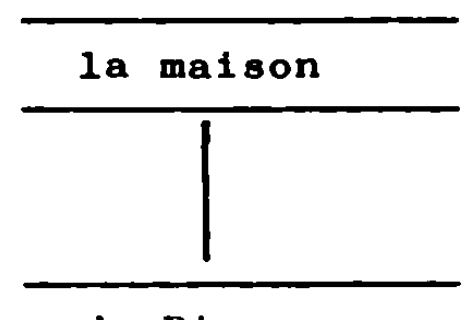

= nucl $18 \mathrm{~s}$

de Plerre

= nucleus

Auf der begriffilchen Ebene wirde man dem mot subsidiaire 'de' eher eine Stellung zwischen den Semantemen maison' und 'Pierre zuordnen. Dies wirde der semantischen Ebene entsprechen ('de' = mot vide), auf strukturaler Ebene wäre 'de' mot subsidiaire, wie unter $\$ 7$ dargestellt. Das "mot subsidiaire" Tesnidres und das "funktionale Monem" Martinets sind Entsprechungen. Bel Tesniere missen wir die unscharfe Trennung von "mot" und "Elbment" (Morphem) beanstanden, bel Martinet, daB bei diesem

\section{9 ebenda.}

20 Martinet, Andr6: Grundzlige der al1 gem Spracklter Andresen-9783954793396 Stuttgart 1963, s. 101. 
die aögliche Glelchwertigkelt suffixaler und nicht gebundener Monemo nicht genigend berucksichtigt ist.

8 11. Fur die Translation benutzt Tesnidre elne eigene Tereinologie und eine graphische Darstellung: Das zu transferierende Wort wird als transforende (Transferendum), das Mittel der Translation als translatif (Translativ) und das Ergobnis als transferb bezelchnet. Graphisch repräsentiert sich die Translation folgendermaben:

\section{Transf8r6}

\begin{tabular}{l|l} 
Translatif $_{\text {prepos }}$ & Transfirende
\end{tabular}

Transférb

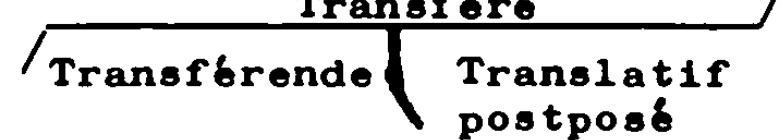

Aus den unter $\$ 9$ angefinrten Fugungen ist ersichtlich, daB jewetls ein Substantiv entweder durch ein Adjektiv im traditionelien Sinne oder durch ein Substantiv Im Genitiv determiniert wird (etwas oтцево мbсто - отьца мbcto). Im woiteren Verlauf dieser Arbeit werden beide Erscheinungsformen als attributive Adjektive zu bezeichnen sein.

\$ 12. In diesem Zusammenhang muB erwähnt werden, daB Tesnière konsequenterwelse unter "Adjektiv" auch Wörter einstuft, die die konventionelle Grammatik nicht als solche bezelchnet. Was unter "Adjektiv" zu verstehen ist, wird anhand der nachstehenden Tabelle am besten ersichtlich ("Adjektive in prädikativer Funktion" gehören zum Verb):

\begin{tabular}{|c|c|c|c|}
\hline \multirow[b]{2}{*}{ attributifs } & \multirow{3}{*}{$\begin{array}{l}\text { de } \\
\text { qualite } \\
\text { de } \\
\text { quantité }\end{array}$} & \multirow{2}{*}{$\frac{\text { gendraux }}{t \in 1}$} & \multirow{2}{*}{$\begin{array}{l}\text { particuliers } \\
\text { rouge } \\
\text { (adjectifs qualificatifs }\end{array}$} \\
\hline & & & \\
\hline & & $\operatorname{matnt}$ & $\begin{array}{l}\text { deux } \\
\text { (adjectifs numbreux) }\end{array}$ \\
\hline de rapport & personnels & $\begin{array}{l}\text { mon } \\
(\operatorname{adjectifs} \\
\text { possessifs) }\end{array}$ & $\begin{array}{l}\text { rus. Ivanov } \\
\text { (adjectifs d' } \\
\text { appartenance) }\end{array}$ \\
\hline & $\begin{array}{l}\text { circon- } \\
\text { stanciols }\end{array}$ & $\begin{array}{l}\text { ce } \\
(\operatorname{adjectifs} \\
\text { domonstratifs) }\end{array}$ & al1.morgig \\
\hline
\end{tabular}


Wir sehen, daß Numeralia und Pronomina der traditionellen Grammatik hier als Adjektive aufreten. Uns interessieren in diesem Zusammenhang nur die in der Tabelle doppelt umrandeten Adjektive und diese nur, sofern sie aus Substantiven transferiert sind. In $\S 9$ war nur ein kleiner Teil der Translative angefuhrt worden, die fur die Translation $0>$ A in Frage kommen. Lis missen, will man alle Translative behandeln, rund zwanzig Suffixe bericksichtigt werden, hinzu kommen als Konkurrenten Genitiv, Dativ, Instrumental, Lokativ, Präpositionen sowie Kompositionselemente.

§ 13. Die Translationslehre Tesnières umfaßt also traditionelle Zweige der Sprachwissenschaft wie Wortbildungslehre, Kasuslehre und schlieblich auch die Lehre von den Präpositionen. Lies erweist sich in der Praxis von grobem Nutzen, insofern sprachliche Konkurrenten 1. terminologisch einheitlich benannt werden können und 2 . das zusammengefaßt wird, was seiner Funktion nach zusammengehört. Zu dem Satz etwa aus der LaurentiusChronik придоша послании от С̆̈тополка на погубленье Гльбу L. 136 existieren zwei Varianten der Hypatius-Chronik, wo es einmal heiвt: Гльба Hyp. 123, zum anderen Гльбово (Ch. Р., a.a.0.).Dativmorphem, Genitivmorphem und Suffix -ov-können einheitlich als Translativ bezeichnet werden. Der Name ist hier das Transferendum, Гльбу, Гльба, Гльбово das Produkt der Translation $O>A$ (transforb). DaB Präpositionen als Konkurrenten in Frage kommen, zeigen folgende Variantens яко то есть середа в земли моеи L. 67 , середа земли моеи ( $R, A$, ebenda). Schlieblich wird man Asyndeta wie das bereits erwähnte царь колокол oder komposita wie богоявленье hier nicht ausschließen dürfen. Nun ist das Thema "Genitiv und Adjektiv", wie wir bereits im 1. Kapitel gesehen haben, nicht neu. Die Translationslehre Tesnières erschließt aber neue methodische Aspekte, wodurch allerdings der zu untersuchende Stoff wesentlich erweitert wird. Gegenstand dieser Arbeit sind aus Substantiven transferierte Adjektive. Dadurch, daB wir jedoch mit Tesnière die Translation nicht von der Konnexion trennen, werden diese transferierten Adjektive jeweils in ihrem Kontext (d. h. zumindest "determinierendes Adjektiv = 
subordonne + determiniertes Substantiv = Regens) zu untersuchen sein.

\$14. Wir haben es bei der Translation von Subs̄tantiven in Adjektive mit der einfachen Form der Translation zu tun. Selbstverständlich muBten wir bel der Darstellung der Translationslehre Tesnières vieles vereinfachen. Neben der einfachen Translation steht die doppelte, die dreifache, die vierfache. Ein Beispiel Tesnières: 'des aubergines a la parisienne'
$" 1$ ( $1>A) \quad$ - Translation du substantif Paris en adjectif au moyen du suffixe de derivation $\mathrm{fbm}$. - ienne.
$2(A>0)$
- Translation de l'adjectif ainsi obtenu en substantif désignant la façon dont sont accommodées les aubergines, au moyen de l'article defini, 1 a.
$3($ O $>A)$
$4(E>A)$
- Translation du substantif ainsi obtenu en adverbe de manière au moyen de la préposition à.
4 (E $>A)$ - Translation non marquee de 1 'adverbe de manière ainsi obtenu en adjectir." 21

Diese Sonderformen der Translation können im Rahmen unseres Themas unbericksichtigt bleiben, auf die translation double (doppelte Translation) werden wir gelegentlich zuruickkommen. Bei der translation double vom Typ $O>A>0$ wird ein Substantiv adjektiviert und dieses transferierte Adjektiv nun wiederum substantiviert. Hecrовое Sr. III, 1588, ist im Altrussischen die Bezelchnung für eine Abgabe. Das Adjektiv leitet sich ab von mecrb'stange' u. dgl,. die substantivierte neutrale Form wiederum dient als Substantiv in der Bedeutung: "пошлина, которая бралась съ шестовъ, употреблавшихся на речныхъ судахъ ". Sr. III, 1588.

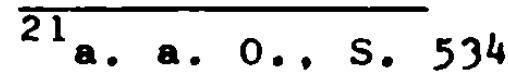


III - Adjektive als Determinanten

$\S$ 15. Wenn wir von einer Fügung wie etwa ar. дворъ Деместиковъ L. 55 sagen, daß das Substantiv дворъ durch das Adjektiv деместиковъ determiniert wird, so ist damit gemeint, dab diese Form der Determination rein begrifflicher Art ist. Grammatisch ist das Verhältnis genau umgekehrt. Franz Schmidt geht darauf in seiner Schrift "Logik der Syntax" unter dem Kapitel "Logische und grammatische Determination" 22 ein. Die logische Determination vollzieht $\mathrm{sich}$ an der Bedeutung der ganzen Wörter, die grammatische an den Formelementen, den Formanten. Danach ist das logisch bestimmende das grammatisch bestimmte und das grammatisch bestimmende das logisch bestimmte Wort und es ergibt sich eine chiastische Stellung zwischen logischer und grammatischer Ebene.

Tesnière behandelt die Determination in dem Kapitel "Kapports de la structure et du sens" 23. Er geht davon aus, das strukturelle und semantische Ebene nicht voneinander abhägig seien. Das entspricht im Prinzip auch der Anschauung Schmidts. Wenn ab schon keine Abhängigkeit existiert, so doch nach Tesnière Parallelismus, die strukturelle Ebene "n'a d'autre objet que de rendre possible l'expression de la pensefen. In der Konnexion manifestiert sich für Tesnière auch die "connexion sémantique": "Le sens du subordonne porte sur celui du regissant dont il dépend". In dem Satz 'les petits ruisseaux font les grandes rivières' ist 'petits' syntaktisch 'ruisseaux' untergeordnet, aber ich begreife, daß die "Kleinheit" die kigenschaft der Bäche ist. Ls besteht ein inverses Verhältnis zwischen Determinans und syntaktisch untergeordnetem Glied (subordonné). Tesnière bringt dies durch folgende Stemmata zum Ausdruck:

$\begin{array}{ll}\text { ruisseaux } & \text { ruisseaux } \\ \text { petits } & \text { petits }\end{array}$

Incidence structurale Incidence semantique

22 Schmidt, Franz: Logik der Syntax, Berlin 1961, S. $20 \mathrm{ff}$.

23a.a.0., S. 42. Die folgenden Zitate ebenda. 
Auf semantischer Ebene determiniert das untergeordnete Glied - das Adjektiv - das Regens. Nach Tesnière gibt es keine strukturelle Konnexion ohne parallele semantische Konnexion. 24 Dieser Anschauung schlieben wir uns hier an.

§ 16. Die Lehre Tesnières uber die Determination unterscheidet sich von denen anderer in einigen Punkten. Als Determinanten von Substantiven kommen die in der Tabelle auf Seite 22 angefuhrten Adjektive in Frage. Zu den Adjektiven zählen hier die ublicherweise als Pronomen und Numeralia bezeichneten Wöter. Andererseits wird unter "Adjektiv" nur das attributiv gebrauchte Adjektiv verstanden, also in seiner Veterminationsfunktion (so wie das Adverb das Verb determiniert). Dies ist absolut folgerichtig, insofern das prädikativ gebrauchte Adjektiv in einem Nucleus mit einem Hilfsverb zu den Verben, den sogenannten "verbes d'état", gehört. Tesnière spricht hier von einem dissozilerten Nucléus. Das Hilfsverb verkörpert die strukturelle Funktion, das Adjektiv die semantische. 'Alfred est arrivé' hat also die gleiche Struktur wie 'Alfred est grand' 25 ,

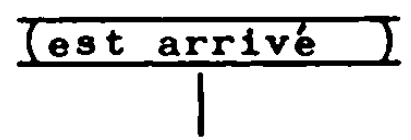

Alfred

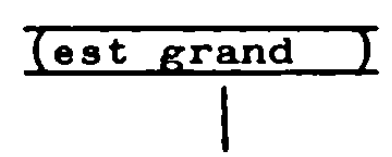

Alfred

Ahnlich wie Schmidt und auch Tesnière versteht A. A. Reformatskij 26 unter определение elne logische Determination, und zwar benutzt er diе Begriffe определающй член (t) und определяемнй член ( $\left.t^{\prime}\right)$ fur seine Aufgliederung des Satzes in Syntagmen. Mit определяющй член wird das Glied der Fügung bezeichnet, welches sinngemäb bei Schmidt das logisch determinierende wäre.

\footnotetext{
24"En effet il n'existe jamais de connexion structurale sans connexion semantique", a.a.0., S. 44. 25a.a.0., S. 46, vgl. dazu auch S. 72 ("verbes d'état"). 26 Keformatskij, A. A.: Vredenie v Jazykoznanie, Moskva 1960 , S. 270 f.
} 
Deutlich sieht man die Andersartigkeit einer Syntax, als deren kleinste Einheiten nicht Vörter, sondern Lexeme (Semanteme) und Morpheme angesehen werden bel Martinet 27 . In der Fugung 'avec les grosses valises' werden als Determinanten die Moneme "bestimmt" (/1/), "Plural" (/e/) und "grob" (/gros/) bezeichnet. 28

Hans Marchand geht auf den Begriff der Determination in seinem Aufsatz "Expansion, Transposition and Derivation" ein. 29 Ist das Determinatum ein selbständiges Wort wie etwa bei 'boathouse', so ist jede Kombination als Expansion zu bezeichnen. 'Boat' als Determinans ist gleichzeitig transponiert: "Transposition is the use of a word in another than its normal runction. Applied to a morphologic syntagma this would mean that a substantive is naturally the determinatum (head, nucleus) of a nominal construction, while an adjective is designed to be its determinant (modifier, satelitte). A substantive as determinant, as $s t o n e i n$ s $t o n e$

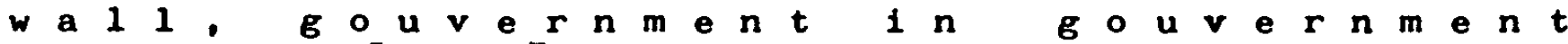

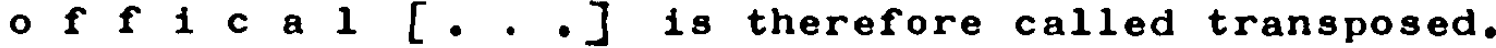
$B 1 a c k$ in $b l a c k b i r d$ is not a transposition as the adjective naturally modifies a substantive." 3o

Transposition eines Wortes in die Rolle eines Veterminane in einem Syntagma, in dem das veterminatum ein abhängiges Morphem ist, nennt Marchand Derivation, also z. B. 'steamer' gegenüber 'steamboat'. Dazu ist zu bemerken: Wenn man vom Morphem als der kleinsten möglichen Einheit eines Syntagma - das ja nach Marchand e $i \mathrm{n}$ Wort sein kann - ausgeht, kann man andererseits nicht von einer nicht definierten kleinsten Einheit "Wort" ausgehen. Im übrigen enthält das, was liber die Transposition ausgesagt wird, das gleiche, was in der Translationslehre Tesnières bereits festgestellt wurde. Nur ist bei Tesnière der Kreis der adjektivischen Determinanten konsequenterweise gröBer gehalten. Bei 'stone wall' wüde Tesnière nicht von einer "anderen als normalen Funktion" eines Substantives reden. 'Stone' ist das Ergebnis der Translation $0>A$ und erfült die gleiche Funktion wie ein primäras Adjektiv oder ein durch Kasus

27 Martinet, André: Grundzüge der Allgemeinen Sprachwissenschift, Stuttgart 1963.

28 a.a.0., s. 107 .

${ }^{29}$ In: La linguistique 1, 1967, s. $15 \mathrm{ff}$. 30 a.a.0., s. 16 


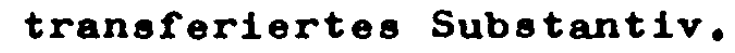

Translation ( $\mathrm{X}$ ) $\mathrm{A}$ erzeugt also auf strukturelier Ebene untergeordnete Glieder eines actant ( 0 oder Äquivalent), auf begrifflicher Ebene adjektivische Determinanten nicht primärer Art. 
IV - Zum Problem der Beziehungen zwischen Syntax, Vortbildung und Morphologie

$\$ 17$. In den vorhergehenden Kapiteln wurde mehrfach auf Beruhrungspunkte zwischen Wortbildung und Syntax hingewiesen.

M. Dokulil hat einige Aufsätze veröffentlicht, die sich mit diesem Thema befassen. 31 Dokulil geht auf die Definition des Syntagma von $\mathrm{Ch}$. Bally ein und meint, daß man es prinzipiell im Satzbau wie im Wortbau mit zweigliedrigen Strukturen der Bedeutungseinheiten, und zwar als bestimmenden (determinierenden) und zu bestimmenden (determinierten)Gliedern zu tun habe. 3 Ebenso könne in zusammengesetzten Wörtern wie 'listonor' = 'Briefträger' zwischen den beiden Kompositionselementen dasselbe Verhälnis festgestelit werden wie zwischen den Gliedern des Syntagma 'nosiz listú' bzw. 'ten, který nosl listy'. Wir haben also drei verschiedene Fugungen - Zusammensetzung, determinierendes Adjektiv + determiniertes Substantiv und Relativsatz - welche den gleichen Aussagewert besitzen. Damit begrindet sich auch eine grundsätzliche Transformationsmöglichkeit. Ferner bringt Dokulil die Beispiele Eech. 'rychllk' (suffixale Bildung), 'rychlovlak' (Zusammensetzung), 'rychly vlak' (Adjektiv + Substantiv) 'Schnellzug'. Bei 'rychllk' kann der semantische Gehalt des Suffixes eigentlich nur durch Transformation erschlossen werden, und welche Transformationsmöglichkeiten sich anbieten, wird hier bereits durch die konkurrierenden Fügungen gezeigt. Dokulil sieht die prinzlpielle Möglichkeit, eine syntaktische Konstruktion zu finden, die imstande ist, den entsprechenden "beschreibenden Ausdruck" - mit den gleichen Semantemen - wiederzugeben. Wenn man '11stonor' mit 'ten, který nosl listy' gleichsetzt, betritt man bereits den Boden der Transformations-Grammatik. Dies ist insofern

${ }^{31} \mathrm{~V}_{\mathrm{g}}$. besonders Milog Dokult1: Zur Frage der stelle der Wortbildung im Sprachsystem. In: slovo a slovesnost XXIX, $1(1968)$. S. 9 ff.

Derselbe: Zum wechselseitigen Verhaltnis zwischen Wortbildung und Syntax. In: Travaux linguistiques de Prague I. $(1964)$, S. 215 ff.

32 Zum wechselseitigen Verhältnis .... s. 215. 
nicht ganz unproblematisch, als hier die Benennungsfunktion auf die Aussagefunktion zuriukgefuhrt wird. Dokulil ist sicher kein Vertreter dieser Transformations-Grammatik. Ja er zweifelt mit einigem Recht die Legitimität solcher Transformationen an, sofern Benennungs- und Aussageebene vertauscht werden. Dokulil geht es darum, die Berechtigung der Wortbildungslehre als einer selbständigen Disziplin der Grammatik darzustelien. Hier stimmt er überein mit dem von $E$. und $K$. Gunther in dem Aufsatz "Die Haupttypen der nominalen und verbalen Wortbildung im Russischen" dargelegten Grundsätzen. 33 In diesem Bemihen schränkt er die im ersten Teil seines genannten Aufsatzes gegebenen Hinweise auf die Verbindungen zwischen Syntax und Hortbildung wieder ein. Seine Argumentation richtet sich möglicherweise gegen die transformationelle Methode der polnischen Doroszewski-Schule. So konstatiert er:

"Insofern wir unter Syntax die Lehre vom grammatischen Satzbau, von den Satzgliedern verstehen, können wir keine direkte Verbindung zwischen ihr und der Wortbildung annehmen. [...] Die eigentlich syntaktischen Beziehungen (syntaktische Abhängigkeit: Unabhängigke1t. Formen und Mittel zum Ausdruck der syntaktischen Abhängigkeit) bleiben [...] auBerhalb der Wortgeb11de." 34

So könne beispielsweise bei Komposita des Typus 'krajinomalba' = 'Landschaftsmalerei'. 'olejomalba' = 'ölmalerel', 'ölgemälde' nicht von syntaktischer Abhängigkeit zwischen dem ersten und zweiten Gliede der Zusammensetzung die lede sein, nichts deute auf den Unterschied in der Art der syntaktischen Abhingigkeit, der zwischen mit den Typen korrelativen syntaktischen Gebilden bestehe, etwa 'malba krajin' = 'Malerei der (von) Landschaften' - 'malba olejem' = 'Malerei mit 01 ' bzw. 'malovat krajiny' = 'Landschaften malen', 'malovat olejem' = 'mit ul malen'. 35

$\$ 18$. Wenn ein nominales Syntagma auf einen Satz "zuruickgeführt" wird (d. $h$. von der Benennungsfunktion auf die Aussagefunktion), zumal dann, wenn der Verbalbegriff nicht eindeutig fest-

33In: Zs. F. Slawistik 5, 1960, S. 446 .

${ }^{34}$ Zum wechselseitigen Verhältnis .... S. 220.

35 ebenda, S. 217 . 
legbar ist, halten wir dieses Verfahren obenfalls für sehr problematisch. Dokulil vermischt hier aber zwelerlei: Fihrt man 'krajinomalba' auf 'malovat krajiny' zurick, so handelt es sich um echte Transformation, 'malovat krajiny' wäre il Sinne der transformationellen Grammatik die sogenannte Tiefenstruktur zu 'krajinomalba'. Transformation liegt aber nicht bel konkurrierenden Fügungen vor. 'Krajinomalba' und 'malba krajin' können 1. absolut gleichberechtigte konkurrierende Strukturen innerhalb einer Sprache und 2. Konkurrenten bei der Ubersetzung von einer Sprache in eine andere cein. Im Russischen wird das tschechische Kompositum 'krajinomalba' etwa mit пейзахная хивопись wiedergegeben, eine typisch slavische Konstruktion. Das Suffix erfullt also die gleiche Funktion wie der Bindevokal -o-der tschechischen Komposition. Deshalb hat Tesnière recht, wenn er von der "composition biradicale" sagt, daB das determinierende Gited Objekt einer Translation sei, welche es befuhige, subordonnt des determinierten Gliedes zu sein. 36

§ 19. Sehr deutlich laBt sich sehen, wo sich die traditionellen Disziplinen Syntax und Wortbildung beruhren, wenn man die Konkurrenz von adnominalem Genitiv und suffixal gebildetem Adjektiv anhand des Vergleichs verschiedener Handschriften betrachtet. Vgl.?

аще обряпеть въ вусть Днвпрьскомь L. 51

Die entsprechende Stelle der Hypatius-Chronik lautet:

... въ устьи Днвпра Нур. 39.

Das Suffix mübte als Mittel der Wortbildung, das Genitivmorphem als Mittel der Syntax, welches glelchzeitig Gegenstand der Morphologie wäre, zu bezeichnen sein, obwohl beide Mittel in ihrer Funktion absolut gleichwertig sind, sonst könnten sie Ja nicht ohne weiteres ausgewechselt werden. Eine Modifizierung der Aussage liegt hier nicht vor. Dieses Problem hat

\section{5 obenda, S. 217 .}

36 a.a.0. 
Tesnière erkannt und methodisch gelöst, sowohl Genitivmorphem wie Saffix sind nach ihm einheitlich als Translativ zu bezeichnen.

Besonders problematisch ist der Begriff "Wortbildung" bei den suffixal gebildeten Adjektiven, deren Transferendum ein Personenname oder ein Appelativum, das zur Bezeichnung von Personen dient, ist, wie z. В. Володимерь, настольниковъ u. dgl. Нier wird das Suffix ja rein fakultativ gebraucht. Es entsteht kein neuer Begriff, der uber das durch das Transferendum Gegebene hinausgeht. Wir mussen Володимерь etwa im Deutschen wiedergeben mit 'des Volodimer' oder 'Volodimers'. Wenn $E$. und $K$. Günther sagen: "Uns erscheint daher der Standpunkt gerechtfertigt, wonach die Wortbildung - bei aller Abhängigkeit von der Grammatik gerade in formaler Hinsicht - dennoch von der Morphologie getrennt und der Lexikologie zugeordnet wird" und "[...]zeigt sich deutlich die Mittelstellung der Wortbildung zwischen der Grammatik einerseits und der Lexikologie andererseits. Doch ist die Verbindung zur Lexikologie enger, denn dem Bereich der Wortbildung fehlt die Kategorialität der grammatischen Erscheinungen" 37 , so ist dem im Prinzip zuzustimmen, jedoch mute hier in bezug auf die Wortbildung eine differenziertere Betrachtung erfolgen. Gerade bei den oben angefuhrten Beispielen werden ja gar nicht neue lexikalische binheiten geschaffen. Die Kategorialität besteht in der automatisch wirkenden Möglichkeit der absoluten Austauschbarkeit von Genitivmorphem und suffixalem Morphem in den genannten Fallen. Der Begriff der Translation ist hier umfassender und neutraler zugleich.

$\S 20$. Zur Problematik Vortbildung und Morphologie einige Beispiele aus dem Altrussischen: Betrachten wir das Suffix-ov-. Dieses Suffix wird generell benutzt zur Bildung von Adjektiven, die von Substantiva abgeleitet werden. In den russischen Grammatiken ist es allgemein tiblich, daB die Adjektive auf -ov-mit nominalem kndungsmorphem als Possessivadjektive bezeichnet werden. Daß eine solche Unterscheidung unglucklich formuliert ist. soll noch dargelegt werden. In der Tat aber steht fest, das der

37 a.a.o., s. 447 . 
Gebrauch des Suffixes -ov- je nach folgendem pronominalem oder nominalem Endungsmorphem verschieden 1st. Im strengen Sinne der Wortbildung wirde Jedoch kein Unterschied bestehen. Die Bezeichnung "bestimmte" und "unbestimmte" Adjektive muB man fur unzweckakib halten. In Ярославль сннъ ist das Adjektiv Ярославлः nicht als "unbestimmt" zu bezeichnen, weil thm das pronominale Endungsmorphem fehlt. Die Bestimmtheit ist in diesem Falle ja durch die Nennung der Person gegeben.

Seit langem ist bekannt, daB das Suffix -ov- in Verbindung mit nominalem Endungsmorphem in erster Linie zur Ableitung von Personennamen und Appellativa zur Bezeichnung von Personen dient. Zieht man allein die gesammelten Belege aus der LaurentiusChronik heran, so sieht man, daß ca. 90 Prozent der Transferenda Personennamen sind, wie etwa Bz oбpase hC XОВb L. 197 (Исусъ Хрстосъ wird als ein Transferendum behandelt, d. $h$. der Name'Jesus' wird weder dekliniert noch suffixal abgeleitet) царство Доментианово L. 39, от города Киева L. 31 (нier ist Kиевъ wohl bereits substantiviert.). Im modernen Kussisch werden Adjektive, deren Transferenda Bezeichnungen für Bäume sind, Im allgemeinen, wenn auch nicht ausschließlich, mittels des Suffixes -ov- + pronominalem Endungsmorphem gebildet. Vgl.: дубови червь 'Gallwеsре', елевая питка 'Tannenzapfen', тисовое дерево 'Тахия', липовая кора 'Lindenborke'. Im Altrussischen geschieht dies in der Mehrzahl der Fälle durch -ov+ nominalem Endungsmorphem. Vgl.: кора липова Sr. II, 23 'Lindenborke', березова пень Sr. I, 70 'Birkenstamm', кровать тисова Sr. III, 960 'Bett aus Kiefernholz', сльмена елова Sr. I, 824 'Fichten(Tannen-) balken'. 38

Es ist nicht verwunderlich, daB Personennamen als Transferenda mittels des Suffixes -ov- + nom. Endungsmorphem transferiert werden, da die Bestimmtheit im allgemeinen gegeben ist. Zieht man das Suffix -ov- + pronom. Endungsmorphem als Translativ zum Vergleich heran, so sieht man, daß hier als Transferenda

38 Neben яблоновии Sr. III, 1632 steht im Aruss. яблоньнки Sr. III. Supp1. 271. Im Neuruss. Ist ольшанй neben ольховын belegt, im Aruss. Findet sich bei $S r$. nur letztere Form. Die suffixalen Abl. von лиственица haben -n-Suffix, aruss. листвьнатии, neuruss. лиственичнй . 
Sachbezeichnungen, Tiernamen und einige Abstrakta belegt sind. Feste Fugungen sind häufig, etwa мировая rpaмora Sr. II, 145 'Friedensurkunde', туча дохдевая Sr. I, 754 'Regenwolke' u.a. Es findet sich auch häufig der Typus $0>A>0$, den Tesnière als "translation double" bezeichnet, etwa cтанв (0), становое ( $>A>0)$, Sr. III, 491 als Bezelchnung für Abgaben: 'Liegegeld'.

$\$ 21$. Aus dem Vorhergehenden ist ersichtlich, daB die Wahl des pronominalen oder nominalen Endungsmorphems abhängig sein kann von dem Transferendum, der "Basis" im Sinne der Wortbildungslehre. Schliebt man sich den Erkenntnissen der Translationstheorie Tesnières an, so wird man sowohl Suffix wie Endungsmorphem - den traditioneller Kategorien Wortbildungslehre und Morpholofie zugerechnet - als Translative in Betracht ziehen mússen. Es gibt beispielsweise abgeleitete Adjektive, bei denen das kndungsmorphem alleiniges Translativ ist wie ar. золотыи, бользныи, дерныи, сквьрныи, свиныи, другыи, гобьзыи, гнусыи, гнильи, златокрильи.

Tesnière geht in zwei besonderen Kapiteln auf das problem Translation : Derivation ein. 39 Derivation definiert er als "translation figée", als erstarrte Translation. 40 In der Fugung 'des btapes fatiguant les plus resistants' beispielsweise bewahre das Partizip präsentis wie das Verb 'fatiguer' die Fähigkeit, Regens eines weiteren actant zu sein (hier: 'les plus resistants'). Dagegen habe in der Fügung 'des etapes très fatiguantes' das Verbaladjektivum diese Fähigkeit verloren, es sei erstarrt zum Verivat. 41 Tesnière definiert die Derivation so: "bile [d. h. die Translation] est figfe quand le transferende n'est plus vivant et n'a plus qu'une valeur étymologique." 42 Fü Tesnière ist die Translation ein leben-

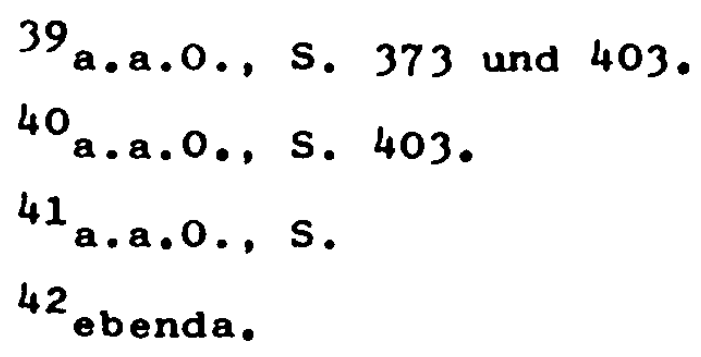


diger Mechanismus. Was im Einzelfall als Derivation, was als Translation zu bezeichnen ist, dieses Problem wird nicht immer absolut befriedigend zu lösen sein.

Das Verblassen der eigentlichen, urspringlichen Bedeutung des selbständigen Transferendums nach der Translation ist ein Indiz dafur, daB die Translation als lebendieer Mechanismus nich mehr existiert. In dem deutschen Adjektiv 'herrilch' ist der semantische liert von 'Herr' modifiziert. Es ist das eingetreten, was man am besten als semantische Modifikation des urspringlichen Transferendums bezeichnen kann. Solche Adjektivtypen gibt es natürlich auch im Ar., wie etwa погодьливыи (von погодь = 'нухда') 'dienstfertig', 'schmeichlerisch'. дивьныи (von диво 'Wunder'), 'wunderbar' im Sinne von 'schön', 'herrlich'. Wie sich eine solche Modifikation vom Altrussischen bis hin zum modernen Kussisch vollziehen kann, sel an zwei Adjektiven beispielhaft demonstriert: правильный heiвt im modernen Kussisch 'richtig', 'regelmäBig', 'korrekt', 'normal' (nach dem wörterbuch von Pavlovskif). Fur das Ar. gibt ireznevskij die Bedeutung wieder: 1. 'sich auf die Kirchengesetze beziehend', 2 . 'den Kirchengesetzen gemäB', 3. 'gesetzmäßig', 'eine gesetzmäßige Kraft habend'. Kuss. искренны 'aufrichtig', 'wahrhaftig', bringt Vasmer in Zusammenhang mit ar. искрь 'nahe', aksl. искрьнь 'der Nächste'. 43 Die Bedeutung des Transferendums war ursprünglich anders als die des neuruss. Adjektivs. Im Ar. existiert das transferierte Adjektiv (E>A) искрьнии Sr. I, 1120, In den meisten Failen in substantivierter Form belegt $(E>A>0)$.

Trotz der in einigen Punkten erhobenen Linwände werden wir der Translationslehre Tesnières folgen. Sie allein gibt uns die Möglichkeit, die konkurrierenden adjektivischen Fügungen methodisch einheitlich zu erfassen und eine Differenzierung der Translative durchzufuhren, die zusatzlich zur Funktion der Tran lation eine semantische Beziehungsbedeutung haben bzw. eine Fixierung der Bedeutung des Transferendums bewirken.

43vasmer, Max: Russisches etymologisches iörterbuch. Heidelberg 1953, Bd. I, S. 488. 
\$22. Wir hatten bereits erwähnt, daß das slavische eine uberaus groBe Vorliebe fur suffixale Ableitungen hat. Dies zu wissen, ist besonders für die lbertragung aus dem Russischen von Wichtigkeit. Es gibt Fälle, wo bei der tibertragung eines russischen suffixal gebildeten Substantivs in eine rügung vom Typus "determiniertes Substantiv + determinierendes Adjektiv" ein fixierbares Regens aus dem Suffix dieses Substantivs und das determinierende Adjektiv (subordonné) aus dem Stamm (nicht Transferendum, da sich durch die suffixale Ableitung die Wortklassenzugehörigkeit nicht aindert) erschlossen werden kann. Къняхичь Sr. I, 1400 bedeutet "Sohn des Fürten". Es entsteht also bei der libertragung ein neues Regens, welches aus dem $S u f f 1 x$ abstrahiert werden muB, während die elgentliche Basis zum subordonnt wird. Aus einem Einwortlexem entsteht eine rugung, die ein neues subordoniertes Glied benötigt. Damit kann auch den Suffixen unter gewissen Bedingungen ein semantischer Gehalt zugesprochen werden, sie wirden in diesen Fällen den Lexemen naher stehen als den Morphemen, um in den Begriffen Martinets zu sprechen.

Der semantische Kern des Suffixes läbt sich für eine Reihe von suffixalen Ableitungen fixieren. Dies gilt in erster Linie für

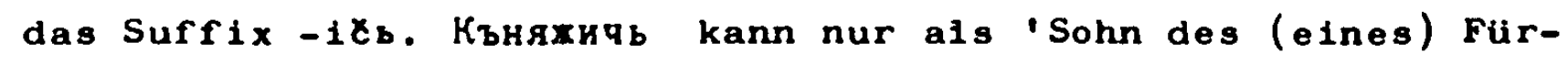
sten' ubertragen werden. Das Suffix enthalt in sich das Lexem 'Sohn'. Als subordonné muB bei der Ubbertragung die Basis des Derivats gelten. Diese Basis ist bei Ableitung auf - its immer lersonenname oder ein Appellativum, das eine Person bezeichnet. Die Ableitung къняхичь von кънязь darf nicht als Transiation im Sinne Tesnières bezeichnet werden, da sich ja kein Wechsel der wortklassenzugehörigkeit vollzieht. Vgl. die Belege zu-itb

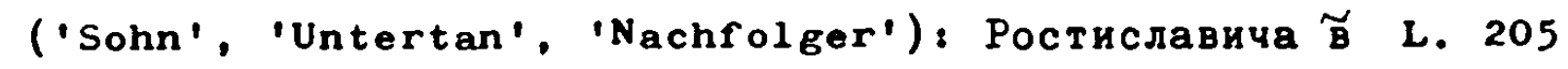
'die zwel Söhne des Rostislav', ЯрославичI Изязлавъ Стославъ Всеволодъ L. 181, не хочю розути робичича L. 76 'ich will nicht dem Sohn einer Sklavin die Schuhe ausziehen', a Bятko cᄒде[...] по Оць, от него хе прозвашася вятичи LL. 14. Mit вятичи sind 'Sühne' im weiteren Sinne gemeint: 'Untertanen'. 'Nachfolger' oder dergl. So wird sich auch die Entstehung des Dorfnamens vom Тур Ольхичи (и есть село ее Ольхичи и доселе L. 60) zu erklaren haben: 'Wohnsitz der Untertanen 0lgas'. 


\section{VGl. Ferner:}

стрничичв Sr. III, 564 'Sohn des Onkels'

сестричичь Sr. III, 341 'Sohn der Schwester'

поповичв Sr. II, 1194 'Sohn des Popen'

отьчичь Sr. II, 832 'Nachfolger des Vaters'

мачешичь Sr. II, 120 'Sohn der Schwiegermutter' (matecha)

королевичь Sr. I, 1289 'Sohn des Königs'

дядьковичь Sr. I, 804 'Sohn des Erziehers der Kinder'

братичичв Sr. I, 169 'Sohn des Bruders'

блудничичь $\left(-1 \mathrm{ZZ}_{b}\right) \mathrm{Sr} . \mathrm{I}, 117$ 'Sohn einer Hure'.

Der semantische Kern des Suffixes läßt sich ferner fixieren bei Ableitungen auf $-(j)$ aninb als 'Bewohner von ...' : римляне

L. 114, корсуняне L. 109, украинянинъ Sr. III, 1185,

слободъчанинъ Sr. III, 415, поселянинъ Sr. II, 1230,

посаханинъ Sr. II, 1230, городъчанинъ Sr. I, 558, vgl. auch

Stammesnamen wie Деревляне L. 57 und Поляне LL. 13, и придоша ко Мьньску и мъяне затворишася L. 166. Merkwirdig ist Кыяне L. 147, da als Basis nicht der Ortsname, sondern der personenname des sagenhaften Begrunders dient, hier darf also nicht ubertragen werden 'Bewohner Kyjs', sondern 'Bewohner Kievs'.

Ganz ähnlich sind natürlich die Черниговци L. 201 'die Einwohner Cernigovs', ebenso vgl.: Новъгородци, Бълозерци , Переяславци u. dgl. ähnlich den Bildungen auf -er im Deutschen ('jchweizer', 'Engländer' u. a.).

Bel der Vorliebe der Slaven für suffixale Bildungen ist es nicht verwunderlich, wenn dort, wo wir Komposita oder Genitivkonstruktionen verwenden, im Russischen solche suffixalen Bildungen stehen.

Die Fixierung des semantischen Kerns kann manchmal nicht für die gesamte Gruppe der Suffixe einheitlich vorgenommen werden, sondern nur im Einzelfall. Wohl ist тетеревина Sr. III, 953 'Fleisch der tetereva' (Fasan) und говядина Sr. I, 533 'Fleisch vom Rind', aber овьчина Sr. II, 597 kann auch 'Scharfe11' bedeuten, ebenso телятина Sr. III, 946 'Ks1berhaut' und дъдина Sr. I, 782 schlieBlich bedeutet 1.'Erbe', 2 . 'Herr- 
schaft', 3. 'Sitto', 4. 'Gesetz der Vater (Großväter)'. Eln отьчникъ Sr. II, 832 lst ein Paterikon, ein rостиньникъ Sr. I, 567 ubersetzt Sroznovokij mit "coдерхатедb rостиници ". Vil. rerner:

вьрбница 'Palmsonntag', Sr. I, 460

ПLековица
Хоревица $\quad \begin{aligned} & \text { 'Berg des Jtek.bzw.Chor' } \\ & \text { (in der Laurentius-Chronik) }\end{aligned}$

Овчухъ Sr. II, 598 'Schafhirt'

братана Sr. I, 166 'Tochter des Bruders'

стрынна Sr. III, 564 'Frau des Onkels' (Bruder d. Vaters)

братаанина Sr. I, 167 'Tochter des Bruders' (братанъ)

очина L. 67 'Vatorland'

дъдичьство Sr. I, 783 'Erbe des Großvaters'

дьдьньство Sr. I, 783 'Recht auf das Erbe des Großvaters'

Im letzten Beleg mussen dem Suffix sogar zwel Lexeme (Sememe)

bei der ibertragung zugeordnet werden.

Bei den oben angefihrten Belegen sind die wichtigsten Suffixe angefuhrt, bei denen sich ein somantischer Kern herauskristallisieren laBt. Eine einheitliche Fixierung des neuentstehenden und zu bestimmenden Regens $1 \mathrm{BBt}$ slch allerdings nur bel einigen von ihnen vornehmen. 
V - Die konkurrierenden adjektivbildenden Translative und Möglichkelten einer Differenzierung

$\S 23$. Bei der Behandlung adjektivbildender Translative in Altrussischen ist es im Rahmen dieser Arbeit natürlich nicht mög$11 \mathrm{ch}$, Jedes einzelne dieser Translative so eingehend zu behandeln wie dies bei einer Einzeldarstellung - etwa uber den adnominalen Genitiv - der Fall sein mubte. Andere, wie die Suffixe -ov-it- oder -ov-at- werden schlieblich kaum berucksichtigt. Neben anderen häufig vorkommenden Translativen sind sie in einer so geringen Zahl belegt, daB sie als Konkurrenten innerhalb eines Systems von konkurrierenden adjektivbildenden Translativen kaum eine Rolle spielen. Ziel der Arbeit ist ja, nach unterscheidenden Merkmalen einzelner Translative gegenüber deren Konkurrenten zu suchen. Wenn nun sechshundert gesammelten Adjektiven auf -bn- nur drei bis vier auf -ov-it-gegenuberstehen, läbt sich uber mögliche unterscheidende oder identische Merkmale wenig sagen. Wir missen hier also eine gewisse Auswahl treffen, indem wir kaum gebrauchte adjektivbildende Translative ausklammern. Andererseits können bestimmte Mittel der Translation $0>A$ nur exemplarisch behandelt werden, da sie zwar unter den methodischen Aspekten dieser Arbeit von Interesse sind, thnen aber schon auf Grund ihrer Bedeutung und der uberaus großen Fülle an Belegen eine eigene Varstellung gebürte. Es handelt sich dabei vor allem um die Kumposita und präpositio. nale Fügungen. Sie werden in den folgenden Kapiteln nur kursorisch unter Bericksichtigung der methodischen Aspekte der Arbeit behandelt.

$\S 24$. Als Translative der Translation $0>A$ sind zu bericksichtigen:

a) Kasus: adnominaler Genitiv, adnominaler Dativ, ferner Instrumental und Lokativ, Präpositionen + Kasus,

b) Kompositionselemente,

c) die einfachen Suffixe -ov-/-ev-, -in-, -j-, -bj-, -bn-, -bsk- (bst-) $44,-a t-,-a v-,-1 v-,-11 v-$ sowie die zusam-

44-bsk-wird hier nicht von -bst-getrennt, da-bst- nur die lautliche Sonderentwicklung von -bsk- ist. 
nengesetzten Suffixe -ovit-, -ov-bok-, -bnj-. Einige nur als Rarititen belegte Suffixe worden in dieser Arbeit nicht berlicksichtigt. In diesem Zusawenhang sei auf den Bd. I von Vondraks "Verglelchender slavischer Granatik" hingewiesen, 45. ferner auf die bereits erwähnte Arbelt von Brodowska-Honowska, welche auf der Basis aks1. Materials beruht und alle suffixal abgelelteten Adjektive anfürt.

d) Endungsnorphene als Translative (vgl. 'zolotoj').

-) Translatir "z6ro", d. h. die Translation besitzt kein sichtbares Zeichen. (Es handelt sich hierbei um asyndetische Fugungen.)

In dieser Arbelt werden im wesentlichen adnominaler Genitiv und Dativ sowie die wichtigsten Suffixe als Translative der Translation O) A behandelt. Translative, deren Bedeutung oine gesonderte Behandlung erfordern, können nur exemplarisch herangezogen werden.

\$25. Die Adjektive werden von den russischen Forschern in allgemeinen in drel Klassen eingeteilt: "kacestrennye". (Qualitätsadjektive). "otnositel'nye" (Bezienungsadjektive) und "pritjazatel'nye" (Possessiv- oder Zugehörigkeitsadjektive). EIne solche Klassifizierung ist schon deshalb problenatisch, weil semantische und strukturelle Gesichtspunkte veralscht werden. Tesnière tut dies ebenfalls, wie anhand der bereits auf 5.22 angefuhrten Tabollo ersichtlich ist. Der Begriff "Wualititsadjektive" hat mit struktureller Syntax nichts zu tun. Indessen hat Tesniòre ja zwischen struktureller und semantischer Ebene im allgemeinen unterschieden. Der Vorgang der Translation wird durch eine zusätzliche Differenzierung der Adjektive (adjectifs d'appartenance, adjectifs qualificatifs u. dgl.) nicht beruhrt. Heder "Qualitäts"-adjektive noch Numeralia müssen transferiert sein. Dennoch ist eine Differenzierung auch der transferierten Adjektive notwendig, die zu allgemelne Bezelchnung "Beziehungsadjektive" genügt nicht. Die traditionelle Unterteilung aber lot kaum befriedigend.

45 Vondrak, Wenzel: Vergleichende slavische Gramatik, Bd. I, Lautlehre und Stammbildungslehre, Göttingen 1924. 
Ein groBer Teil der Adjektive, die als "otnositel'nye" bezeichnet werden, sind beispielsweise gleichzeitig durchaus als Qualitätsadjektive zu bezeichnen, geht man von ihrem semantischen Gehalt aus, wie etwa ar. высокоумьнии 'sehr klug', племенитын 'nobilis', боязливыи 'ängstlich'.

§ 26. Ganz abzulehnen ist die Bezeichnung "Possessivadjektive". Cernych zum Beispiel hat in seiner historischen Grammatik der russischen Sprache solche sogenannten "Possessivadjektive" in einem eigenen Kapitel behandelt. Formales Kennzeichen seien die Suffixe -ov-/-ev-, -in-, -j- + nom. Endungsmorphem. 46 sicher mag der Begriff "Possessivadjektive" für manche dieser Adjektive im konkreten Fall zutreffen, etwa сестринъ домъ. obwohl auch possessiv höchstens die Beziehung zwischen Transferendum und Kegens genannt werden kann. Andererseits könnte eine Vielzahl der "otnositel'nye" genausogut in diesem Sinne al Possessivadjektive gelten, z. В. в сельхъ нбеныхъ L. 138 , Лядьскую землю L. 145, Гречьскую землю L. 110 u. a. m. Dаgegen liegt in Figungen, wie слово о плъку Игоревt oder солъ Игоревъ L. 46, о оубьньи Борисовь L. 132 (Objektverhältnis!), wo die Adjektive herkömmlicherweise als "Possessivadjektive" bezeichnet werden, doch definitiv kein Besitzverhältnis vor. Eine scharfe Grenze zwischen Beziehungsadjektiven und Possessivadjektiven läßt sich so kaum feststellen. Mit dem russischen Begriff "prinadleznost" wird wohl ein umfangreicherer semantischer Bereich erfaßt. Darin lieBen sich aber bei weiter Auslegung des Begriffes alle möglichen Figungen unterbringen, so daß er dann absolut wertlos wäre. Kudolf Zimek nimmt in seinem Aufsatz "K chápań posesivnosti" zum Problem der sogenannten "Possessivität" folgendermaßen Stellung: "[. .] posesivnost, jako kategorie logicko-sémantická, se musl dát vyjádrit - podle

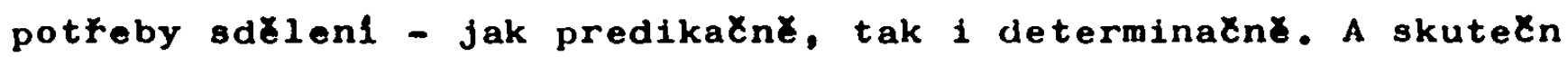
pozorujeme dưsledný paralelismus mezi posesivnostl téhoz věcného významu, vyjádxenou jednou atributivne, jednou predikazne [.. g $]^{n}$. In allen Fällen, in denen eine solche

${ }^{46}$ Tschernych, P. J.: Historische Grammatik der russischen Sprache, Halle 1957, S. $176 \mathrm{ff}$.

47 Zimek, Rudolf: K chápání posesivnosti. In: Kusko-ceské studí Praha 1960, S. 133. 
Parallelitä, wie 'moja kniha - mbe knihu' nicht rorliege, könne man nicht von Possessivität sprechen. Zieek bedient sich also - ohne dies ausdrucklich so zu nennen - des Mittels der Transformation. In der Tat ist aber auch zimeks Versuch, oin Possessivverhältnis zweier Substanzen zueinander auf Grund der transformationelien Methode festzustelien, nicht sonderlich brauchbar. Dies liegt darin begrlindet, daß der Verbalbegriff, der der Transformation zugrundegelegt wird, nicht in allen fällen eindeutig zu fixieren ist: Vergleiche etwa rpanz Ольговъ L. 75 'die Stadt Olegsi: Die Stadt kann 0leg "gehören", er kann "In ihr herrschen". Was gemeint ist, geht in den meisten Fällen nur aus dem Kontext hervor, nicht aber aus einer einfachen Transformation auf die sogenannte Ausdrucksebene. Vergleiche ebenso: яma корабль Гльбовъ L. 136. Aus dem Kontext geht hervor, daß $Г \pi \sigma_{b} \mathrm{sich}$ auf dem genannten Schiff zum Zeitpunkt seiner Gefangennahme aufhielt. Ob es thm gehöt" hat, läbt sich ohne weiteres gar nicht sagen.

$\$ 27$. Admoni 48 unterscheidet qualitative (absolute) und relative Adjektive, unter den relativen wiederum syntaktisch-relative, semantisch-relative und etymologisch-relative. Die semantisch-relativen Adjektive fordern den syntaktischen ZusammenschluB mit zwei substantivischen wörtern (z. B.: 'ähnlich', 'gleich' u. dgl.). Hier sind eigentlich nur die semantischrelativen und etymologisch-relativen Adjektive von Interesse. Bei den semantisch-relativen Adjektiven findet "ein Verhältnis, eine Kelation" statt, die außerhalb des Dinges hinausfihrt, das vom Adjektiv bestimmt wird:

Man hat es hier also mit zwei Dingen zu tun, die aufeinander bezogen sind, wogegen bei den nicht relativen Adjektiven (sie werden "qualitative" genannt) nur von einem Dinge und seiner Eigenschaft die Rede ist. Die relativen Adjektive dieser Art, die den qualitativen gegenuberstehen, werden wir als semantisch-relative bezeichnen. Formell unterscheiden sich die semantisch-relativen Adjektive von den qualitativen dadurch, daB sie keine steigerungsformen aufweisen, wenn sie nicht in ubertragener Bedeutung als qualitative Adjektive gebraucht werden. Zweitens werden von den semantisch-relativen Adjektiven meist keine Kurzformen gebildet (gilt nicht fur das Ar.)." Den seman-

48 Admoni, A.: Stroj nemeckogo jazyka - Der Bau der deutschen Sprache. Moskva, Leningrad 1966. 
tisch-relativen stehen die etymologisch-relativen gegenuber: "Nur wenn man die Relativitat der Adjektive als etymologische Relativitát versteht, ist es möglich, die Stoffadjektive, wie es in der Regel geschieht, zu den relativen Adjektiven zu zăhlen. In den Adjektiven 'hölzern' ('die hölzerne Bank') und 'golden' ('die goldene Uhr') deutet ja die Semantik des Grundmorpheme keineswegs auf die Relation zwischen zwei Dingen: 'Holz' und 'Gold' erscheinen hier nicht als irgendwelche abgesonderten Dinge, die von soIchen Dihgen, wie 'Bank' und 'Uhr', abgetrennt sind und thnen gegenuberstehen, sondern als der Stoff, aus welchem die Bank oder die Uhr gemacht aind [...] Hier findet kein äußeres, sondern ein inneres Verhältnis statt. Vom Standpunkt der semantischen Relativitat aus sind also die Stoffadjektive qualitativ." 49

In der Fügung глава коняча L. 74 hätten wir ein semantischrelatives Adjektiv vor uns, in neuruss. заячья manka jedoch ein etymologisch-relatives. Wir sehen, die "osnova" spielt auch bei Admont gar nicht die allein entscheidende Kolle, vielmehr auch das syntagmatische Gefige, der Kontext. Die Darstellung Admonis scheint noch am meisten Konsequenz zu zeigen, wenn auch der Begriff "Qualitätsadjektive" stört, denn die Qualitát des Determinatums kann ja auch grundsätzlich durch eine begriffliche Beziehung zum kegens fixiert werden, wobel der Kontext zu berucksichtigen ist. In der Fügung сукин сын 'Hundesohn' wird durch begriffliche Verknupfung von 'Sohn' und 'Hündin' uber die"Qualität" einer im Kontext ganannten Person ein Urteil abgegeben.

\$28. Isazenko unterscheidet die Adjektive folgendermaßen:

1. "Adjektive, die das Morkmal des Gegenstandes nicht unmittelbar nennen, sondern durch einen Hinweis auf einen anderen Gegenstand oder durch einen Vergleich ausdricken." (Beziehungsadjektive)

2. "Adjektive, die das Merkmal unmittelbar nennen oder dieses Merkmal als Érgebnis eines werturteilo hinstellen." (Qualitätsadjektive)

3. "Adjektive, die ein Besitzverhältnis oder die Zugehörigkeit zu einer Person ausdrucken." (Possessivadjektive) 50

Zumindest die Unterscheidung zwischen Beziehungsadjektiven und

49 a.a.0.. S. 145-146.

50 Isacenko, A. V.: Die russische Sprache der Gegenwart, Te1l I, Halle 1962, S. 134-135. 
Possessivadjektiven ist eindeutig falsch, wie bereits dargelegt. Wenn Isatenko fur "относитедьные придагатедьные " als Belspiel cобачья конура 'Hundehutte' bringt, so muB nan sich wirklich fragen, ob denn hier kein "Zugehörigkeitsverhailtnis", von dem ja sonst immer gesprochen wird, vorliegt. Im ubrigen wirde auch nach der Klassifizierung Isacenkos fur die "притяхатедьные прилагательные " die Definition wie unter 2) gelten, so daß die Dreiteilung wieder aufgehoben wäre. Wenn im folgenden bei Isacenko formale Kennzeichen fü die "Qualitäts"-adjektive gegeben werden, wie z. B. der Gebrauch der Kurzform in prädikativer Stellung, Bildung von Steigerungsstufen, Verbindung mit Gradationswörtern 51 u. dgl., so ist dies richtig beobachtet. Es ist jedoch fraglich, ob man gerade solche rein formalen Kennzelchen heranziehen sol1, um einen Begriff wie "Qualitäts"-adjektive zu deuten. Man könnte dann genausogut zwischen Adjektiven unterscheiden, fur die solche wie die aufgezahlten formalen Kennzeichen gelten oder nicht gelten. Wie problematisch die Klassifizierung Isazenkos ist, wird durch die Elnfuhrung des Begriffes "relativ-wertende Adjektive" (die "etymologisch-relativen" bei Admonil) ersichtilch: "Das Adjektiv e $i$ e $n$ enthält einen Hinweis auf einen bestimmten Stoff [...] und meint soviel wie "aus cisen". Es ist somit ein Beziehungsadjektiv. Wird es aber in libertrigener Bedeutung gebraucht, z. B. $\quad i s$ e $r e N$ e $v$ en, dann verliert es diese seine Bedeutung und erhält die Bedeutung eines relativ-wertenden Adjektivs [. . ] $]^{\text {n } 52}$

Dazu ist zu sagens 1. wird nicht nur das Adjektiv, sondern bereits das Transferendum in ubertragener Bedeutung gebraucht, 2. könnte 'eisern' auch in nicht libertragener Bedeutung Art und Beschaffenheit eines Gegenstandes kennzeichnen, 3. wenn man sagte: "Nerven wie Eisen", dann machte das keinen großen Unterschied zu den sonstigen "Beziehungsadjektiven" aus, gleichgultig ob es sich um eine ubertragene Bedeutung handelt oder nicht.

\footnotetext{
${ }^{51}$ Is axenko, a.a.0., s. 135 . 52 a.a.0.. s. 137 .
} 
Indessen ist das Problem bei Isazenko im Kern sehr wohl erkannt. Er nennt es nUbbergang der Adjektive in eine andere semantische Klasse". Isatenko bringt Beispiele wie nоверхностная хенщина 53. Hier ist in der Tat ein direkter Vergleich zwischen поверхность und женщина nicht möglich. vir mussen sagen - Isatenko bringt solche Begriffe nicht -, daß hier eine Modifikation des Transferendums durch das Translativ bewirkt wird, denn im Begriffe der oberfläche ist nicht eo ipso der einer negativen charakterlichen Eigenschaft enthalten. Aus diesem Grunde muß man auch von dem Adjektiv 'oberflächlich' ein Substantiv 'Oberflächlichkeit' (nach Tesnière "translation doublen') bilden, da das mit 'Oberflächlichkeit' Gemeinte nicht schon im Begriffe der Oberfläche von vornherein enthalten ist. Im Russischen ist der Vorgang ganz ähnlich, hier bildet man von dem Adjektiv nоверхностны, das wiederum aus поверхность transferiert ist, das Substantiv поверхностность mit Suffixreduplikation. Ein ähnliches Beispiel bringt $H$. Wissemann mit dem Adjektiv голубои, welches Hauptbegriffe determiniert, die mit dem Substantiv 'Taube' nichts zu tun haben. 54 Indessen ist es zugegebenermaBen oft sehr schwierig, hier die Grenzen genau zu bestimmen.

$\$ 29$. In dieser Arbeit werden Adjektive grundsätzlich als Determinanten nominal-syntagmatischer Fügungen, welche in den Bereich der Determination und Subordination fallen, untersucht. A. Martinet spricht von zwei Arten der Erweiterung, der Koordination und der Subordination. 55 Koordination liegt dort vor, wo die Funktion des hinzugefugten Elementes mit der eines im selben Kahmen schon vorhandenen blementes bereits identisch ist im Gegensatz zu der Subordination, wo die Funktion des hinzugefügten Elementes angezeigt ist, entweder durch die stellung des neuen Elementes gegenuber der Einheit, bei der es eine Funktion ausubt, oder durch ein sogenanntes funktionales Monem. Zum Be1-

53 a.a.0., s. 137 .

54 uissemann, a.a.0.. S. 285

55 Martinet, Andre: Grundzüge der Allgemeinen Sprachwissenschaft Vom Verf. autorisierte dt. Ausgabe, Stuttgart 1963, S. 117. 
spiel in 'poussière de la route' wird die Erwelterung durch Subordination mittels des funktionalen Monems 'de' angezelgt. 56 Martinet definiert das funktionale Monem dahingehend, daß es dazu diene, die Funktion eines anderen Monems anzuzeigen. In dem Satz 'il a donnb le livre à Jean' zeigt 'à' die Funktion von 'Jean' an, d. h. die Beziehung zwischen einen Erfahrungselement und der Erfahrung im Ganzen wird gekennzeichnet. So wird auch die Funktion der Lrweiterung - hier Unterordnung 'de la route' in 'poussière de la route' durch das funktionale Monem 'de' angezeigt. Martinet stimmt mit Tesnière darin uberein, dak der Begriff der Subordination bet inm ahnlich definiert wird. Durch das funktionale Monem 'de' wird 'la route' 'poussière' untergeordnet. Martinet geht aber nicht so weit, 'de la route' als Adjektiv zu bezelchnen. Ferner räumt er den Suffixen nicht eine gleiche mögliche Funktion ein. Man wird aber zugestehen müssen, daß es relativ belanglos in bezug auf die Funktion ist, ob das Monem nun lsoliert auftritt oder in der Ableltung. Fur Martinet vollzieht sich auch kein kategorialer Wechsel durch Subordination. Das funktionale Monem nimmt in dem erwähnten Beispiel elne Stellung zwischen - um die Terminologie Tesnières zu gebrauchen - dem Regens und dem Transferendum ein. Tesnière hat die mögliche Gleichwertigke1t von Kasusmorphem, Präposition und Suffix besser erkannt als Martinet, der mehr von der besonderheit der französischen Sprache auggeht.

Wir hatten gesehen, daB die Translationstheorie Tesniéres Konkurrenten zusammenfuhrt, die ihrer Funktion und ihrer Stellung im noeudsubstantival nach gleichwertig sind. Eine weitere Differenzierung dieser transferierten idjektive ist für die strukturelle Syntax Tesnières gar nicht von Interesse. Wenn im folgenden also mit Begriffen Tesnières gearbeitet wird, auch dann, wenn semantische Sachverhalte charakterisiert werden sollen, so deshalb, um nicht ein zweischichtiges Begriffssystem zu benutzen. Man wird dann also sagen müssen, "das Transferendum bezeichnet", "das Regens bezeichnet" u. dgl. Damit wird die strukturelle Autonomie der Tesnidre'schen Syntax nicht beruhrt, $\overline{56 \text { a.a.0., s. } 118 \text {. }}$ 
es geht um zusätzliche Funktionen oder Bedeutungen, etwa des Translativa oder des Transferendums.

$\$ 30$. Fragen wir uns nun, wie wir zu einer Differenzierung der Adjektive unter Zuhilfenahme der Terminologie Tesnières kommen können. In dem berelts erwähnten Aufsatz H. Wissemanns wird festgestellt, daB allen adjektivbildenden Translativen im Russischen die Funktion der Translation, Subordination und Determination zu eigen ist. Daneben aber gibt es Translative, die eine zusätzliche fixierbare Beziehungsbedeutung beinhalten:

"Durch die Translationen хелезисты und медисты determinierten die Nebenbegriffe железо баw. медь nur solche Hauptbegriffe, durch die zu den Nebenbegriffen железо bzw. медь eine ganz bestimmte Beziehungsbedeutung realisiert wird, nämlich: 'das enthaltend, was der Nebenbegriff (das Transferendum) bezeichnet'." 57

Damit wären grundsätzlich zunächst einmal zwei Adjektivtypen gekennzeichnet. Ls gibt Adjektive, deren Translativ alleiniges Mittel der Syntax ist. Sio entsprechen genau Martinets runktionalem Monem. Es lassen sich dafur ganz bestimmte Translative ausmachen. Daneben gibt es ldjektive, deren Translativ eine fixierbare Beziehungsbedeutung zwischen kegens und Transferendum beinhalten. Hier muB man unterscheiden zwischen zwei Gruppen: nämlich solchen Adjektiven, bei deren Translativ in einer iberwiegenden Mehrheit eine bestimmte Beziehungsbedeutung festzustellen ist und solchen, bei denen sich dies nur im konkreten Einzelfall tun 1äBt. Dies bedeutet eine gewisse Modifikation der in dem Aufsatz von Wissemann gemachten Definition insofern, als man bei den meisten Translativen naturlich auch im Einzelfall eine fixierbare Beziehungsbedeutung feststellen kann, wenn dies auch nicht fiir die Mehrheit des gleichen im Gebrauch befindlichen Translativs gelten muB. Man wird hier am besten unterscheiden zwischen translativgebundener Beziehungsbedeutung und nicht translativgebundener Beziehungsbedeutung. Im ersten Fall läBt sich bei der Anwendung eines bestimmten Translativs meistens eine einheitlich fixierbare Beziehungsbe-

57 a.a.0., s. 289 . 
deutung feststellen, im zweiten Fall gilt dies nicht fü die uberwiegende Mehrheit des gleichen Translativs, sondern nur für Einzelfäle. Das Suffix -bn- etwa kann grundsätzlich reines Mittel der Syntax sein. Vergleiche: церковнур красоту L. 38 'Schönheit der Kirche', на оученье книжное L. 118/119 'Erforschung biblischer Schriften' (Objekt der Handlung). Es lassen sich auch die verschiedensten Beziehungsbedeutungen feststellen: дыло законьное Izb. 285. 'eine dem Gesetz gemäße = gesetzmäßige Suche', силу крестнуо L. 172 'vom Kreuz ausgehende Kraft', wobei eine Fixierung für die Gesamtheit nicht möglich ist. Dennoch unterscheiden sich die auf-bn-gebildeten Adjektive von denen etwa auf -j-gebildeten, wo die Fixierung einer Beziehungsbedeutung nicht einmal im Einzelrall mög1 ich ist.

Martinet ist sich nicht schlussig, ob er die Affixe den Lexemen (Semantemen) oder den Morphemen zuordnen soll: "Lexeme und Morpheme bilden zwei Pole, ohne das Vorhandensein vermittelnder clemente auszuschlieBen, die spezifischer sind als die Modilitäten oder die funktionalen Moneme und weniger spezifisch als in Vurchschnitt die Lexeme". 58 Aus dem bereits Gesagten ist ersichtlich, daB manchen Translativen nur eine syntaktische Funktion zukommt. Diese mußten nach Martinet eindeutig als funktionale Moneme charakterisiert werden. Es gibt jedoch andere Translative, die daneben noch einen semantischen Gehalt aufweisen und damit den I,exemen näher stehen.Dieser semantische Gehalt "ird allerdings erst durch Obertragung sichtbar, so etwa, venn wissemann железисты . медисты und andere gleichgebildete idjektive überträgt mit 'das enthaltend, was das Transferendum bezeichnet'.

Ls bliebe jetzt noch die Gruppe der Adjektive, die Isacenko relativ-wertend nannte. Diese entsprechen den etymologisch-relativen bel Admoni. Bei Adjektiven wie поверхностның könnte man von Modifikationstypen reden, diese sind auch im Altrussischen vorhanden. Aber nehmen wir etwa rолубой nесец 'Blaufuchs', so könnte übertragen werden 'Fuchs von der Farbe der

\footnotetext{
58 a.a.0., s. 126
} 
(wilden) Taube'. Indessen ist die Feststellung wissemanns treffend, daß hier keine direkte Beziehung zwischen "Fuchs" und "Taube" (wie etwa bei уств Днвпра zwischen устз und Днвпръ) besteht. Dis Translativ ist also nicht etwa funktionales Monem im Sinne Murtinets, es bedarf weiterer $Z_{w i s c h e n g l i e-~}$ der ('Farbe des Gefieders', 'Farbe des Felles'), um schlieblich noch zu einer Beziehungsbedeutung zu kommen, aber dies wird oft schon ein lieg über die Sprachgeschichte sein. Im Bewußtsein dessen, der голубой gebraucht, ist die Bedeutung von голубъ verblaßt. Wir missen diese Adjektive in ihrer Determinantenfunktion als den primären gleichiertig ansehen. Die Grenzen sind hier indessen wohl sehr fliebend.

Wir haben also drei Gruppen von transferierten Adjektiven zu unterscheiden:

1. Transferierte Adjektive, deren Translativ allein syntaktische Funktion besitzt. Wollte man in Begriffen der traditionellen Grammatik sprechen, mubte man beispielsweise die Suffixe (z. B. -ov-), die solche Adjektive bilden, als primär zur Morphologie und Syntax und nicht zur sortbildung ge. hurig betrachten.

2. Transferierte Adjektive, deren Translativ einen zusätzlichel semantischen liehalt hat, d. h. bei denen sich eine Beziehungsbedeutung fixieren läbt.

3. Trinsferierte Adjektive, die den primären gleichwurtig sind Die Adjektive entwickeln sich zum reinen bigensch ftsbegrif: wobei die Bedeutung des Transferendums verblassen oder sich ändern kann. Hier handelt es sich im allgemeinen um Modifik tionstypen.

59 a.a.0., S. 285 . 
fors

(40)

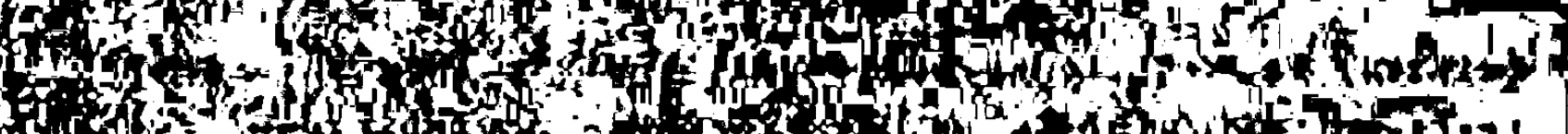
2. 740 a

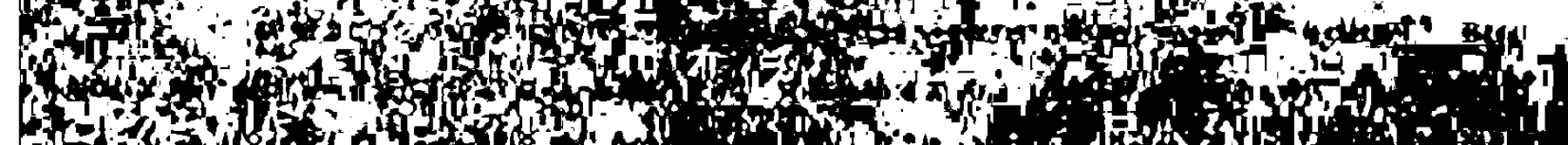
6)

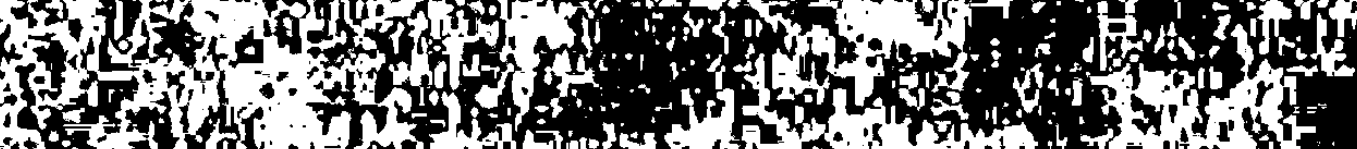

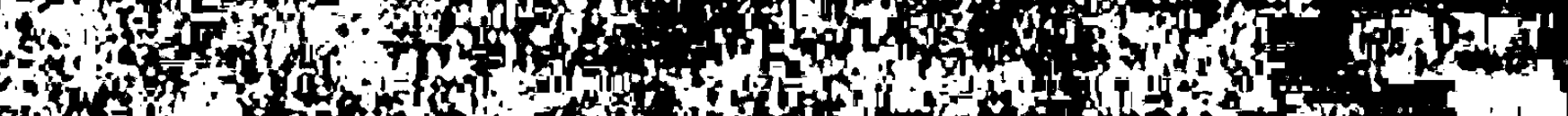

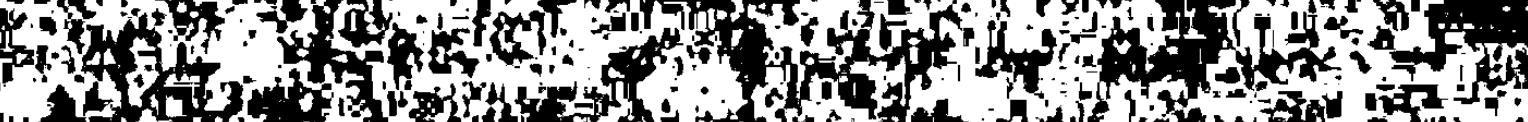

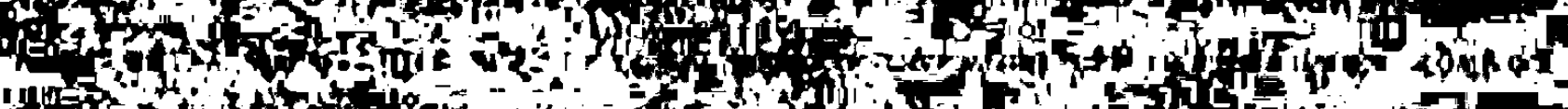

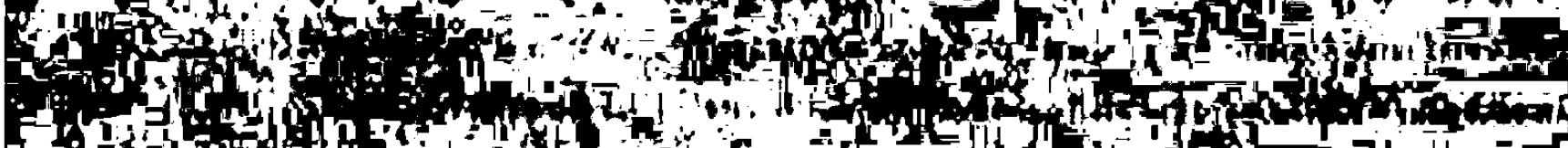
E4.

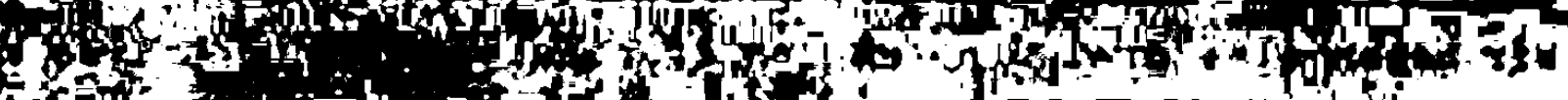

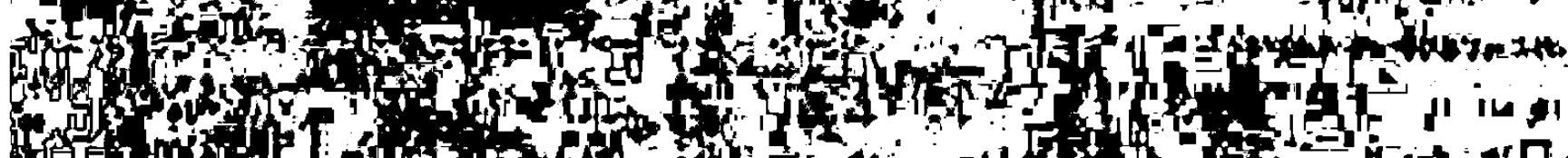

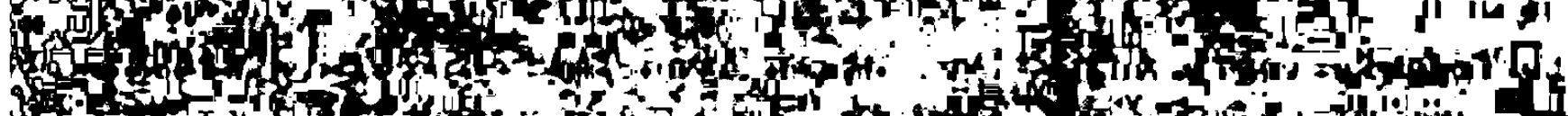
$f=\alpha$ a

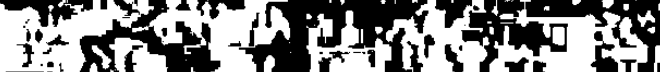

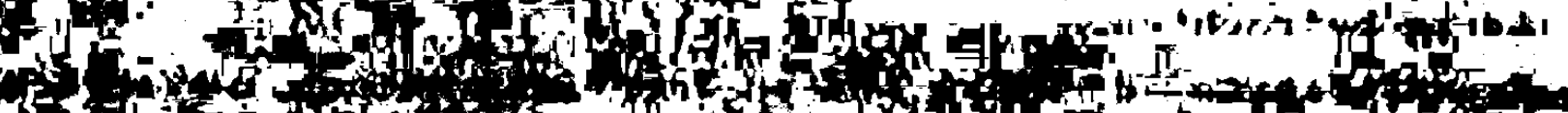

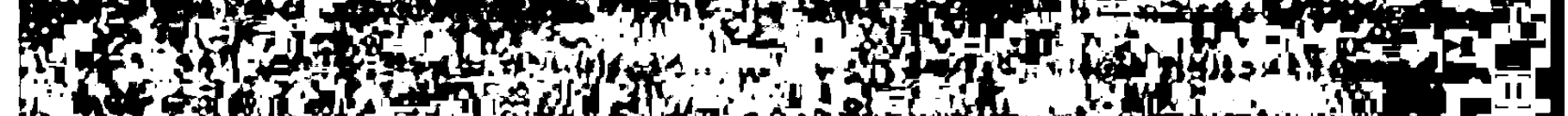

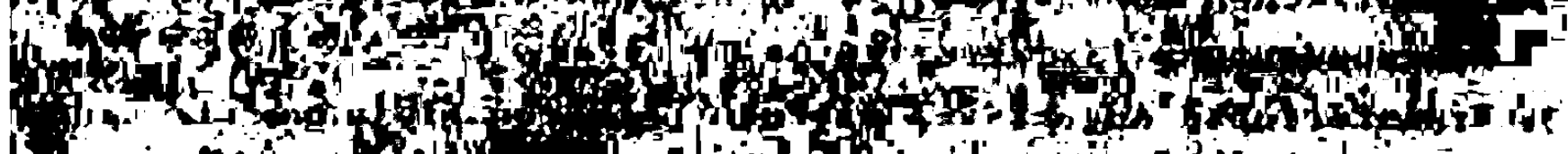

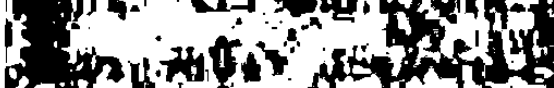

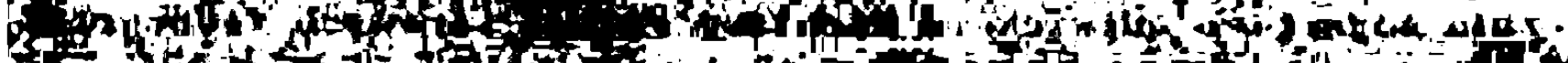

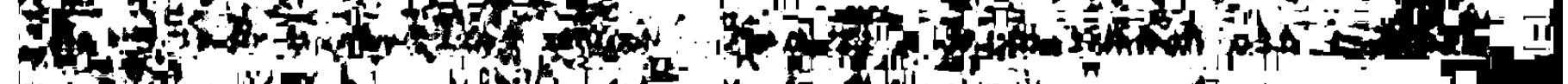

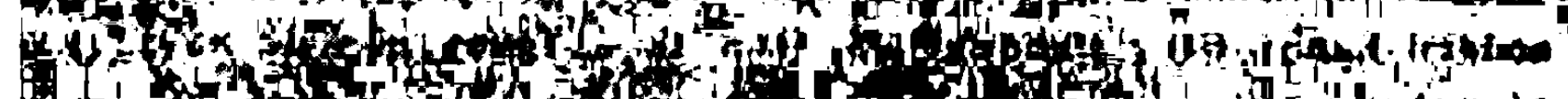

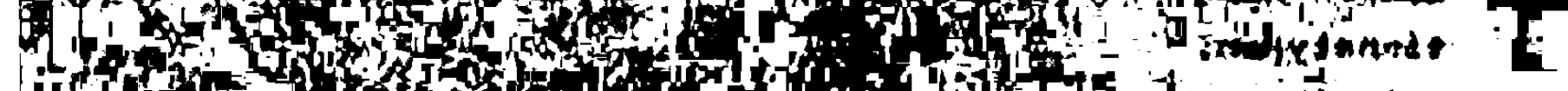

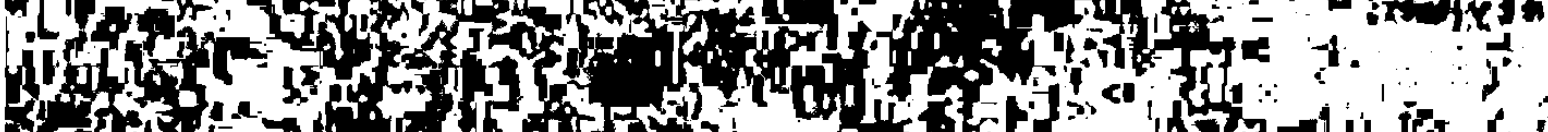


B. SPEZIELLER TEIL

I - Transiation O) A mit rein syntaktischer Funktion

\$31. Adjektive, die durch Translation $0>$ A entstanden sind und deren Translativ allein syntaktische Funktion hat, bestimmen innerhalb des noeudsubstantival die Seinsweise des Regens (des determinierten Gliedes) nur durch den adjektivinhärenten Bestandteil, der durch das Transferendum gegeben ist. Wir haben es mit einer begriffilchen Determination durch Relation zwischen Transferendum und Regens zu tun. Eine Fixierung der Bedeutung des Translativs im Einzelfall oder fü ein bestimmtes Translativ im allgemeinen kann nicht vorgenommen werden. Das Translativ wird gembib den Bedirfnissen des Kontextes fakultativ gebraucht. Wenn wir eine der oben beschriebenen Syntagmen transformieren, so wird bei der Transformation ein zusätzliches - nicht fixierbares - Glied benötigt, vgl. z. B. в законь Г С L. 97: Das Gesetz kann "erlassen werden", "eingehalten werden" "ausgeubt werden" u. dgl., d.h. der Verbalbegriff, der in der Beziehungsbedeutung steckt, labt sich nicht fixieren.

Translative mit rein syntaktischer Funktion sind im Altrussischen Genitiv, Dativ, Präpositionen, Kompositionselemente, das Translativ zéro (Asyndeta) sowie vornehmlich die Suffixe -ov-, -in-, -j-, -bj- jeweils in Verbindung mit nominalem Endungsmorphem. Im folgenden werden im wesentlichen die Kasus und die Suffixe behandelt, die ubrigen Translative nur kursorisch.

§32. a) Genitiv

Der Genitiv, der als adnominaler Genitiv im Altrussischen wie in allen älteren slavischen Sprachen eine geringe Rolle spielt mul in gewissen Fugungen stehen, d. $h$. der Genitiv kann nicht mit Suffixen konkurrieren - ähnlich gilt dies für den adnomina len Dativ sowie fur die Präpositionen - in folgenden Fällen, wie es Maria Widnäs dargestellt hat:

"I. когда при существительном со значением лица имелось определение (прилагательное или местонмение) ...

2. если существительное со значением лица имело при себе 
придохение, которое в свор очередь часто опредедядось прихагатедьным иди местовмением ...

3. есди собственное имя состоядо из двух иди трех сдов [...] 4. есди существитехьное со значендем дица бндо по своему происхохденио субстантввированным придагатедьным иди причастием [...] 5. когда необходимо было виразить принаддехность двум иди нескодьким дицам [.. ]" 60

Zu ergänzen wäre noch, daß der "roditel'nyj kacestrennyj" rom Typ чедовек высокого pocra und der "roditel'nyj kolicestvenny " vom Typ qama воды ebenfalls keine suffixalen Konkurrenten bel der Translation $0>A$ haben. Die Substanz dieser Feststellungen ist im wesentlichen seit den Zeiten von Miklosich bekannt. Vondrak weist indessen darauf hin, dab beim Gebrauch der sogenannten possessiven Adjektive zumindest im Altkirchenslavischen auch einige Fulle nachweisbar sind, wo die "Namen der Besitzer" d. 1.: der Transferenda noch von einem zusatzlichen Attribut begleitet sind, so z. B. etwa: vo drorb archiereov nartcamago Kaiffa Mt. 26,3 , stado svinoe monogo Lc. 8, 32 Sav. 61

Perner wird der Genitiv dort gebraucht, wo zwar ein konkurrierendes Translativ in Gestalt eines Suffixes vorhanden ist, sich aber bel den suffixal transferierten Adjektiven eine zusátzliche Beziehungsbedeutung feststelien labit bzw. diese in die klasse der transferierten Adjektive mit primärer Funktion (Modifikationstypen) fallen. Wollte der Schreiber suffixal transferierte Adjektive benutzen, so wirde dies dann zu MiBverstandnissen Innerhalb des gegebenen Kontextes fuhren. Vgl. etwa: исходъ его от дини въка L.100 oder до конца вька L.72. Letzterer Beleg ist dem Vertrag mit den Griechen vom Jahr 971 entnommen, es heiBt dort wörtlich: хочр имьти миръ [...] до конца вька. In der Sprache der Diplomatie heibt dies 'einen ewigen Frieden schließen'. Wenn es sich im vorliegenden Fall

60 Widnäs, Maria: 0 vyrazenil prinadleznosti pritjazatel'nym prilagatel'nym 1 roditel'nym padezom prinadleznosti v russkom jazyke XVIII - XIX VV. In: Scando-Slavica IV, 1958, S. 168.

61 Vondrák, Wenzel: Vergletchende slavische Grammatik, Göttingen 1928, S. 232. 
nicht um einen sprachlichen Topos 62 handeln wirde, der in der vorliegenden Form sicher aus dem Griechischen ubernommen wurde, so hätte man statt der vorliegenden Fugung durchaus вьчьныи миръ gebrauchen können, въчьныи миръ wäre glelchbedeutend mit миръ до конца въка, ьеide Fugungen wären lediglich stilistische Varianten.Nicht möglich aber lst do konbca vitsnago, was beweist, daB die Wahl des Translativs auch vom Regens innerhalb der syntagmatischen Fugung abhängig ist. Falls man do konbca vetsnago überhaupt übersetzen wollte, ergäbe sich der sinnlose Ausdruck 'zum ewig dauernden Ende', und das konnte der Schreiber nicht meinen.

§33. Diese Fälle, wo der nicht erweiterte Genitiv einfach stehen muB, nehmen unter den aufgefundenen Belegen, in denen sich der nicht erweiterte Genitiv in seiner adnominalen Funktio uberhaupt findet, den gröbten Raum ein. Vgl. dazu:

- смьшеньи языкъ L. (R,A)94 'Vermischung der Sprachen', налитье языка L.165 'AusgieBung der Sprache'. Die suffixale Translation erfolgt durch die Suffixe-bn- und -bsk-:язычьныи Sr.II 1649,язычьскыи Sr.III, 1650. Das Adjektiv язычьныи ist bei Sreznevskij nur in der Bedeutung иноплеменны und не христианския, языческий bеlegt. Für язычьныи werden fünf Bedeutungen angegeben: 1 . относящийя до языка, „2. болтливый, 3. невоздержный на язык, 4. иноплеменның, 5. не христианский. Die Ein deutigkelt der Beziehung auf языкъ im Sinne von 'Sprache' in de gegebenen Kontext bleibt also nur durch die Anwendung des Genitivs gewahrt.

и О призваньи странъ L.98 'Herbeirufen der (fremden) Stämme'. Zu dem Transferendum cтрана gibt es die suffixal transferierten Adjektive страньныи Sr.III, 540, страньскыи Sr.III, 541. Страньныи ist bei Sreznevskij belegt in der Bedeutung 1 . 6оковой, 2. иноплеменныи, 3. чухой, 4. удивительный, ป. непостихимын, 6. отварительныи, 7. зазорнын; страньскыи in der Be-

62 wir verstehen darunter den wiederholten oder ausschlieblichen Gebrauch einer Konstruktion, ohne dab formal ein Grund besteh gerade diese zu benutzen. Die Konstruktion lst jedoch im Verla der Sprachgeschichte zum traditionsgebundenen Begriff gevorde welcher oft wiederkehrt und aus anderen Sprachen ubernommen sein kann. 
deutung 1. "прилаг. отъ сл. страна въ знач. чугон народъ, 2. язнческин. In allen Fällen, in denen eln von cтpaнa suffixal abgeleltetes Adjektiv benutzt wirde, wäre also nicht klar zu erkennen, ob nicht eln Modifikationstyp vorliegt, obwohl sowohl dem Adjektiv страньннम wie dem Adjektiv cтраньския das Transferendum in der Bedeutung чухой народ zugrunde liegen kann. Beide Adjektive jedoch beinhalten auch andere Bedeutungen, so daß sie im Kontext nicht eindeutig zu fixieren wären.

на путь хеланіа Pat. 28

Dieser Beleg ist im Zusammenhang des Textes zu sehen. Dort ist dil Rede von elnem Jungen Mann, der das Bestreben hat, nach Kiev ins kloster zu gehen, er flieht von seinem Zuhause und findet zunächst den Weg nicht, nach Kiev zu gelangen. Nun könnte man путь хеланіа 1. als 'der gesuchte Weg', 2. als 'der Weg der Sehnsucht interpretieren. Im ersten Fall wirde mit Sicherhelt das Adjektir желаньныя Sr.I, 848 stehen, im gegebenen Kontext wäre die Fugung zu ubersetzen mit 'der gewungchte Weg', wobei nicht klar wäre ob es sich nur um den gesuchten Weg im geographischen Sinn handelteoder um den 'Weg des Verlangens'. Belde Möglichkeiten könnten grundsätzlich durch das suffixal transferierte Adjektiv ausgedrickt werden. Jedoch 1 st der Text im ganzen so pathetisch gehalten, das hier das eindeutige und stilistisch sicher höher liegende sprachliche Mittel gewählt wurde, nämlich der Genitiv.Damit lst dann eindeutig festgelegt, dab желание als von Gott eingegebene 'Sehnsucht' zu interpretieren ist. Dies erweist auch der weitere Text, wo es einige Zeilen welter - die Person, von der die Rede ist, hat nach Kiev gefunden he1Bt: "[..] яко въ тъи град идуть, възрадовася духомъ и прослави Бога, исполнившаго хеланіе сердца его [...]"

и обещася приьщати благодатіо даровъ Раt. 91:

Es gibt wohl ein даровьныи Sr.I, 630, aber nur in verengter Bedeutung, wobel das Transferendum Im Deutschen als 'Abgabe', 'Tribut' o. dgl. zu übersetzen wäre, vgl. etwa: A язъ далъ роукор своею и осеньнее полюдне даровьное польтретия десяте гривьнъ стиоу хе Георгиеви (Грам. II30 г.) Sr.I, 630 
да и мнь подасть чрдотвореніа даръ Pat. 125:

Das suffixal transferierte Adjektiv чудотворьнии bedeutet 'wundertitig', 'wunderwirksam'. Im Text des Paterikon lst aber'die Gabe, Wunder zu wirken' und nicht eine 'wundertatige Gabe' gemeint.

прилохеніа бользни Раt. 180:

Es existiert wohl das ohne Suffix und nur mittele des Endungsmorphems gebildete Adjektiv бользьнии Sr.I, 149, dessen Bedeutung nach Sreznerskif gleich 'malus' ist ("slovo bolrzno"), jedoch handelt es sich dabei um ein transferiertes Adjektiv mit primkirer Funktion mit der Bedeutung 'krank', im gegebenen Kontext könnte es nicht verwendet werden, da die Fugung dann ke1nen Sinn ergabe.

$\$ 34$. Wie berelte aus den bisher angefuhrten belegen hervorgeht lst das Regens oder die HauptgröBe, d, h. das determinierte Gli des Syntagma, sehr oft ein Verbalabstraktum, es liegt dabei diesen Substantiven die Transiation $I>0$ zugrunde. In der Tat machen diese Falle ungefahr neunzig Prozent der gesammelten Belege aus. In der Regel liegt dabel der sogenannte genitivus oblectivus vor. Vgl.:

в льт[0] созданиа иира $\tilde{c} \cdot \tilde{\mathbf{y}} \cdot \tilde{\mathrm{K}} \mathrm{L} \cdot 37$

- проклятьи земля L.89

и О сиьшеньи язика (язикъ) L.94

- призваньи странъ L.98

в оставленье грьвъ L.103

(нур.90, Ch.,p: rpbxоm = Dativ)

в отпущенье грьховъ L. 121

на погубление Гльба (Ch.,р:Гльбово !) нур.123

крови пролитье L.164/165 (Es kann sich hier un den adnominalen Genitiv wie Dativ handeln, L., R. und A sowie Hyp., Ch. und P. 153 haben hier Komposition: кровопролитье)

проявленье рати L.165 (Ganz analog lst elnige Zeilen weiter нахохенье рати L.165 gebildet.)

цвлованьь креста L.167. 
Man könnte sich lelcht zu dea voreiligen Schlub verleiten lassen, es sei den genttivischen Konstruktionen und den Komposita mit Kompositionsvokal -o-/-e- rorbohalten, das Objokt der Handlung auszudricken. Diese Ansicht läBt sich nicht halten. Denn schon anhand der im folgenden angefuhrten Belege, die ja nur repräsentativ fur eine beschränkte Auswahl aus der Fulle altrussischen Textmaterials sind, ist ersichtlich, daß auch mittels suffixal transferlerter Adjektive das objekt der Handlung ausgedruckt werden kann. $V_{\mathrm{g}} 1 .:$

чьтение книхьное Izb.185

на ученье книхное L.118/119

думая о строи земленем L.126

- крещеньи дытиннмь Sr.I. 795

на убинство Авғлево Нур.76

по убьеньи [...] герьцюковt Sr.I, 513

дїевьная ицеления Sr.I, 751

гудовное гьорение Sr.III, 601

Hierher gehören auch:

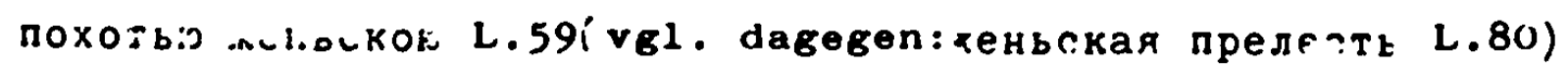

Воднбі danieis L.109 U. 221.

Wenn das Objekt der Handlung grundsätzlich auch durch ein suffixa: transferiertes Adjektiv ausgedruckt werden kann, so missen also andere Kriterien namhaft gemacht werden, will man erklären, daB als Determinans nur ein nicht suffixal transferiertes Adjektiv in Frage kommt. Bereits auf $S .52 \mathrm{f}$ wurde auf diese Kriterien hingewiesen. Der Genitiv - und dies gilt binnlich auch fur den adnominalen Dativ und die Komposition - wird in der Regel dort angewandt, wo das entsprechende suffixal transferierte Adjektiv, vorausgesetzt, daB eine solche Konkurrenz vorliegt, nicht eindeutig ausschließlich in die Klasse der Adjektive, deren Translativ allein syntaktische Funktion hat, fallon wirde, stattdessen durch seinen eigenen semantischen - u.U. modifizierten- Gehalt das Regens zusätzlich begriffilch determinierte. Eine vom Kontext abstrahierende, das Regens nicht beachtende Untersuchungsweise kann keine Aufschlusse geben.Anhand der Transferenda язнкъ und странаwar dies bereits exemplifiziert worden. Vergleichen wir noch einige der auf 5.55 angefuhrten Belege mit den konkurrierenden suffixal transforierten Adjektiven: 
В льто созданиа мира L.37:

мировыи, мирьныи, мирьскни, мировьныи haben als Transforendu мирз in der Bedeutung 'Velt' wie 'Frieden': amse миръныихъ (0>A>0) не останетъся печальи (Панд. Ант.) Sr.II, 151, завьтъ мирнии (Чнс.цXУ.) Sr.II, 151. In Verbindung att dem Regens co3дание wird der Gentiv zum Mitel der Fixierung der Eindeutigkeit.

- проклятьи земля L.89:

Die von земля bzw. земя abgeleiteten Adjektive земьныи, земьскии, земляныи können sich auf земля Im Sinne von Materie', 'Besitz' u. dgl. beziehen. Vgl. dazu §85.Im gegebenen Kontext wäre ihr Gebrauch $u$. U. verwirrend.

в оставленье грьховъ L.103 (Нур.90, Ch., Р.:грьхомъ) :

Das Adjektiv rpbшвныи findet sich durchaus als Modifikationstyp so z. B. wenn es griech. ن̀ıนós (изиде ис тебе нечистъи и

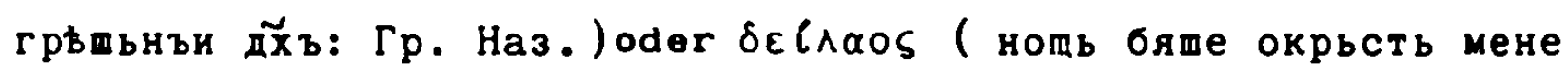
rрьшьнааго и не разоумьахъ: Гр. Haз.) Sr.I, 605 wiedergibt. Das durch das Suffix -ov-bn-transferierte Adjektiv rpвховьнии dürfte 'sündig' im Sinne eines primären Adjektivs 'schlecht' be deuten:rрвховьныими страстьми ( C6. I070 r.) Sr.I. 603.

Anhand dieser und der bereits vorher angefuhrten Belege wird der Unterschied zwischen Translativen mit nur syntaktischer Funktion und den Translativen, die elne Modifikation zum Eigenschaftsbegriff bewirken, deutlich. Wenn nur signalisiert werden sol1, daß elne begriffilche beziehung zwischen Regens und Trans ferendum des transferierten Adjektivs besteht, so wird der Genitiv bevorzugt, da er In der Regel das Regens eindeutiger determiniert. Die Adjektive auf -ov-, -in-, - j-, -bj-sind - insbesondere bel Transferenda, die Personennamen oder Appellativa für Personenbezeichnungen sind - hier die nächststehenden konkurrierenden Translative. So heibt es etwa in Hyp.123: на погубление Гльба, wăhrend Ch., Р. погубление Глебово haben.

§35. Auch wenn kein genitivus obiectivus vorliegt, wird, wenn das Regens ein Verbalabstraktum auf - ie oder ein Abstraktum uberhaupt ist, sehr häufig der Genitiv gebraucht: 
оскудыніе оч1р Pat.101

хеланіе сердда раt.28

премудрости глубину Раt.142/43

страсти человьчества L.113

удивашася терпенію муха Pat.169

начинанір сана Pat 101

ведичьства хенн Pat 148

от теченіа крови Pat. 148

Es erhebt sich die Frage, warum gerade als Regens so viele Verbalabstrakta wie uberhaupt Abstrakta auftreten. Dies kann darin begrundet sein, daß bei Adjektiven, deren Translative nicht eindeutig nur syntaktische Funktion hätten, eine Determination durch Adjektive mit zusätzlicher Beziehungsbedeutung bzw. primärer Bedeutung erfolgen wirde. Gerade das wäre aber bel dem Gebrauch des genitivus obiectivus unmbglich, dort, wo Verbalabstrakta als Regens am häufigsten auftreten. Es wäre naturlich denkbar, statt величьства жены Pat. 148 величиство женьское zu sagen. Aber dann wirde die Art von величьство bestinmt und damit uber 'die Gröbe von Frauen 1 m a 1 l e me 1 n $n$ ' etwas ausgesagt werden.

Bei manchen Fällen lst man geneigt, den Gebrauch des Genitivs als rein stilistisches Mittel anzusehen, beispielsweise bei закон отьць L.16 'das Gesetz der Väter', diese Fügung ist in der Laurentiuschronik auBerordentlich häufig belegt und als sprachlicher Topos anzusehen. Vgl. etwa auch и Соломон премудрости глубину постигъ раt.142/43; es gibt etwa auch прбмудростьныи источник Sr.II, 1668, jedoch dürfte diese Fügung als impropria dictio anzusehen sein. Gemeint ist ja 'die Quelle der Weisheit' und nicht die 'weise Quelle', was das suffixal transferierte Adjektiv grundsätzlich auch zum Ausdruck bringen könnte. Ein suffixal gebildetes Adjektiv mit an sich primärer Bedeutung ('weise') wird hier in rein syntaktischer Funktion angewandt. Im Izbornik von 1076 findet sich ein weiterer Beleg, der noch eindeutiger in den Berelch der impropria dictio gehört: не посмьи ся чюхему паденир Izb.296.ніer handelt es sich um ein nicht transferiertes primäres Adjektiv in rein syntaktischer Funktion. 
\$36. Eine weitere aurfullige Gruppe bilden die genitivischen Fugungen, wobel ein goographischer ort genauer bezelchnet wird. VG1. dazu:

въ устьи Дньпра нур.39 (einige Zellen velter: зимоватв въ вустьв Днвпра)

на устьи Пексни L.178

оба поль Днвпра L.141

( и сташа оба подъ рькы Бига L.169)

и ста Вододимеръ об онъ подъ города L.109

и съде о деснур отца L.113

въ отиа жсто L.132/ въ отиа mbто Pat.170

Въ Ярополка mbcro L.205

Wie wir noch sohen werden, wird bet ortsbezelchnungen auberordentlich huufig das Surfix -bsk-gebraucht. Jedoch lat don Fule gon mit so gobildeten Adjektiven oin stark generalisiorendes Moment zu elgen. So sollte man bel русьская земдя, welches die regulare geographische Bezelchnung ist, keine direkte determinierende Beziohung zwischen Русь und зekrsim Sinne der poetischen Ubersetzung 'russisches Land' annehmen, es handelt sich um eine absolut erstarrte Fugung.

Bekannt ist, dab bel genauen Zeitangaben rom Typ индикта двта L.226, въ I亏 день Aвгуста Pat.14 der Genitiv benutzt werdel muB. Mir kennen aus dem modernen Russisch otwa ein aвrycroвckih день 63 , os handelt sich bel dem gegebenen Beispiel jedoch nicht ue 'oinen bestimmten Tag im August', sondern un 'irgendeinen Augustag schlochthin'. Dies lst gomeint, wenn hier und im folgenden der Bogriff "goneralisierend" benutzt wird.

Es finden sich daneben - allerdings in nicht sohr grober Zahl Belege für den adnominalon Genitiv, wo die Möglichkelt einer Kategorisierung gering sind. In diesem Fall gibt os dann aber auch zahlreiche Varianten fur den Genitiv in Gestalt anderer konkurrierender Translative bereits in den Handschriften. VGl.:

63Aus: Slovar' sovr. russk. 11t. Jazyka, Moskva - Leningrad 1950-1965. 
сестра хе бь Добрыня (Gen. я furb) L.69:

R.: Добрынь (Gen.) А.: Добрынина (Suff.)Добрыня, Р.: Добрыни (Dat.) : Hyp. 57

никто те от другины князя L.(R.)154:

L.: княхее, А.: князь (P1.?)

къ вратом манастыря Pat.113:

0: монастырским.

Diese Varianten zeigen bereits die häufigsten Konkurrenten des Genitivs, sie werden ihrerselts weitaus häufiger als der Genitiv selbst im Altrussischen gebraucht.

Was die Bedeutung des adnominalen Gentivs im Altrussischen angeht, so kann man sagen, daß seine Anwendung sparsam erfolgt, mit Ausnahme der Fälle, wo er, wie eingangs erwăhnt, angewandt werden muB, in der Regel wird das suffixal transferierte Adjektiv benutzt. Insofern sollt man eher von einer "Ersetzung des Adjektivs durch den Genitiv" reden als von Adjektiven in sogenannter genitivischer Funktion. Das Altrussische - und vermutich gilt dies auch fur das Altkirchenslavische - rechtfertigt eine solche Diktion der Indogermanisten wohl nicht. Ebenso ist es wenig sinnvoll, vom adnominalen "Dativ in der Funktion eines Genitivs" zu reden. Adnominaler Genitiv wie Dativ konkurrieren miteinander im Altrussischen.

$\S 37$. b) Dativ

Mrázek bemerkt, daß der adnominale Dativ im Altkirchenslavischen die gleichen Beziehungen ausdrucken kann wie der Genitiv, mit. zwe1 Ausnahmen:

"а) никогда не появляется на месте родительного качественного, т. е. в типе младьньць млжьска полу [...]

о) Почти никогда не выступает в позиции т. н. родительного количественного, т. е. в типе чаша воды." 64

Mrázek zieht dabei nicht in Betracht, daß der Krels der konkurrierenden sprachlichen Mittel gegenuber dem adnominalen Dativ

64Mrázek, R.: Datel'nyj padez v staroslavjanskom jazyke. In: Issledovanija po sintaksisu staroslavjanskogo jazyka.

Praga 1963, S.248. 
größer ist und nicht nur den Genitiv betrifft, sondern auch Translative in Gestalt von suffixalen Elementen $u$. a. umaßt. Die Ansicht ron Borkovakij 65, daB der Datir immer in Postposition stehe, bestatigt sich librigens nicht. VGl.: лодям погыбель, градом забралы 66 ,ъ граду бранр L.77. Ebenso dürfte die Annahne, der Dativ könne keine weitere Bestimmung bei sich haben, nicht richtig sein. 67

\$38. Sehr hiufig sind die Falle, bei denen nicht zu entscheiden ist, ob der Dativ auf die Satzaussage als ein Ganzes bezogen 1 st oder wirklich als adnominaler Dativ bezeichnet werden kann. $D$. $h$. wir können oft nicht unterscheiden zwischen eigentlicher Translation und dem, was Tesnière "translation fonctionelle" nennt: "C'est ainsi que le translatif fr. d est un translatif fonctionnel, lorsqu'il fait passer le prime actant à la catégorie du tiers actant tout en le laissant d linterieur de la catégorie du substantif: Alfred donne le livre à Bernard."68 Vgl. etwa: и бысть вдовицам заступникъ Pat.70. Es bestehen hter zwei Möglichkeiten fur die Ubersetzung: 1. 'und er war ein Wohltäter fur die Witwen', 2. 'und er war den Witwen ein Wohltater'. Was den Aussagewert angeht, so besteht sicher kein grober Unterschied. GemäB der strukturalen Syntax Tesnidres wäre in jedem Fall zu entscheiden, ob das Substantiv im Dativ subordonné des Verbs, welches als dissozilerter Nukleus 69 zu betrachten wäre (бысть заступникъ), oder aber eines anderen Substantivs ist. Bei dem angefuhrten Beleg würde man dazu tendieren, das Substantiv im Dativ als subordonné des dissozilerten prädikativen Ausdrucks anzusehen. Noch schwieriger ist eine Entscheidung bei Belegen wiе инъ хе законъ Гилиомъ (zu ergänzen: ...есть) L.15: 1.'anders

${ }^{65}$ Borkovakij, V.J./Kuznecov, P.S.: Istorileskaja grammatika russkogo Jazyka. Moskva 1963, S.431.

${ }^{66}$ Belege nach: Lomter, T.P.: oterk1 po lotorileskomu sintaksisu russkogo jazyka. Moskva 1956, S.438.

67vgl.: aksl. poidemb vssi mæstu vabemu szboru,Supr. $22,19$. Nach: Miklosich, Franz: Vergleichende Syntax der slavischen Sprachen. Wien 1868-1874, S.605.

68 a.a.0., s.401.

${ }^{69} v_{\text {gl }}$. dazu die Ausfuhrungen auf $\mathrm{s} .21$ und 26. 
let dae Gesetz der G.', 2.'den G. Ist ein anderes Gesetz'. Hier wăre bеi l.Гидиомъ zu законъ zu ziehen, bel 2. zu den zu ergunzenden ecть. Der Nukleus wirde jewells andere auseehens 1 . инз есть, 2. инъ законъ. In der Tat glbt es kelne andere Moglichkelt, als jeweils auf der Grundlage des Kontextes zu entscheiden.

Sachmator meint, daB der adnominale Datir aus Fügungen mit бbTb hervorgegangen sel, etwa: "Ни Богу свеча, ни чорти кочерга (он есть) 70. Diese These läbt sich angesichts der Fulle von Fugungen im Altrussischen, die eine solche Deutung zulassen, tatsächlich auch nicht von der Hand weisen.VGl.:

и бъ Добрына оун Володимеру L.69

но прблгии бо не хотя смоти грвшникомъ L.79

еда страхь есмь брату своему L.89

то глава есть земли L.140

посем хе бысть звъздамъ теченье L.165

бывъ [...] игуменъ Печерьскому мнастырю L.226

и бысть вдовицамъ заступникъ Рat.70

Schon Miklosich schreibt: "Der dat. bezeichnet das verhältnis der zugehörigkeit, das auch durch den gen. oder durch ein adj. ausgedruckt wird. [...] wie der entsprechende gen., so gehört auch dieser dat. nicht zum verbum, und dadurch zum ganzen satze, sondern zu dem nomen, dessen attribut er bildet.in manchen Fällen lot es zweifelhaft, ob der dat. zum verbum oder zum nomen gezogen werden soll. völlige gleichheit der bedeutung belder ausdrucksweisen list nicht anzunehmen."7l Die Fúlle solcher zweifelhaften Belege lst größer als die, wo mit Sicherheit der Dativ als adnominal bezeichnet werden kann.

Die Möglichkeit, daß sich dieser adnominale Dativ also aus solchen Fugungen entwickelt hat, ist nicht auszuschlieben. Wir muisten dabel drei stufen unterscheiden:

1. Fugungen mit Hilfsverb oder Verb wie bereits oben angefunrt: еда страхь есмь брату своему L.89

2. Elliptische Sätze wie:

инъ же законъ гилиомъ ... (zu ergänzen: есть) L.15

70 Sachmatov, a.a.0., s.318.

71 syntax, a.a.0., s.605. 


\section{Adnominaler Datir:}

в оставденье rptхом

In der Tat undert elch die Satzaussage als solche nicht, gleichgultig ob der Dativ rom Verb oder einen weiteren Nomen abhangig lst, dies veranschaulichen besonders deutlich zwel Varianten von Laurentius - und Hypatiuschronik:

бивъ прехе игумень Печерьскому манастиро L.226

бывшу [...] игумену Печерьскаго манастиря нур.217

Das Problem wird auch deutlich, wenn man altrussische Bolege mit lhrer griechischen Vorlage vergleicht: матери бдагиниям ch суть Izb.302. Hier könnte man den Dativ ohne weiteres als vom Hilfsverb abhängig ansehen. Das Griechische hat hier aber der

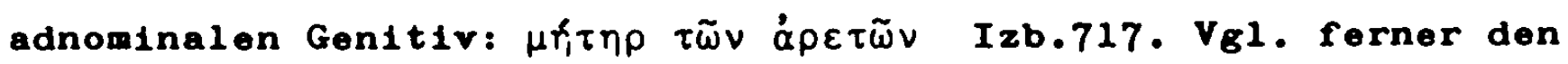
Beleg: мати зьльмь дьность [.. есть Izb.287. Damit schl1eßt der Satz ab, os handelt sich also mit Sicherheit um eine Ellipse. Im Griechischen lautet dies etwas anders: $\mu \eta \tau \xi \rho \alpha$ หน

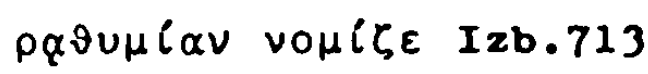

Ganz bhnlich stellt sich die Frage der Abhangigkeit auch beim Lokativ bzw. Praposition + Lokativ. VGl. онъ же сьде на столь Черниговђ L.147. Es gibt zwei Möglichkeiten der Ubersetzung: 1.'er hatte in Cernigor den Thron inne', 2.'er hatte den Thron von Cernigor inne (er saB auf dem Černigover Thron)'. Soll man Черниговь als subordonne eines dissozilerten verbalen Nukleus oder als vom Substantiv столъ abhängig betrachten? V.gl. ähnlich: яко то есть середа в земли моеи L.67. Aus den Hss. A.. R. 1st zu ersehen, daß земля subordonne von cepera lst, dort heibt es: середа земли моеи.

\$39. Der tatsächlieh als adnominal zu bezelchnende Datir als Konkurrent gegenuber Genitiv und suffixalen Translativen spielt ohnehin im Altrussischen keine grobe Rolle, eher ist er ein Charakteristikum des Altkirchenslavischen. Vondrak weist darauf daß der Gebrauch dieses Dativs im Bulgarischen - Im Gegensatz zu Russischen - weiter un sich gegriffen hat. 72

Der adnominale Dativ findet $81 \mathrm{ch}$ vornehmlich dort als Translativ wo sowohl Transferendun wie Regens innerhalb der gegebenen Fu- 
gungen Nicht-Stoffliches bezelchnen. $V_{\text {gl }}$ :

царствие красоть и вьнець доброть 2.69

( вьнець ist hier nicht Sachbezeichnung, sondern wird il ubertragenen Sinn gebraucht)

Tpeбy Bory L.95

Cвњ с странамъ L.99 (странамъ steht hier für 'Wolt' schlechthin, mit 'CBbr' ist Christus gemeint.)

творец каноном Pat. 126

въ честь своему погрьбенір Pat.15

год объду Рат.46/ къ граду бранью 2.77

Ausnahmen wie уныша бо градомъ забрали I.22 sind relativ selten.

Dies stimmt damit uberein, daß in den weiter oben angefuhrten Fügungen durch den Dativ, der mit einem Verb bzw. Hilfsverb verbunden werden konnte, sehr häufig eine Hinwendung an eine Person bezelchnet wurde, etwa: и бь Добрыня уи Володимеру L.69. но Богъ [...] не хотя смерти грвшникомъ L.79, и бысть вдовицамъ заступникъ L.70 u.a. In dieser Funktion findet sich der adnominale Dativ auch noch im modernen Russisch; "Pamjatniki V. J. Leninu $v$ Leningrade" (Titel einer Broschüre von A. Ja. Rozina und G. N. Pavlov, Leningrad 1970) sind 'Denkmäler für V. I. Lenin' und nicht 'von $V$. J. Lenin'.

Das Objekt der Handlung wird durch den adnominalen Dativ im Altrussischen seltener ausgedruckt als durch den Genitiv und die mit ihm konkurrierenden Suffixe. Immerhin finden sich belege wie в оставленье грыхом Нур.90, Ch., Р.. от слохеніа миру Pat.23 (Hier könnte es sich auch um einen Genitiv auf -u handeln.)

Für den Gobrauch des adnominalen Dativs gilt ahnliches wie fur den Genitiv. Oft ist ein konkurrierendes Translativ in Gestalt eines Suffixes zumindest in den "Materialy" nicht nachweisbar, so etwa bei krasota und pogrebenie - vgl. die angefunrten Belege-. Bei anderen Transferenda entständen, würden sie suffixal

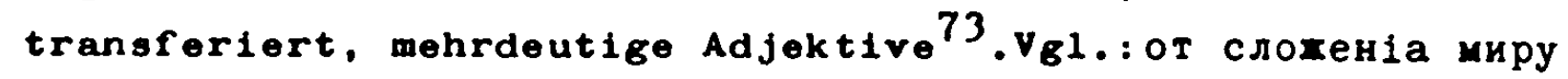
Pat.23. Die suffixal transferierten Adjektive waren bereits 
unter $\$ 34$ behandelt worden. Wir hatten gesehen, daß durch Verwendung des Genitivs die Eindeutigkeit der Bedeutung des Transferendues al. 'Velt' fixiert wurde. Das gleiche gilt fur den Dativ. Vgl. auch: конець хитір прияти Рat.56. Die Adjektive хитии und хитьняи sind bel Sreznevekij nur in festen Fugungen wiе хитьи лоди bеlegt (Sr.I, 878 u. 880), das Adjektiv хитиискыи lot al. Konkurrent frei: хитииское богатьство (Панд. Ант. ХI в.) Sr.I, 878, jedoch düfte in diesem speziellen Fall das Transferendum xитие die Bedeutung 'Leben in seiner materiellen Prägung' tragen. Wir begegnen durchaus dem Phänomen der funktionellen Neutralisation, wenn auch nicht haufig. VGl. Tpeoy bory L.95 gegenuber dem in solchen Fugungen nahezu ausschlieblich verwendeten бохии, vgl. ferner творед каноном Pat.126 etwa neben каноньныихъ поведьнии (Ефр. Крм.) Sr.I, 1191.

§ 40. c) Instrumental, Lokativ, Praposition + Kasus Die folgenden Ausführungen erheben nur Anspruch auf exemplarische Geltung. Selbstrerständich gebuhrte etwa den Präpositionen eine eigene umfangreiche Darstellung. Es geht hier darum, weitere mögliche Translative mit alleiniger syntaktischer Funktion anzufuhren und unter den mothodischen Aspekten dieser Arbeit einiges zu ihrer Verwendung darzulegen.

$\S 41$. Als Konkurrent gegenuber Genitiv, Dativ, Práposition + Kasus und Suffixen tritt der Instrumental nur in ganz bestimmten Fugungen auf. Das Regens muls stets ein substantiviertes Partizip (I>0), ein Part. Prät. Pass. oder Part. Präs. Pass.., sein. Das Transferendum bezeichnet in der Regel eine Person. Bel einer möglichen Transformation in elnen Satz wäre das Transferendum Subjekt, das Regens Prädikat. Vgl.: послании хе сли Игоремъ L.53. Die Hss. R. und A haben hier: посль ге Игоревы Ein Determinans im Instrumental konkurriert also mit einem durch das Suffix -ov-transferierten Adjektiv.Vgl. ferner избрании Богом L.121, бъ бо сеи любим Борисом L.134. Ве1 и рече Блудз къ посломъ Володимеримз .76 hat die Laurentiushandschrift ein durch-j-transferiertes Adjektiv, ebenso die entsprechende Variante der Hypatiuschronik ein durch -ov- transferiertes Adjektiv bei einem Partizip als Regens: посланымъ Володимеровым Daß hier bei einem substantivierten Adjektiv als Regens ein 
durch Suffix transferiertes Adjektiv cobraucht wird, ist nicht verwunderlich, da die Translation I) 0 bei nocданыh bereits fest geworden ist und das Partizip glelchberechtigt neben nocods stoht.

Die von Śachmatov angefuhrten Belege wie yдар naдkон, посадка рядами und nрогулка садом 74 sind dem modernen Russisch ontnommen. Das Regens lst auch hier das Produkt der Translation $I>0$, wenn es sich auch um "translation figé" im Sinne Tesnidres handelt. Vergleicht man die von Bauerová für das Altkirchenslavische angefuhrten Belege zum Gebrauch des Instrumental 75, so sieht man, daB dieser eng zum Verbum gehört. Tatsächlich kann er als Translativ der Translation $O>A$ in Konkurrenz etwa zur adnominalen Genitiv, Dativ oder suffixalen Translativen stehen, wenn hier auch der Anwendungsberelch, wie dargelegt, ong begrenzt ist.

$\S$ 42. Von einem adnominalen Lokativ wird im allgemeinen nicht gesprochen. Dennoch kann er grundsatzlich als Konkurrent bel der Translation $0>$ A gelten. Vgl. etwa: онъ xe cbде на cтоды Черниговы L.147Als konkurrierende Fugung wäre hier durchaus denkbar: на стоды Черниговьскыимъ. Es erhebt sich hier die Frage, die wir auf $\mathrm{S} .61$ schon berihrten: Soll ctje und Черниговь zusamengezogen werden oder на столt und Черниговь? Wie berelts gesagt, ändert die Verschiedenheit der Konnexion nichts an der Satzaussage.

\$ 43. Kasusmorpheme als Translative der Translation 0 > haben wir bereits kennengelernt, in Erwägung ziehen mub man ferner Präpositionen + Kasusmorphem als "translatif dissocié". Es ist nicht zu bezweifeln, daß jede Praposition oo ipso im Sinne A. Martinets als Funktionales Monem zu betrachten ist, da diese die Funktion eines benachbarten Monems anzeigt. Folgende Prăpositionen sind hier zu berucksichtigen: 1zb, otz, sz, $u$ Genitiv, po, $\mathrm{kb}_{3}+$ Dativ, o, $v_{3}+$ Lokativ, sb + Instrumental. Damit kehren auch alle Kasus wieder, die als Translative der Translation

74 a.a.0. S. 320 .

75 Bauerova, M.: Bespredloznyj troritel'nyj padez $v$ staroslavjans-

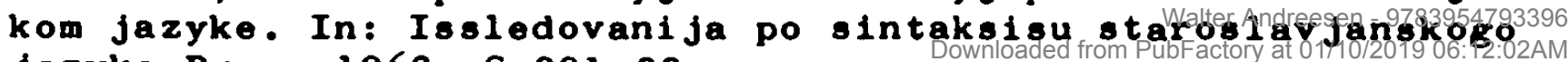
jazyka.Praga 1963, S.291 ff. 
$0>A$ blsher Gegenstand der Untersuchung waren.

123 + Genitiv: Das Transferendum ist in der Regel Bezeichnung für geographische Benennungen, elnen Herrschaftsbereich o. dgl.., das Regens bezeichnet melst elne Person oder Personengruppe, deren Herkunft durch das Transferendum bestimmt wird.Vgl. $z_{\text {. B.: }}$ варязи изъ заморья L.19, мух из царства нашего L.49, R., A. (L. hat hier den bloben Genitiv ohne Praposition, woraus das Konkurrenzverhältnis bereits belspielhaft sichtbar wird.) ob f Genitiv: pocow с небеси Pat.69.

otb + Gentiv: 1. Das Regens ist ein Verbalsubstantiv oder Abstraktum, dann ist das Transferendum in der Regel Bezelchnung fur eine Person oder Institution: дарования от Бога L.89, благословленье от Святыя Горы L.156/57, спасенье от Бога L.99. проказа нькака от грекъ L.51, от прадыд показаньемъ L.15. 2.Das Regens bezeichnet eine Person oder Personengruppe, dann wird durch das Transferendum (Person, Personengruppe, Herkunftsland etc.) die Herkunft dieser Person oder Personengruppe bestimmt: слы от братья моея L.24, послании от Святополка L.136. лодии от страны Руския L.52, Господа съ небесь Раt.109. 3.Das Regens bezelchnet elnen Tell dessen, was durch das Transferendum ausgedrückt wird: ce кость от кости моея L.88.

$v b+L o k a t i v: D a B$ die Präposition $v_{b}$ + Lokativ mit dem adnominalen Genitiv etwa konkurrieren kann, zeigt folgender Beleg: яко то есть середа в земли моеи L.67, R., A. haben hier: cepeда земли моеи, еbеnso нур.55. Vgl. auch: ис тебе бо изидеть старьишина быти въ князехз во Израилиіn der Laurentiuschronik, dagegen die Variante der Hypatiuschronik: быти князь ихз въ Нур Zu den ubrigen Präpositionen selen nur einige Belege angefuhrt, um das Problem der Konkurrenz liberhaupt sichtbar zu machen: po + Dat1v: бв путь[...] по Дньпру LL.11, u + Genitiv: законъ хе у Ктирианъ L.14; kъ + Dativ: князь бо есть БХиии слуга къ чл̃вком Izb.242. VGl. dazu auch aus dem modernen Russisch: дед моћ по отцу, мон брат по музе, по человечеству мои брат. 76

Die Prápositionen + Kasus als Translative der Translation $0>A$ sind hier nur exemplarisch angefthrt worden, um darauf hinzuwe 1

76 Aus: Izmenenija $v$ sisteme slovosotetanij $v$ russkom literatur-

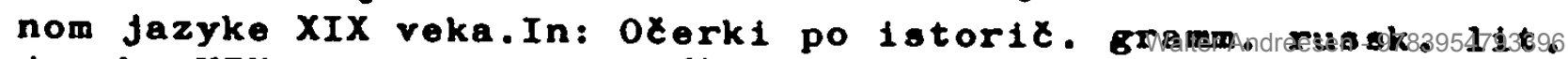
jazyka XIX veka. Moskva 1964, S.211. Downloaded from PubFactory at 01/10/2019 06:12:02AM 
sen, daß sie in den Gesamtkomplex der Translation 0 > gehören. Ausfuhrlich kann wegen des groben Umfangs des Untersuchungegegenstandes nur in einer eigenen größeren Abhandlung darauf eingegangen werden. Von einigem Interesse mag sein, dab es gelang. wenigstens zwel Belege zu finden, die zeigen, daB das Altrussische Suffixe in der Ubersetzung verwendet, wo das griechische Original Práposition + Kasus als Translativ hat.Die Belege stammen aus dem Izbornik von 1076:

отьвраштяи ся хитинскыя радости Izb.278

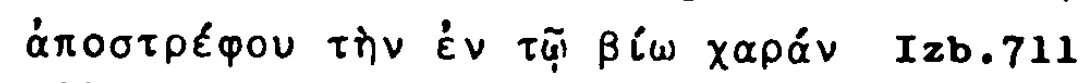

Цйквь домашьнов къхдо насъ имьи умъ свои Izb.292

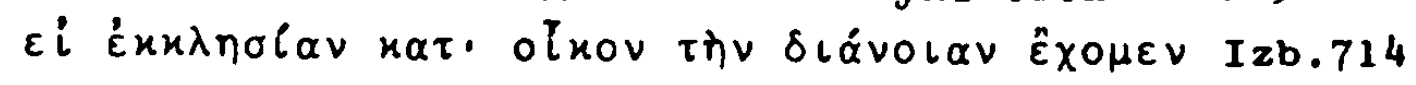

Mit Sicherheit 110 Ben sich weitere Belege aus der Ubersetzungsliteratur finden, ist doch das Suffix das bel weitem bevorzugtere Mittel der Translation im Altrussischen.

d) Suffixe

$\S 44 .-$ ov- / -ev- + nom. Endungsmorphem

Das Suffix -ov-/-ev- t nom. Endungsmorphem tritt in der Regel - nur wenige Ausnahmen sind zu beobachten-als Translativ mit allein syntaktischer Funktion auf. Bei der semantischen Fixierung des Transferendums läßt sich eine eindeutige Regel feststelien. Etwa neunzig Prozent aller Belege aus der Laurentiuschronik sind Personennamen, der Rest mit wenigen Ausnahmen Appellative, die Personen bezeichnen; das gleiche Bild ergeben die Belege aus den "Materialy". Diese Tatsache ist nicht unbekannt.

Vondrák, der die Adjektive auf -ov-mit dem Genitiv der u-Stämme in Verbindung bringt 77 und damit im Einklang mit den Anschauungen Vaillants ${ }^{78}$ steht, schreibt in seiner "Stammbildungslehre": "Im Slavischen haben sie [die Adjektive auf -ov-] aber speziell die Geltung poss. Adjektive libernommen, also den Gen. sg. vertreten, wenn es sich um die Benennung eines 'lebenden' Wesens

77 a.a.u., s. 523 .

${ }^{78}$ vaillant, A.: Les adjectifs en -ovü. In: Bulletin de la Societé de Linguistique de Paris. Paris 1929, Bd. 29, 5.40-43. 
handelt. Von a- und 1-stkmmen werden derartice Adjektire nicht mit -ovo, sondern mit -ino gebildet." Diese Darstellung, die sich in mehr oder minder variferter Form in allen historischen Grammatiken des Russischen wiederfindet, lst etwas vereinfachend, da 1. der Begriff "Possessiradjektive" an sich schon nicht brauchbar ist, wie bereits einfuhrend dargelegt wurde, 2 . man nicht von einer "Vertretung des Genitivs" sprechen kann, dies wurde im ersten Teil dieses Kapitels erörtert, und 3. sich einige wenige Transferenda, die durch das Suffix -ov-transferiertwerden, finden, die keineswegs "lebende Wesen" bezelchnen. In diesem Zusammenhang ist nicht von Interesse, ob gerade diese Transferenda die urspringlichen waren, mabgebend ist hier lediglich der Zustand, den das Altrussische bietet.

$\$ 45$. Bemerkenswert ist, dab sich beim Gebrauch des Regens in Fugungen mit Adjektiven, die durch das Suffix -ov- transferiert sind, bestimmte Gruppierungen feststellen lassen. Das Regens kann sowohl Sach-wie Personenbezelchnung als auch Abstraktum sein, ist in seinem semantischen Gehalt weitgehend festgelegt durch den relativ eindeutig fixierbaren Gebrauch des Transforendums. Bei der gröbten Zahl der gesamelten Belege zeigt sich, da $B$ eine Beziehung zwischen Regens und Transferendum hergestellt werden kann, und zwar:

1. Das Regens bezeichnet eine Person oder Personengruppe, die zu der Person, die durch das Transferendum des determinierenden Adjektivs bezeichnet wird, a) in einem Verwandtschaftsverhältnis steht, zum Geschlecht gehört, b) zum Gefolge gehört.Vgl.:

а) сынъ Рюриковз L.23

Аронъ брат Аврамовъ L.92

от кольна Цавыдова L.102

поповъ сынъ Sr.II, 1194

в) друхина Игорева L.46

отроци Володимерови L.76

и бусть Давыдовз вои p L.271

со царевым мухемъ L.31

ученикъ антихритстовъ Sr.I.25. 
2. Dae Regen: bezelchnet einen Bereich, uber den die durch dae Traneferendun bezeichnete Person in Irgeneiner Form Gewalt ausubt:

до предьда Симова LL.10

въ хребии Симовъ LL.12

от города Киева L.31 (Kievъ lst hier möglicherweise Substantir) въ градъ Ольговъ L.74

Феодосьева мнастыря L.198

Man wird hierbei die haufigen Belege, wo durch das Regens die Grabstatte elner Person bezeichnet wird, nicht ausklammern; der Herrschaftsbegriff erhält hier einen abstrakteren sinn:

у гроба Феодосьевым L.282

Дирова могила L.23

над гробомъ Феодосьевым L.284

могила Ольгова L. 38

3. Das Regens bezeichnet ein Abstraktum, wobel Vorgánge oder Vorfalle, die von Personen oder Personengruppen, die vom Transferendum bezeichnet werden, a) erlitten oder durchgefuhrt werden, b) ihren Ursprung von diesen ableiten, von ihnen ausgehen, geistiger oder materieller Herrschaftsbereich von ihnensind. VGl.:

исхохенью Моисъева L.18

за Адамово преступленье L.100

влъхова клятва Sr.I. 382

Игоревы смерти L.54, двиства супостатову Sr.III, 620

царство Доментианово L.39. рбчи Игоревы L.54

Genau wie etwa beim Genitiv kann hier das Transferendum Objekt der Handlung sein:

на убииство Авълево Нур.76

по убьеньи [...] герцюковь Sr.I, 513

4. Das Regens bezeichnet einen Körperteil der Person, die durch das Transferendum bezeichnet wird:

мчттлева оуста Sr.I, 199

съ главы царевы L.94

кровь Авелевы L.144 
Sachbezelchnungen wie etwa in gaa xopaбxb ГxbбOBb L.136 ind als Regens kaum nachweisbar, was wiederum beweist, dab die Bezeichnung "Possessivadjektive" für die Adjektive auf -ov- fehl am Platze ist.

Neben Personennamen und Personenbezelchnungen sind auch elntge Tierbezelchnungen als Transferenda belegt:

знаменье зииево явися L. (R.,A.) 149

Kъ коневу хвосту Sr.I, 1268

от китово чрђва Sr.I, 1210

ядв аспидовъ Sr.I, 31

Einige Transferenda mussen als Personifikationen anzusehen sein, so vor allem der Name des Landes Israel:

иди в землю Израилеву L.102

сыны Израилевы L. 100

домъ Израилевъ L.99

лукъ Израилевъ L.98

царство дому Израндева L.98

сыны Израилевы L.96

сыновъ Израилевъ L.96

\$ 46. Bei den letzten Belegen handelte es sich um reste Fügungel Auch andere geographische Bezeichnungen aus dem Heiligen Land u. dgl. werden des öfteren mit den glelchen Translativen transferiert, durch die in der Regel Personenbezeichnungen transferiert werden. Vgl. etwa auch: ты Вивлевоме доме Ефрантовъ L.100 (nach Micha 5, 1: "Und du, Bethlehem Ephrata, die du klein bist unter den Städen in Juda, aus Dir soll wir der kommen, der in Israel Herr sel ..."). Vgl. dazu auf S.75die Translation durch das Suffix-J-, welches ausschlieblich Transferenda, die Belebtes bezelchnen, transferiert. Bemerkenswert lst, daB bei den gleichen oder bhnlichen ortsbezeichnungen der Genitiv in der Funktion des Akkusativ steht. Vgl.:

и разъгнввася $\widetilde{\Gamma_{b}^{C}}$ на из̆ла [Израила] L.97 
подогна Иярусалима L.418

подогипа Иер̆хма яко оводное хранихвпе L.463

и pên ему испусти Иа̃

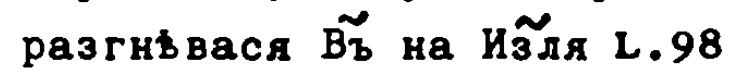

H. Jelitte woist in seinen Aufsatz "Probleme und Aufgaben einer strukturalistischen Darstellung der altkirchenslarischen Deklination"79 darauf hin, daß als beseelt im Altkirchenslarischen neben народъ und язикъ auch einige Orts- und Tierbezeichnungen emprunden werden. Zu den Ortsbezeichnungen gehören:

Вавулонъ (Babylon): Psalt. 115 a, 31

Eгипть (Ägypten): Psalt. 175 b, 21

Ерихонъ (Jericho): Mark. 10, 46 (Zogr.)

Ерусолимъ (Jerusalem): Psalt. 105 b, 16, 169 a, 3, 177 a, b Издраиль (Israel): zahlreiche Belegstellen

Vgl. dazu auch ar. имать погубити всего Erynta L.94. Es handelt sich dabei durchweg um biblische Namen. Aurfallend lst die Ubereinstimmung zwischen Gebrauch des Akkusativ-Genitiv-Kasus (Kennzeichnung der Kategorie der Beseeltheit) und der Suffixe, die in der Regel Appellativa, die Personen bezelchnen bzw. Personennamen transferieren. Um eine Personifikation des Transforendums handelt es sich sicher bei dem Beleg образовъ день Sr.II, 539 ( праздникъ Нерукотвореннаго 0ораза). Mit oбразъ lst hier eine nicht von Menschenhand erschaffene Heiligenabbildung gemeint.

Gelegentilch finden sich Transferenda anderer Art wie bel Tbpновъ вьнець Sr.II, 1086, унца грыхова Sr.I, 845. Zu dem auch im Altkirchenslavischen belegten rрьновъ, das in allen Abhandlungen als Rarität angefuhrt wird, hat Brodowska-Honowska eine Hypothese aufgestellt. Sie geht ohnehin bei der Behandlung der Adjektive auf -ov- von den nicht sehr zahlreichen Belegen aus, wo das Transferendum Sachen bezeichnet, und ist der Meinung, daß sich der "possessive" Charakter der Adjektive aur -overst später entwickelt habe, d. h. die Transferenda, die Apellative für Personenbezeichnungen oder Personennamen sind, seien nicht die ursprunglichen. Diese Ansicht, die von Zverkovskaja

${ }^{79}$ In: Slovo $15-16,1965,5.334$. 
getellt wird, ILBt sich kaum beweisen. 80 "Yydaje siq", schreibt Brodowaka-Honowska, "ze wydzielente tmnov w osobna kategorla nie wa podstaw realnych, zwlaszcza io najprawdopodobniej reprezentuje wlabnie temat na $-u-$, goc. thahrnus, nadto zyskuje poparcie w drugiej formie wykazujacej rómiet przypuszczalny temat na -u-: dbzderb. W takim ujectu dakoby ale pomiefcit materialu odrzeczownikowych formacjl na -ovb. Typ trsnors odpowiadalby notowanemu z rzadka w Indoeuropejszczýnio dopeiniaczowi materialu: "Gen. des Stoffes", lat. lactis imber [...], cerk. vb grobr mramora[... " 81 . Zumindest im Altrussischen dúfte das Suffix-ov- in Verbindung mit nominalem Endungsmorphem keine Beziehung zum vermuteten Ursprung (Gen. PI. der uStámme) aufweisen. Man könnte ${ }^{\circ}$. -ov-+ nom. Endungsmorphem transferierten Baumamen zahlen, welche zusammenfassend unter $\$ 83$ behandelt werden. Es ist nicht au zuschlieBen, daB die Translation solcher Transferenda durch Translative, die im allgemeinen Appellative, die Personen bezeichnen, transferieren, als Reflex der Anschauung von der Beseeltheit der Baume anzusehen ist. Ar. Tьрнъ bedeutet auch 'Dor strauch' neben 'Dorn', vgl, auch skr. trn 'Schlehdorn', alnd. troam 'Gras', 'Kraut'. 82

Bemerkenswert ist die Fügung mесто краньево L.103, wo die Trans lation an einem aus dem Griechischen entlehnten Transferendum vorgenommen wird, vgl. griech. $\tau \delta$ kpaviov 'Schädel'. 'Schädelstäte'. Dieses Transferendum existiert offensichtilch nicht als substantivisches Lehnwort im Altrussischen. Man wird annehmen missen, daß die Translation in Anpassung an einheimische Translationstypen wie Киевъ градъ, отьцево мысто erfolgte.

Vondrák sieht bei dem aksl. jugorb (Supr. 349, 23) in der Basis die eine Himmelsrichtung bezelchnet, eine Personifikation.

${ }^{80}$ Zverkovskaja, N.P.: Prilagatel'nye 8 suffiksami -ov- 1 -ovbnv drevnerueskom jazyke, a.a.0., S. 171 ff.

81 a.a.0., S.28

${ }^{82} v_{\text {gl }}$. Vasmer, Russ. etymolog. Ho., Bd. III, S.98. 
Reiter weist in seinea Aursatz "Die Funktion der Surfixe -j-, -bsk-, -bn- im Altkirchenslavischen" ebenfalls unter Hinweis auf Brodowska-Honowska darauf hin: "In den Bereich der Mythologie gehören auch die Himmelsrichtungen. Darauf ist schon verschiedentlich hingewiesen worden. Ist der als Person vorgestellte Wind gemeint, so wird das Adjektiv mit-j-gebildet [- für Reiter ist - j-eine Variante der Suffixe-ov-, -in- -], vgl. jugovb, severovb. Soll die Richtung angegeben werden, dann mit -bn-, z. B. i poide na vbstotnqje stranq supr. 15, 22, und ist von Ländereien die Rede, wird-bsk-verwendet, z. B. Carrca juźsskaa rostaneto na sqdo Mar., Luk. 11, 31."83 Man milite hier natülich weitere Belege heranziehen, wenn die Aussage beweiskräfiger sein soll. Wichtig ist die Tatsache, daB etwa ein

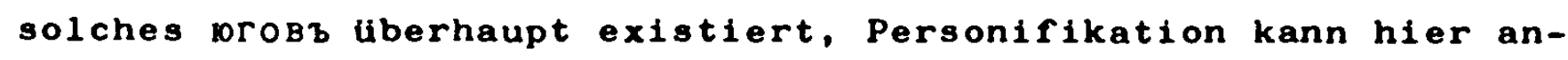
genommen werden. Man denke auch daran, daB Stribogb im Russischen der Gott des Windes ist. Das Adjektiv Crpuбоxb wird bezeichnenderweise durch das Suffix-j-, welches im allgemeinen Appellative, die Personen bezeichnen oder Personennamen transferiert, Gebildet. Die Translation von Baumnamen mittels des Suffixes -ov-t nom. Endungsmorphem soll an anderer stelle behandel $t$ werden.

$\S 47$. Sufrix $-j-$

Eine weitgehende Fixierung des semantischen Gehalts des Transferendums läbt sich vornehmen. Es kommen hierbei nur Personennamen und Appellative, die Personen bezeichnen, in Frage. Auch die adjektivischen Ableitungen von den Götternamen Стрибогъ und Перунъ zu Стрибожь Sr.III, 547 und Перунь Sr.II, 920 wird man hierher zu zählen haben. Vgl. auch Mbcячb Sr.II, 252 von мъсяць 'Mond'. Selene bedeutet im Griechischen 'Mond' und ist zugleich der Name der Mondgöttin. Für das Transferendum мbсяць im Sinne von 'Monat' existiert ein mit -j-transferiertes Adjektiv nicht. Das slavische mbcяub weist nach Vasmer vermutich auf einen Schmeichelnamen. 84

${ }^{83}$ Reiter, Norbert: Die Funktion der Suffixe-j-, -bsk-, -bnim Altkirchenslavischen. In: Die Welt der slaven, Bd. 12 , 1967, S. 400 . 84 vasmer, Russ. etymolog. Wo. Bd. II, S. 125. 
Bel der Translation des Stidtenamen. 'Jerusalen' durch das Suffix-J-11egt vermutlich, wie bereits in $\$ 46$ erlkutert, Personifikation vor. Vel. до пльненья Иерусадимд L.18 (A und Hyp. 13 haben hier -ov-: Иерусахимова). Jerusalen wird dadurch als die besondere Stadt vor anderen stidten der Erde hervorgehoben, ahnlich wie das berelts erwihnte Bethloher. Bel der Translation durch das Suffix-J-tritt diese Tatsache noch deutlicher hervor als bei-ov-, da-j-sonst ausschlieblich Transferenda, die Belebtes bezelchnen, transferiert.

In den Fügungen mit durch das Suffix -j-transferierten Adjektiven bezeichnen Regens und Transferenda der transferierten Adjektive Personen, die a) in einem Verwandtschafts-oder b) in einem Untergebenenverhbitnis zueinander stehen. Hier wird die Nähe zu dem Suffix -ov-t nom. Endungamorphem sichtbar. Appellative, die Personen bezelchnen, sind als Transferenda gegenuber den Personennamen allerdings weltaus weniger gebräuchlich, im ubrigen ist der lexikalische Bestand offensichtilch nicht sehr umfangreich. Von sechzehn Belegen aus der Laurentiuschronik weisen acht дьяволь und sechs кънязь als Transferendum aus. Man wird auch hier eine starke Traditionsgebundenheit der altrussischen Texte zu sehen haben, was uns bereits vorher von sprachlichen Topoi reden 11eB. VGl.:

по зависти дьяволи L.82

по дьяволь научению L.91

но азъ есмь роду княха L.23

дворъ княхь L. 55

Ausschlieblich werden diese Transferenda natülich nicht gebraucht, vgl. etwa дъщи фараоняL.94, aber doch in auffallendem MaBe. Betrachtet man jetzt noch die Belege aus den "Materialy" Sreznevskijo, so fallt auf, daß durch das Suffix-nik-gebildete Appellative, die Personen bezeichnen - und dies gilt vornehm lich fur bestimmte Berufsgruppen - durch das Suffix - j- transferiert werden. VGl.:

корабдьничь Sr.I, 1285

изорничь Sr.I, 1075

доводьдичь Sr.I, 686 
бдудьничь Sr.I, 117

воиничь Sr.I, 286

десятиньничь Sr.I, 659

\$ 48. In Fugungen, in denen durch das Suffix-or-transferierte Adjektive verwendet werden, konnten bestimmte Feststellungen in bezug auf das Regens getroffen werden. Fur die Adjektive auf - jgilt dies ganz ähnlich.:

1. Das Regens bezeichnet eine Person oder Personengruppe, die zu der Person, die durch das Transferendum bezeichnet wird, a) in einem Verwandtschaftsverhaltnis steht, b) zu deren Gefolge gehört. $V_{\text {gl }}$ zu a):

внукъ Володимерь L.129

сынъ Изяславль внук Володимърь L.146

(Нур. 133: ... Влодимеровь)

сына Святославля внука Ярославля L.204

внук Володимерь отець Всеславль L.155

сынъ Ярославль внук Володимерь L.215

Ростиславъ [...] сынъ Володимерь внукъ Ярославль L.163

Charakteristisch fü diese Fügungen ist, daß innerhalb kurzer Satzabschnitte das gleiche oder ein ahnliches Regens gebraucht wird rom Typus сннъ - сынъ/ Внукъ/ Отьив.

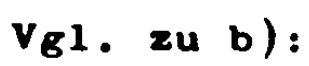

отроци Володимери нур.64

( ᄂ.76: ‥ Володимерови)

къ посломъ Володимеримь L.76

мужь Володимерь L.123

( нур.108, Ch., Р.: ... Володимеровь)

воевода нача Святополчь L.141/42

и бояры Нрославль L. 144

посадника Святополча L.272

друхина Святополча L.277

2. Das Regens bezeichnet einen Bereich, liber den die durch das Transferendum bestimmte Person in irgendeiner Form Gewalt ausübt. V V l.:

дворъ Воротиславль L.55

полата же Володимеря L.111 
манастыря Bceвохоха L.207

Феодосьева манастыря L.198

въ градз Переясдавдь L.227

Святоподтв городз L.299

3. Das Regens bezelchnet eln Abstraktum, wobel, wie die folgenden Belege zeigen, der lexikalische Bestand in somantischer Hinsicht klein ist. VGl.:

от начала дарства Содомоня L.18

княхенья Святославля L. 37

всьх льтъ княхенья Святославля L.74

начало княхенья Ярославля L.141

начало княхениа Всеволоха L.204

до смерти Ярославль L.24

премудрости Соломани L.62

ръчи Святославля L.72

начало княхенья Изяславля L.162

Sachbezelchnungen wie in kb поробу Всеславль L.171 als Regens lassen stch nur in sohr wenigen Fálien nachweisen. Ähnlich war dies auch in Fugungen mit Adjektiven auf -ov-der Fall.

Charakteristischsind Fügungen, in denen das Kegens cынъ fehlt: олег Святославль L.199 (R., A.:... сынъ, ebenso Нур.190) ульов Володиславль (сынъ L.46, Вуерастъ Святославль [ сынъ] L.46). Diese Fügungen lassen sich mit suffixalen Ableitungen auf -i b wie Ярославичи 'Söhne des Jaroslavb'85 vergleichen. Dort mub der semantische Gehalt allein aus dem Suffix abstrahiert werden. Hier wird der Name genannt und, die Bestimmung der fehlenden nachgestellten Apposition (=Regens) für den ersten Namen kann nur çHb sein, aus der Nennung des Namens und der transferierten Form des zweiten Namens das Regens 2 (= subordonné 1) erschlossen.Man kann dies als eine Form der Atrophie bezeichnen.

\$49. Suffix-bj-

Das Suffix-bj-ist in seiner Funktion als Translativ schwerer zu fassen als die bisher behandelten Translative. Dies wird schon deutlich, wenn wir eine feste Fugung aus dem modernen 
Russisch betrachten: заячья manka Hasenfellmutze'86. Bine unmittelbare syntaktische Beziehung zwischen zagu und manka besteht nicht, vielmehr bestimmt заячья('Hasenfell-' in diesem Zusammenhang) die Beschaffenheit von manka. Indessen durften die Figungen, in denen das Suffix eindeutig syntaktische Funtion hat, überwiegen, etwa Bолоса cкотья боra L.73, meкотъ славии I.17. Beim ersten Beleg, wird etwa nicht mehr signalisiertals das Bestehen einer Beziehung zwischen den Signifikaten скотъ und богъ. Bei заячья трава 'Fette Henne' ist der Unterschied zu einem primären Adjektiv schließlich ganz verwischt.

Als Transferenda dienen auberordentlich häufig Appellative, die Tiere bezeichnen. Tatsächlich findet man nahezu sämtliche Tierbezeichnungen in transferierter Form in den "Materialy" Sreznevskijs. VGl.:

тельчии, турия, славии, сучия, стьрчия, сиколия, соболии, козьлии, рыоии, пардужии, осьлии, осетрии, орьлии, олении, овьчии, медве::ии, кунии, коровии, козия, заячии, говяжии, выпеличии, волчии, сын:А.

Als Translativ mit nur syntaktischer Funktion tritt das Suffix -bj- beim Transferendum jorb auf. Vierunddreibig von dreiundvierzig Belegen aus der Laurentiuschronik zeigen als Transferendum corb, achtzehn von neunzehn Belegen aus dem Izbornik von 1076. Die Translation durch -bj-ist hier offensichtlich fest geworden. Als Konkurrent tritt in einzelnen Fällen das Suffix -bsk-auf: оожьственныи ist von dem Abstraktum вожbство abgeleitet. Das Kegens des Adjektivs oorb ist in der Kegel ein Abstraktum wie bei страх имьите Бохии L.241 oder nо Бохью повелt.нь10 L. 186.

Ferner fällt auf, dals nomina auctoris - insbesondere mit -bcgebildete - häufig sind. Vgl. bei Sreznevskij: хивописьчии, кормьчии, ловьчии, мьздоимьчии, народотворьчии, подьячии, посадьничии, посеяьничии, творьчии. Das Suffix ist in den weitaus meisten Fällen syntaktischer Natur. vgl. etwa: xuвописчиемъ худохьствомъ $\mathrm{Sr} . \mathrm{I}, 866$, довчии иарядъ Sr.II, 40, не ослушад заповьди народотворчя Sr.II, 320. 
Appellative, die Sachen bezeichnen, sind als Transferenda selten belegt, etwa мормории Sr.II, 175, синьничин (von синьникъ = 'Stoffballen') Sr.III, 358, съдньчия Sr.II, 735. Bei der letaten Beleg lst nicht ganz auszuschlieBen, daB das Transferendum czдньце personifiziert wurde. Andere wie попирии Sr.II, 1191. охочия Sr.II, 838, розъъзхия Sr.III, 160, съђзхии Sr.II, 869, утрии Sr.II, 1313 widersetzen sich einer weiteren Deutung. Abstrakta als Transferenda sind indessen in geringer Zahl, wie bereits belegt, vorhanden, einige von ihnen wird man als Modifikationstypen anzusehen haben wie обычии Sr.II, 575 'ublich', хитии Sr.I, 878 ( häufig in der festen Fügung хитьи лоди), vgl. auch бъльчии Sr.I, 220 'weltlich' von бъльць 'der Laie' (ursprü $11 \mathrm{ch}$ von бъльи '

$\S 50$. Suffix -in- + nom. Endungsmorphem

Bekanntlich können hier nur Transferenda mit dem Endungsmorphem -a oder -b in Frage kommen. Das Suffix -in- + nom. Endungsmorphem kommt nur in syntaktischer Funktion vor. Die Transferenda sind in der Regel Personennamen oder Appellative, die Personen bezeichnen. Sreznevskij bringt auch einige Tiernamen: обезиянин Sr.II, 500, ехидьнинъ Sr.I, 836, воробиинъ Sr.I, 300, бъчелинъ Sr.I, 200. Diese Adjektive werden selten gebraucht. Mindestens eine Sachbezelchnung als Transferendum ist ebenfalls belegt, Sreznevskif zitiert aus dem Ostromirevangelium: cквозt yши иглины Sr.I, 1019. Ob hier von einer Personifizierung gesproche werden kann - die Nadel hat ein 'Ohr'- ist zweifelhaft. Mit Sicherheit liegt Personifikation vor bei дому Июдину L.99. Dieser Beleg fügt sh gut zu den bisher genannten, in denen das Transferendum einen helligen ort der Bibel bezelchnete und durc Suffixe transferiert wurde, die in aller Regel Appellative, die Personen bezeichnen, transferieren. Diese Tatsache ist an sich bemerkenswert, auch wenn andere Translative konkurrieren. Uber das Regens in Fügungen, in denen Adjektive auf -in- + nom. Endungsmorphem auftreten, kann wenig ausgesagt werden, eine semantische Klassifizierung lst nicht wöglich, vgl.:

ольминз дворз L.23 (Ort)

отец Ивстипинз L.23 (Person) 
реть Рогъньднну L.76 (Äuвегung)

сотонниз двдв L.41 (Vorgang)

Dort, wo dae Suffix -in- + non. Endungsmorpher Substantive, die Personen bezelchnen, transferiert, hat es allein syntaktische Bedeutung, vgl.: даяти именемъ отцевмм и материным Sr.II, 118 , ○ крещеньи дьтинммь Sr.I, 795 (Objekt der Handlung).

Abstrakta sind bei Sreznevskij - vgl зиминъ, друхьбинъ, неприязнинъ - nur in einigen Fallen belegt, aus diesen lassen sich kelne weiteren Schlusse ziehen.

\section{Suffix -bn-j- + nom. Endungsmorphem}

Das Suffix -bn-j- hat ganz eindeutig nur syntaktische Punktion. Der lexikalische Bestand an Transferenda lst eng begrenzt und labt sich fixieren. Es handelt sich hierbel nur um Bezeichnungen für 'Herr', 'Bruder', 'Vater', 'Herrscher'. Am häufigsten ist das Transferendum rocnодь = 'Herr' für 'Christus'. Es liegt in der Natur der uns uberlieferten und von religiöser Thematik bestimmten Schriften, dab das Regens in Fugungen mit durch -bn-jtransferierten Adjektiven in aller Regel, jedoch nicht ausschlieblich, ein Abstraktum ist. Vgl.:

страсти Господня L.38

именемъ Господнимъ L.41

славы Господня L.63

страха Господня L.63 (Objekt)

Auber rocnoдb sind noch einige andere Transferenda belegt, die sich, wie bereits erwahnt, fixieren lassen:

-ots 'Vater' (Vgl. dazu $\$ 5)$

и рече ему воевода отень L.73

братъ :

жену братьно L.78

дьдз :

по устроенью Отьню А ДЪднБ L.27

TbCTb:

овьдами тьстьнями Sr.III, 1090 
Das Suffix -bn-j- transferiert das Substantir gxaduxa dann, wenn es sich seiner Bedeutung nach an rocnodb 'Herr' im Sinne ron 'Christue' anlehnt, rel. etwa на образъ Вйчнв Sr.I, 268 , ревитедь Вдаднчьнь Sr.I, 268. Dagegen kann Translation durch das Suffix -bn- erfolgen, wenn владыradie Bedeutung 'Herr'1= alIgemeinen Sinn hat, etwa: владыньнааго pизу (ebenda, rgl. dazu auch die einzelnen Belege bei Sreznerskij).

\section{\$52. e) Komposita. Asyndetische Determinativrerbindungen}

Hie bereits in $\$ 23$ dargelegt, können Komposita und aeyndetische Fugungen iv Rahmen dieser Arbeit nur ganz knapp behandelt werden. Der Uafang an Material und auch an speziellen Problemen lst hier so groB, daB eine gesonderte Untersuchung in jedem Fall nicht zu umgehen wäre. Ohnehin stehen die durch die Translationstheorie gegebenen methodischen Aspekte in dieser Arbeit im Vordergrund.

653. Es lst kein Zufall, daB Tesniere innerhalb des Kapitels uber die Translation einen Abschnitt der Komposition widmet. Wir hatten berelts gesehen, daB etwa ar. kpoвonpnлитье einem күऽви ирсйітье gegenúbersteht. Es lst nur folgerichtig, wenn Tesnière sagt: "Dans la composition biradicale, le determinant [...] est l'objet d'une translation qui le transfore en une catégorie susceptible d'être subordonné au déterminé [...]. 87 In кповопролитье lot demnach крпв-ь das determinierende, npoлитье das determinierte Glied der Komposition, der Bindevokal das äuBere Zelchen der Translation. Das Verhaltnis ist also dem zwischen determinierendem suffixal gebildeteten Adjektiv und determiniertem Substantiv absolut gleich. Dies wird schon deutlich, wenn man aus einer anderen Sprache in die Muttersprache ubbersetzt, so haben wir im Deutschen hufig Komposita, wo das Russische suffixal gebildete Adjektive benutzt. 'La tour Eiffel" wit dem "marquant zéro" 88 entspricht dem deutschen

87 a.a. . S. S . 406 .

88a.a.0., S.380: "Il arrive que la translation ne soit marque par rien. Dans ce cas, nous dirons que le marquant de $1 a$ translation est zéro [...]. c'est à dire qu'il y a transiation sans translatif [... ]". 
Kompositum 'Eiffelturn'. Benerkenswert lst, daß in Altrusa1schen die Komposition gegenuber dea durch Suffix transferierten Adjektiv die gleiche geringe Rolle spielt wie etwa der nominale Genitiv. In jedem Fall ist zunfachst das durch ein Suffix transferierte Adjektiv bevorzugt.

Ls ist recht erstaunlich, daß Dickenmann in seiner Arbeit uber die Nominalkomposition im Russischen Komposita wie Hов-городъ

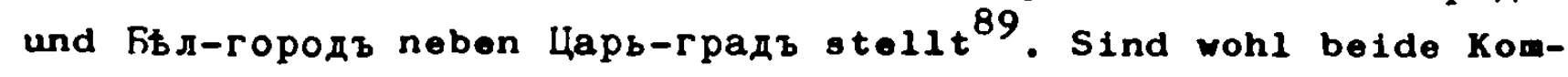
positionstypen als Determinativkomposita anzusehen, so ist doch nach den Gesichtspunkten der damaligen Sprachwissenschaft etwa Новгородъ von Царьградз zu trennen, insofern нов-primáres Adjektiv, uapb Substantiv ist. Indessen sind naturlich nach der Translationstheorie нов- wie царь-innerhalb der Zusammensetzung als Adjektive anzusehen. Die Struktur ist in beiden Fallen gleich, городъ (bzw. rрадъ) ist das Regens, нов-, бвл-, царь- sind subordonne. Entscheidend und differenzierend ist im vorliegenden Fall lediglich, daB es sich bei HOB- und бbJ-um primäre, bei царь- um ein transferiertes Adjektiv handelt. Man unterscheidet oft nach Subjektkomposita gegenuber den ubjektkomposita (jeweils mit einem Substantiv als determinierendem Glied) und Adjektivkomposita. Nach Tesnière wird man besser zwischen transferierten und nicht transferierten Determinationsgliedern unterscheiden.

\$54. Komposita mit transferiertem Adjektiv als Determinationsglied treten im Altrussischen - ohnehin in geringer Zahl, wie bekannt - im wesentlichen als zwei Typen auf: 1. Typus Carbgorodb (translation sans marquant), 2. Typus krovoprolitbe, das Translativ ist hier der Bindevokal. Der Typus baba-branka $90_{-}$ vgl. бабa-яra' 'Hexe' - ist schon kein echtes Kompositum mehr. sondern kann nach Dickenmann als asyndetaăhnliche lose Verbindung charakterisiert werden (Zusammenrickung). Dieser Typus finsich auch im Altrussischen, vgl. etwa Днbnpz pbka LL.1l oder

89

Dickenmann, Ernst: Die Nominalkosposition im Russischen. Berlin 1934, S.61.

90 ebenda. S. 33 . 
сици бо слугы бъси быварт L.135.

Der Typus Carbgrado ist in den literarischen altrussischen Texten nicht gerade häufig, desto mehr läbt er sich in der Volkssprache der Bylinen nachweisen, indessen sind uns diese erst aus sehr viel späterer Zeit uberliefert. Neben Lарьградъ lst etwa Константинъ градъ belegt, letzteres als Asyndeton, vgl. придоша от [...] Богохранинаго Константин града Раt.9, идыи къ Константину граду Раt.36. Царьградз wie Константинъ rрадъ bezeichnen die Stadt Konstantinopel, in einem Beleg ist der transferierte Personenname das Determinans. Im allgemeinen wird dort, wo Ortsbezelchnungen das Regens sind, kein solches Asyndeton gebildet, wenn das Transferendum ein Personenname ist. Vgl. etwa: в градъ Переяславль L.227, Святополчь городъ L.229. Vorwiegend wird hier, wie bereits gezeigt, das Suffix -j-gebraucht. Es scheint, daß Константинъ градъ eher in Analogie zu Lарьградъ gebildet wurde. Fur Lapьrрадъ ist die Binnenflexion charakteristisch, und zwar wird dabei der determinierende Teil wie ein jo-stamm dekliniert, vgl.: бь не дошел Царяграда L.71, то не бы ходилъ Царюгороду LL.13 (vgl. auch подъ Царемъ-градомъ Hilferd. III, 108) 91 . Die Erklärung von Dickenmann, die Binnenflexion sei vom Genitiv ausgegangen 92 , ist nicht unbedingt zwingend, es stellt sich die Frage, warum dann der Genitiv nicht auch in den Nominativ eingedrungen ist, man muibte dann ein Carjagradz anfuhren können. Es ist auch gar nicht ausgemacht, ob mit Lарьградъ urspringlich 'stadt des Kaisers' (Genitiv) gemeint war, ondern vielmehr die besonders hervorragende Stadt unter anderen Städten. Darauf weist die grobe Zahl von Zusammensetzungen mit uapb-in Bylinen und Mărchen hin, vgl. etwa царь Огонь и царица Грозная Молния. 93 Keller bringt zahlreiche Belege dafur, daß slavische Asyndeta häufig im zweiten Glied durch einen obliquen Kasus oder Práposition mit Kasus aufzulösen sind. Dies gelte vornehmlich fur

$91 v_{\text {gl }}$. Dickenmann, a.a.0., s.61.

92 ebenda, S.62.

93 $v_{\text {gl }}$. Keller, Siegmund: Das Asyndeton in den balto-slavischen Sprachen. Heidelberg 1922, S.14. 
Ubersetzungen aus dem Griechischen. "[...] es wird z. B. Im Griechischen das erste Glied in Stammesgestalt, Im Russischen dafur aber Asyndeta gesetzt, hier wie dort ist das zweite Glied nicht untergeordnet, sondern koordiniert[...]. Ähnlich sind auch zu fassen: carb kolokol = carb kolokolov, carb rak A. VII, 275 carb rakov." 94 Gemeint ist also etwa 'Zar der Glocken, d. i. 'elne besonders schöne und grobe Glocke', nicht aber 'Glocke des Zaren', eine solche Erklärung ist auch fur den Namen der Stadt Царьградъ m 6 g 1 i $c$ angesichts der Fulle solcher Fügungen im Russischen. Griechischer EinfluB lst indessen mit Sicherheit nicht auszuschließen, Vasmer nimmt an, daß eine Ubersetzung von

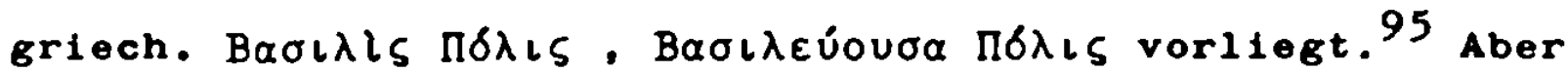
selbst dies schlieBt nicht aus, daB eine freiere Ubertragung in Anlehnung an einheimische Namen vorgenommen wurde. Vasmer selbst welst ja darauf hin, daB Thomsen den altnord. Namen Mikligardr 'Konstantinopel' als Anlehnung an den altrussischen Namen aurfabt. Mikligardr aber bedeutet nichts anderes als 'die grobe, prächtige Stadt', das altnord, mikill entspräche genau dem, was царь- in den meisten Asyndeta bzw. Komposita meint, nämlich: 'hervorragend', 'prächtig', 'grob', 'schön'.

$\$ 55$. Charakteristisch für das Altrussische - wie auch für die russische Volkssprache - sind Fügungen wie жена грекыни L.75. Es handelt sich wie beim Typus Carbgradb um Zusammenrúckung. wenn auch Regens und subordonné getrennt geschrieben werden. Das Determinans steht immer in Postposition. Die Translation wird nicht durch ein "marquant" sichtbar gemacht. Diese Form der Adjektivbildung muB man als typisch russisch ansehen, sie steht gleichberechtigt neben der Translation durch Suffixe, wenn sie auch nicht so häufig ist. Tatsächlich gibt es Varianten wie от царицы грькыны L.160 - от цариць Грьчьское Нур.160 oder ти суть лодье нугородьци L.20 - людье ноугородьстии L.69 (daneben auch die suffixale Ableitung новгородьци L.179), vgl. auch людье Киевьстия L.57. Als den nächststehenden "Konkurrenten" kann man das Suffix -bskansehen, wie die angefuhrten Belege bereits zeigten. Das Transferen

94 keller, a.a.0., s.27.
95 vasmer, Russ. etymolog. Wb. III, S.283. 
lst eehr haufig ein|Ethniku. Vgl. Ferner: y Яponosxa xe xeнa грекини бь L.75, Вододимеръ ге задехе хену братьно Грекино L.78 (Hier let bemerkenewert, daB ein suffixal gebildetes Adjektir (-j-) als zweites Determinans eingeschoben wird.). uyab корсунянинъ стръди L.109, находници варязи L.20.

Das Transferendum muB jedoch nicht ausschlieBlich ein Ethnikum sein, wie u. a. folgende Belege zeigen: хекы дрбодьици L.80, сици бо слугы бъси бнвахт L.135, женам предрбодыицамъ L.91, от супостата дьявола L.69. Bei den zuletzt angefuhrten Belegen läbt sich librigens nicht mit absoluter sicherheit sagen, welches der beiden in Frage kommenden Substantive als transferiert anzusehen ist. Любодьица entspricht sowohl dem griech. mask.

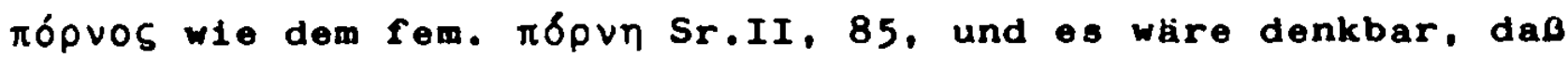
im Altrussischen zeнa nur zur Fixierung des Genus diente. Andererseits kann man so argumentieren, dab eben meHs durch abбoдыицы als solche charakterisiert werden solien. In Griechischen wie im Deutschen steht in diesem Fall ein einzelnes Wort. Ebenso kann man супостатъ дьяволь ubersetzen mit 'der Verfuhrer Teufel' oder 'der Teufel als Verfunrer'. Eindeutig dagegen ist cлyrb бъсы 'Teufelsdiener'. In dem Beleg въздвие дьяволь котору въ братьи сеи Ярославичихъ L.182 wird das Determinans Ярославичи als suffixal gebildetes Adjektiv flektiert, richtet sich aber grammatisch nicht nach братья.

\$56. Eine fur das Altrussische weniger typische und mit Sicherheit stark rom Griechischen her beeinflubte Konstruktion ist das Kompositum mit Bindevokal -o-/-e-. Damit wird nichts uber das Alter dieser Konstruktion an sich ausgesagt. Wenn man annimmt, daß ein ar. богословьцb eine Lehnubersetzung von griech.

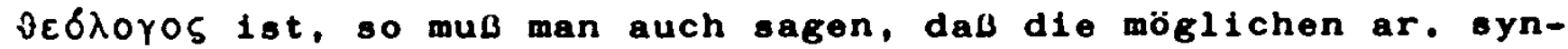
tagmatischen Fügungen, die mit dieser Konstruktion konkurrieren könnten, nicht das gleiche ausdricken wie богословьцb. Unter - словьць бохй wäre eher 'göttlicher Redner' als die spezielle Bedeutung 'Theologe' zu rerstehen. Wenn auch ein Objektrerhaltnis durch suffixal transferierte Adjektive ausgedrickt werden kann, so lst dies doch nicht die uberwiegende Funktion dieser Adjektire, whihrend man dies durchaus von den Komposita sagen darf. 
E. 1et nur folgericht1G, wenn bel einer lohnuberseteung d10 olndeut1gere Fork gewählt wird. An wonlgeten wirde das Adjekt1r бохьственныи hior Inhaltlich zutreffen, da en ja 'gótt11ch' in Sinne ron 'gottahnlich' bedeuten kbnnte.

Venn griechleche Korposita buchotabengetreu übertragen werden, lot zu vernuten, daB gegenuber abglichen adjekt1vischen Konstruktionen, die suffixal transferlert werden, olne gewlose Bedeutungedifferenzierung durchgefuhrt ist. D1e Fulle der Korposita, die In offensichtilcher Anlehnung an die gelehrte griechloche Tereinologie entstanden, let ersichtlich grob, aber, wie noch zu erliutern sein wird, konnte ach das determinierende Glied der Kompostion nicht ohne veiteres in den weleten Filien durch oin ouffixal transferiortes Adjektiv ersetzt werden, wie oben an elnes Beispiel dargelegt wurde. Zunkchst elnige Beispiele:

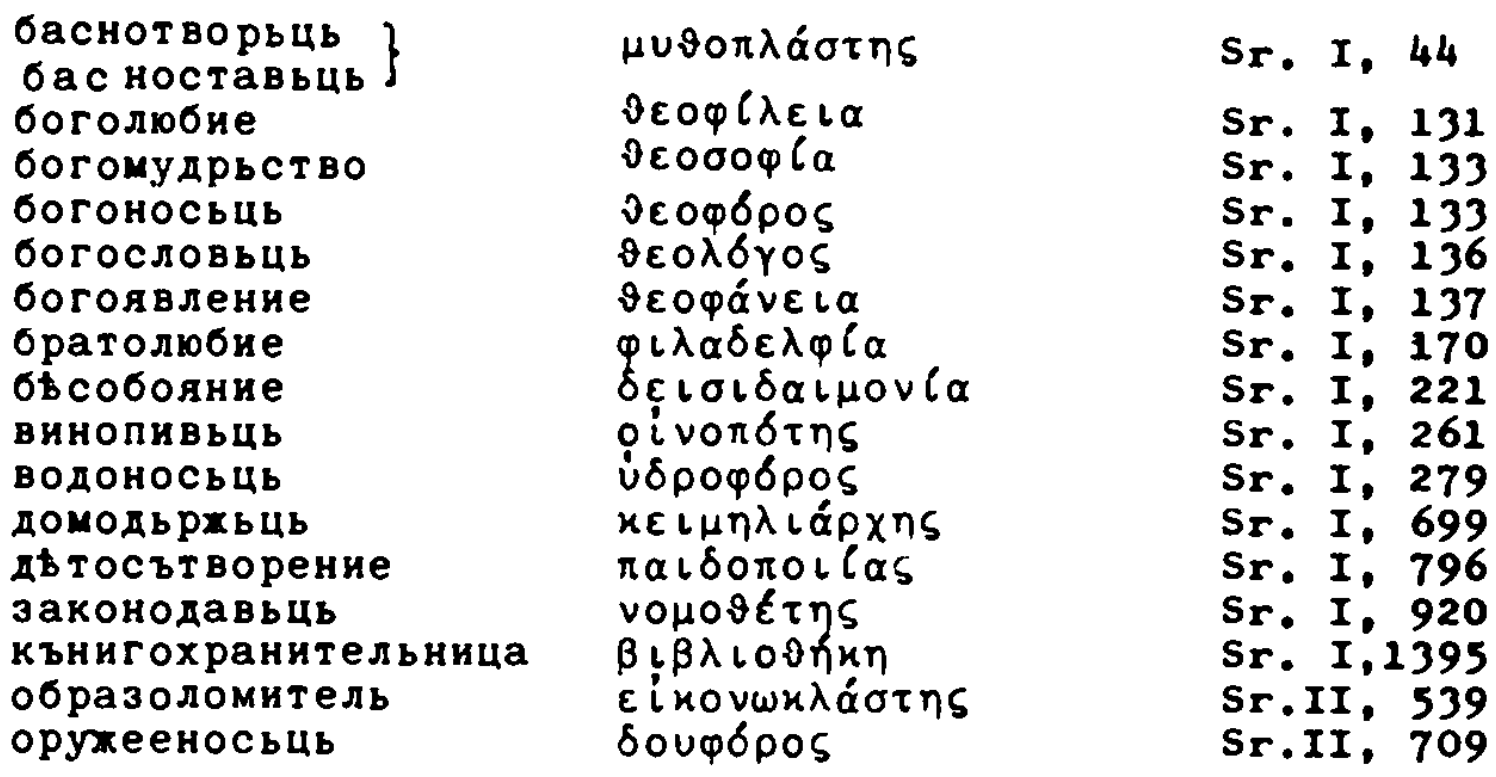

Kehren wir zu der oben aufgesteliten Behauptung zurick, daB das deterinierende Glied der Komposition nicht ohne weiteros durch ein mittelo Suffix transferiertes Adjektiv ersetzt werden kann. Wir kommen zu khnlichen Ergebniseon, wie wir - 1e bel der Untersuchung des adnosinalen Genitive fostotelIen wusten. 96 Das Translatir in Gestalt des Korpositionsrokalo wird dort gebraucht, wo die konkurrierenden ouffixal

$96 v_{\text {Gl }} \cdot \$ 32 \mathrm{f}$. 
traneferierten Adjekt1ve nicht zu der Gruppe der Adjektive cehbren, deren Tranilatir allein eyntakt1sche Funktion hat.

E. Let naturlich auffull1, daß bel der Uberzabl der Komposita das Detereinane gleiche Funktion hat wie der Genitivus obiectirus, vgl. еtта убинстводъица L. 15. кровороднтье L. 77, хенодобець L. 80 u. dgl. Das Determinatum let eohr hufig ein Verbalabstraktum. Man könnte sich leicht zu den Schlus rerleiten lassen, es el den genitivischen Konstruktionen und den Komposita alt Binderokal -0-/-0- rorbehalten, dae Objekt der Handlung auszudricken. D1ese Ansicht laBt eich nicht halten, wie berelte unter $\$ 34$ anhand von Belegen dargelegt wurde.

657. Es missen also andere Kriterien namhaft gemacht werden, w11 aan erklären, daB als Determinans nur ein nicht surfixal transforlertes Adjektiv in Frage kommt. Als krkiärung können die gleichen Grunde wie fur den lebrauch des Genitive gelten. Das Kompositur, gebildet alt Bindevokal -0-/-0-, wird in der Hegel dort angewandt, wo ein euffixal transferiertes Adjekt1v als Determinans nicht aöglich 1st, well es lm Kontext MiBversttindn1sse hervorrufon wirde, Insofern das Translativ nicht allein syntaktische Funktion besitzt. Vgl. dazus reтописаньи L. 17. Ein летьния Sr. II, 80 lat bel Sreznerakif in der Bedeutung 'годовоһ', 'летнй', 'aestivus' und 'охны ' (подуденньи) bеlеgt. 'Годовоһ' und 'охныя' aber wurden in lhrer Bedeutung zu MiBverstándis in Verbindung mit писанье fuhren. Wollte man e1n женолюбець Sr. I, 80, durch женьскии Ioбeцb ersetzen, so mechte man aus einem 'Mann, der die Frauen in besonderem MaBe liebt' einen 'weiblichen Liebhaber'. Бесослухение L. 97 bedeutet 'Teufelsdienst'. 'Dienst an Teufeln', бъсовьское сдуженье wäre Indessen zu übersetzen als 'touflischer Dienst', d. h. das Adjektir hätte in letzterem Falle eindeutig primäre, wertende Bedeutung. Братоненавиденье L. 167 bedeutet 'Bruderhab', ein оратьское ненавиденье kbinte als 'bruderlicher HaB' wiedergegeben werden, was zwar nicht ooh oinnvoll in bezug auf Dritte, aber immerhin mbg11ch ware. Mit законопреступникъ L. 135 lot ein 'Gesetzes- 
Ubertreter' gemelnt, законьния npecтупникъ könnte nur alt 'gesetzlicher (gesetzuBiger) tbertroter' ubersetzt werden. Es zelgt sch, daß bel der Mehrzahl der belege das entsprechende suffixal transforierte Adjektiv, welches als Konkurrent in Frage kbime, bereito prinkre (wertende) Bedoutung angenomen hat. Verabsolutieren labt sich diese Kegel allerdings nicht. Ohne Zwelfel blelbt, das das durch Suffix transforlerte Adjektir als Neterminans die fur das Altrussische charakteristische Form 1st. Wenn stattdessen Konposition oder Kasuskonstruktionen gebraucht werden, dann liegen in den allermelsten Fulien triftige Grunde dafur vor, sol es, daB es sich un dirokte Entlehnungen aus dem Griechischen handelt, sei es, daB die Wahl elnes konkurrierenden durch Suffix transferierten Adjekt1vs MiBrerstandnisse in Kontext herrorrufon wirde. Wenn Determinativkompostion und adnoninaler Gonitiv in Verlaufo der spateron Entwicklung der rusaischen Sprache den Gebrauch des durch Suffix transferierten Adjektivs zuruckgedrangt haben, so lot dies fremdsprachigem Einflub zuzuschreiben. Wie tief verwurzelt die Bevorzugung des Suffixes imer noch lst, davon kann man sich leicht überzeugen: Elne Person, deren Muttersprache Russisch ist, ubersetzte den thr versuchswelse vorgelegten fremden Fachbegriff 'Vegetationskegel' Instinktir mit pacтительный конус oder вereтатионныи k., obwohl in der russischen Facheprache dieser Begriff mit конус нарастания wiedergegeben wird. 
858. Die Inhaltiche Definition der Affixe bel Martinet 97 hatte une veranlabt, zu sagen, daB es elne Gruppe ron abgeleiteten Adjekt1ven Gibt, bel denen - und dabel hatton wir den weitrelchenderen Begriff Tesnières bonutzt - das Transferendur elnzig und allein funktionales Monen ist. Die Bedeutung dieser Translative beschrankt sich also nur auf thre syntaktische Funktion. Hir waren insofern weiter gegangen als Martinet, als wir in bestimeten adjektivbildenden Suffixen die glelche syntaktische Funktion erkannten wie etwa bel Prápositionen, Kasus, Kompositionselementen.

Wenn man einew Transferendur neben seiner Funktion, die es bel der Translation ausubt, elnen semantischen Gehalt zuspricht, d. h. es semantisch zu fixieren sucht, so lst dies eigentlich nur durch elne Form der Transformation möglich. Entscheidend dabel lot zunächst uberhaupt die Möglichkelt elner solchen Transformation. Ein Belspiel: да приведенъ будеть сьдинавни старьць Sr. III, 888. Съдинавни 1st das Produkt der Translation von сђдина 'grave Haare' ( съдина wiederum lot Produkt der Translation $A>0$ von cbla). Man könnte сьдинавыи im gegebenen Falle als 'mit grauen Haaren behaftet' transformieren. Genau das tut man, wenn man solche Adjektive wie neuruss. деревяннй mit 'gemacht aus Holz' wiedergibt. Das glelche Verfahren wendet auch H. Wisemann bel der Bedeutungofixierung elniger Suffixe an, wenn er etwa sagt: "Durch die Translation железисты und медисти determinieren die Nebenbegriffe железо bzw. медь nur solche Hauptbegriffe, durch die zu den Nebenbegriffen xелезо bzw. медь elne ganz bestimete Beziehungsbedeutung realisiert wird, nán$11 \mathrm{ch}$ ' d a e $\mathrm{e}$ h a 1 t $\mathrm{d}$ ' "was der Nebenbegriff (das Transferendum) bezeichnet." $98 \mathrm{Um}$ elne solche Fixierung festotellen zu können, lot lmeer elne Form der Transformation notwendig. Dabel wird in der Regel eine Praposition

97 Martinet, a.a.0., S. 124 fr.

98 Heinz wissemann: Zur Problematik der "Suffixbedeutung" adjekt1vbildender Translative Im Russischen. Ins Siavistische

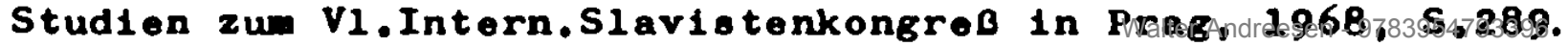


und eln Verb, das als Partizip auftritt, benót1gt. Hissemann selbst welst darauf hin, daß bol Adjektiren vor Typue

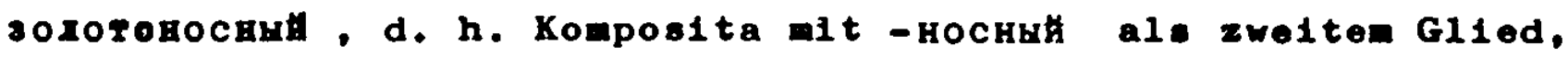
der Verbalbegriff, der fast in jeder Beziehungebedeutung oteckt, aber von der Sprache melst verschwiegen wird, auch als solcher zum Ausdruck komet. 99

D1e Transformations-Grammatik arbeltet ja grundsitzlich ait der Methode, Syntagmen auf eine verbale "Tiefenstruktur" zurfickzufuhren. Wir hatten 1m allgemelnen Tell dieser Arbelt daran Kritik gellbt und gesagt, daB sich der Verbalbegriff auf diese Helse oft gar nicht elndeutig fixieren lasse. Indessen laBt sich bei bestimmten Adjektiven dieser als semantischer Kern enthaltene Verbalbegriff fixieren. Bel einigen Adjektivtypen lst or weltgehend translativgebunden, bel anderen lkBt or sich jewells nur fur den Einzelfall bestimmen. In Altrussischen kann mit an Sicherheit grenzender Wahrscheinlichkeit kein Translativ ausgemacht werden, fur das nur eine einzige Beziehungsbedeutung Geltung hat. Man wird sich hier ait der Formulierung "weitgehende Translativgebundenhe1t" begnigen missen. Fü das von Wissemann belsplelswelse besonders eingehend behandelte Suffix -1st-, wo elne erfolgreiche fixierung der Beziehungsbedeutung möglich 1st, findet sich in den "Materialy" Sreznevakijo nur elne Handroll Belege und bel diesen labt sich keine eindeutige Fixierung vornehmen. Nehmen wir ein anderes Beispiel, das Adjektir kръвавии $S r . I$, 1338. Sreznevskij gibt fü dieses Adjekt1r drel Bedeutungen an: 1. sangineus. Der Beleg dazu: плачуще со слезами кровавнми (Pskov. I. $1.6738 \mathrm{~g}$. ). Sieht man sich den Kontext an, so wird man zu der Erkenntnis gelangen, dass elgentilch nichts anderes zum Ausdruck Bebracht werden sol1, ale die besondere Intensivitit des Schmerzes der betroffenen Person. Das Suffix hat einen gewisgen semantischen Gehalt, insofern es - Innerhalb des Kontextes und unter Berlcksichtigung des Regens - diese Intensivierung zum Ausdruck bringt. Wollte man elne Fixierung des Suffixes in seinem Bedeutungsgehalt

$99 . .0 .0$. S. 291. 
rornobmen, so mbte man ubertragen 'Tranen, die aue Blut beotohen, elt Blut vermiecht sind'. 2. oxpoвaвденнын 'alt Blut bohaftet' ( вив десвиду крьваву). Hier hat des Suffix noch deutlicheren Lexemcharakter: ('behaftet alt der, we dae Traneferendu bezelchnet'). 3. багровын̈, краснын. (я потомъ явия соднце хровави дуча испушамш). Hier lst das Tranelativ weder funktionales Monen in Sinne Martinets noch komt der Lexemcharakter zum Ausdruck. hie die neurnes. Ubersetzung von Sresnevakif ze1gt, let hier кръвавыи einem primbren Adjektir gleichwertig. Es bedeutet ganz einfach 'rot'.

Wie berelto bemerkt, ikBt olch in bezug auf den Lexemcharakter bestinmter Translative iw Altruselschen bel einigen Surfixen eine zienlich weitgehende Translativgebundenhelt festetellen. Wonn eine Fixierung der Beziehungsbedeutung ach nicht fur durchweg alle Suffixe vorgenomen werden kann - insofern sollte man vorsichtiger formulieren, als es beispielswelse die Autoren der Akademie-Grammatik tun - so doch rur einen prozentual hohen Ante1l. Dies gilt fur die Suffixe -av-. $-\operatorname{an}-(-\mathrm{Jan}),-1 \mathrm{v}-,-11 \mathrm{v}-,-\mathrm{at}-$, -ovat-, -1t-, -ovit-, -18t-.

A110 diese Suffixe olnd gegenuber anderen, etwa -bn- oder -bok-, nur wentg belegt, d. h. sie epielen in Altrussischen kelne groBe Rolle. Andererselts erfullen Translative, wie d1. Suffixe-bn- oder-bok-Bedingungen, wie sie fir die drel verschiedenen Kategorien von Adjektiven gelten. Die relativ geringe Bedoutung der genannten Suffixe erklart olch dadurch, daB andere - In diesen Falle eben verbale - konkurrierende Mittel zur Verfugung otehen. Wie berelts oben erklurt, kann das Adjektiv auch ganz adkquat durch ein Partizip eines Verbs + Transforendun des betreffenden Adjektive wledergegeben werden. Eben dies tut wan, wonn wan den semantischen Kern des Suffixes bestimet und die Beziehungobedeutung fixiert.

\$59. Suffix -av- (-jav-)

Sofern das Transferendum elnen $k \ddot{~} r$ er $b$ e $t \mathbf{t}$ - 
t 11 bezeichnet, 14Bt alch fü das Translativ elne zusätzliche Bezlehungsbedeutung fixieren: 'behaftet mit dew, was das Transferendum bezelchnet'. Vgl, cъдинавын Sr. III. 888 'wlt grauen Haaren behaftet's aksl. да приведенъ будеть cъдинавыи старьць (Supr.r.170), ahnl1ch кудрявыи Sr. I, 1358, сьдз главою и брадор кудрявор,кръвавын Sr. I, 1338, 'wit Blut behaftet', краставыи Sr. 1316, короставыи Sr. I, 1291 (von kopocia 'Kruste auf der haut') 'mit elner solchen Kruste behaftet', 'aussktz1g', короставынмъ[...] овьцамъ (vgl, ähnllch крастовыи, крастовая овца Sr. I. I318)

хилавыи Sr. I,874 'm1t Adern behaftet' враскавыи Sr. I, 313 'm1t Runzeln behaftet's враскава коха.

In einigen slavischen Sprachen hat dieses Adjektiv eine modifizierte Bedeutung angenommen, so $z$. B. skr. Zilar 'zkn', 'stark'.

Sofern das Transferendum $n 1$ c $t$ Signifikant fiir einen Körpertell oder Körperbestandteil ist, ist eine exakte Fixierung der Beziehungsbedeutung nicht möglich, es sel denn in Einzelfkllen, z. В. искравыи 'испускавин искры' Sr. I. 1119.

\$60. Suff $1 x$-an-, - Jan-

Die Akademie-Grammatik schreibt dem Suffix - $(j) a n-d i e$ Beziehungsbedeutung 'gemacht aus dem Stoff, den die Basis (основа) bezeichnet' zu, In einigen Fällen sei jedoch eine solche Zuordnung nicht möglich. 100 Berelts das Altrussische zelgt, daß neben der Bezlehungsbedeutung 'gemacht aus dem Stoff, den das Transferendum bezelchnet', die allgemeinsten Beziehungsbedeutungen stehen. $V_{G l}$. etwa: олmаны вьтви Sr. II, 664 'Erlenzwe1ge' (von ольха 'krle'). Immerhin laBt sich aber bel 23 von 30 Belegen die Beziehungsbedeutung 'gemacht aus' feststellen. Selbst Adjekt1re. deren Suffix zunlachst nicht diese Bezlehungsbedeutung aus- 
zudrucken scheinen, lassen elch in dieser Richtung festlegen. Vgl.: бисьряныи Sr. I, 89. Man würde die Beziehungsbedeutung 'geschmickt mit dem, was das Transferendun bezeichnet' vermuten, sieht man sich die Belege aber an, so wus man feststelien, daB die Beziehungsbedeutung 'gemacht aus' durchaus richtig ist (Црокскя бисьряныя ризы, рвзы бисьрьныя Sr. I, 89), da d1e oberflkchenetruktur dieser Gegenstánde diesen kindruck erwecken kann. Die libertragung Srezneraki jв 'бисерокъ украшеннын ' wird man nicht fü die einzig zutreffende halten, wenn man solche Kirchengewäder gesehen hat, die buchstablich 'aus Perlen gefertigt' sind. VG1. Ferner:

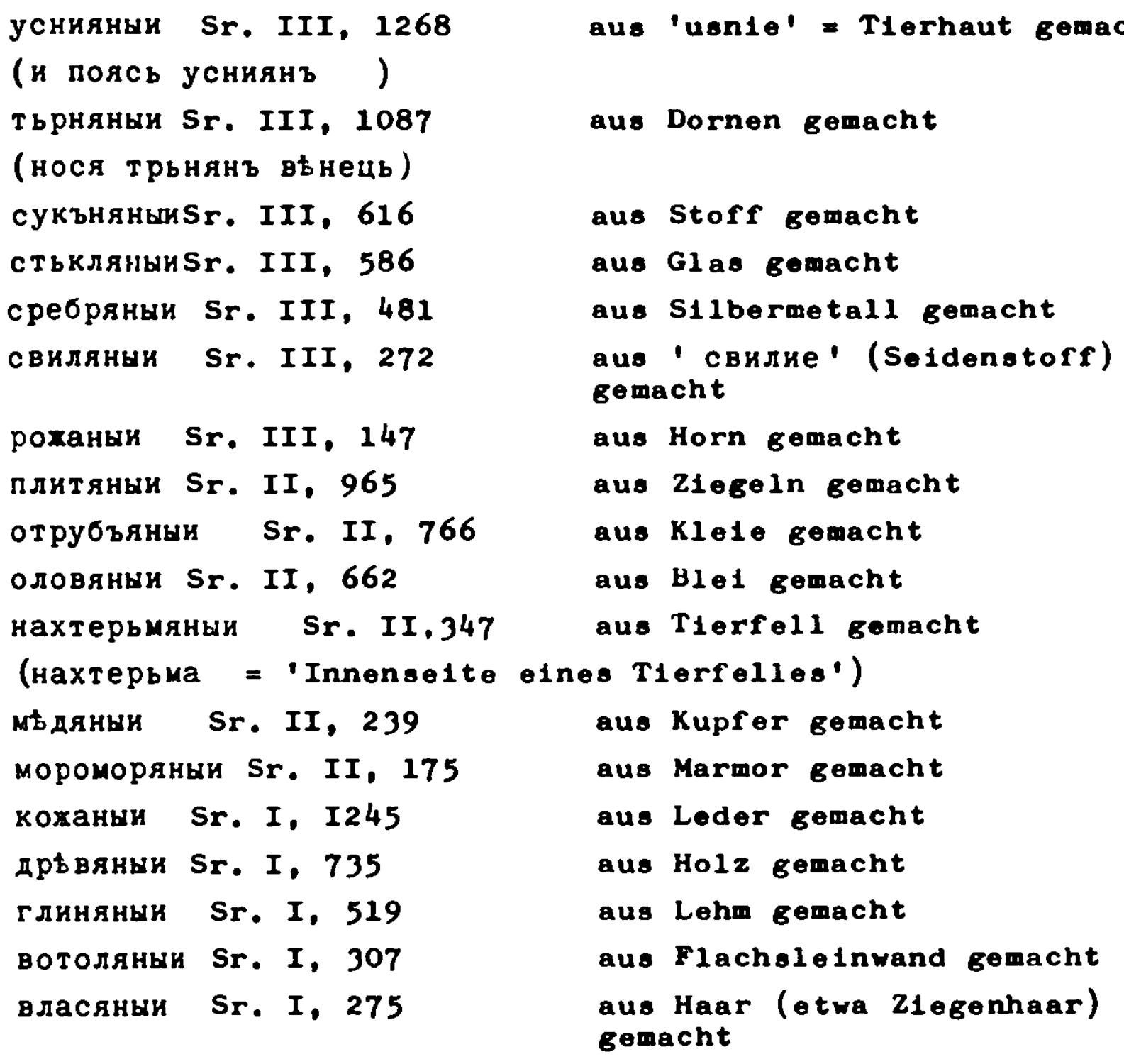

Diese Fixierbarke1t der Bezlehungsbedeutung des Suffixes labt sich dort feststelien, wo das Transferendum eine Materie bezelchnet, die der wesent 11 c 
Bestandtell dessen ist, was durch das Regens bezelchnet wird.

Bei allen Transferenda labt sich eine Fixierung des Translative nicht vornehmen. Соляньи Sr. III, 463 etwa vereinigt in sich weit mehr Bedeutungen als etwa neuruss. соляноя: 1. дамдй соль, 2. относящинся до соли, 3. солянон. Jedenfalls scheint die Fixierbarke1t der Beziehungsbedeutung im Altrussischen noch besser möglich zu sein als im modernen Russisch. 101

§61. Suffix -1v-

In der growen Akademiegrammatik wird folgendes uber das Suffix -1v- ausgesagt: "Посредством суффикса -ив- от основ имен существительных образуются имена придагательные со значением: имеюий что-либо, склонный к чему-либо, что обозначается производящей основон." 102 Diese These, verbunden mit der Aussage, daß der Typ unproduktiv seilo3, besagt, daB Adjektive auf -iv-grundsatzlich von Nomina abgeleitet sind.

Für das Altrussiche gitt dies wohl nicht, ob die Aussage fur das Neurussische ihre Gultigkelt hat, ist zu bezweifeln. Vondrák weist darauf hin, das sowohl Verba wie Nomina als Basis in Betracht kommen: "So haben wir ljubivb '11ebend' Supr. 338, 2 zu ljub1t1 [...] milostivb 'mitleidsvoll' lc, 18, 13 zu milostb [... $]^{104}$. Die Frage, ob Translation OsA oder I A vorliegt, ist zuwellen schwlerig zu lösen. Vgl. aероходивни Sr. I. 7 (neben aepоходьныи). Man mußte nach der Erklärung Vondraks annehmen, dal das Transferendum ходити wäre. Es könnte sich aber grundsatzlich auch um elne frele Blldung handeln, wobel als Transferendum aeps Sr. III, 1382 in Frage käme und, was ziemlich wahrscheinlich ist, der Vorgang der Zusammenrückung mit

${ }^{101} \mathrm{v}_{\mathrm{gl}}$. dazu die Kritik Wisgemanns an der Akademie-Grammatik a.a.0.. S. 294.

102 Grammatika russkogo jazyka. AN SSSR. Moskva I960, Bd. I, S. 336.

103 ebenda, s. 337.

104 vondrák, a.a.0., s. 521 . 
aeps Sr. I, 7 glelchzeltiger Transiation In einselnen nicht eohr rokonstruierbar ware. In solchen Fullen bletet slch der Terminue "freie Blidung" an ehesten an. Die Frage, ob Translation $0>$ A Uberhaupt rorliegt, auB für den Elnselfall beantwortet werden. Hier werden Adjektive ausgeschlossen, die nicht eindeutig das Produkt der Transiation 0 , A sind.

Ähnllch wie beim Suffix - $(j)$ an- labt olch etwa bel zwel Drittel der Belege eine translativgebundene Beziehungsbedeutung festotelien. Das Transferendum lot in diesen Falien me1stens oln Abstraktue. Ist diese Voraussetzung gegeben, so bezelchnet das Regens in Fügungen mit Adjektiven auf - Irin der Regel ein Hesen. Die Adjektive bezeichnen dann die durch das Transferendum ausgedruckte abstrakte Eigenschaft (bzw. Gefuhl). Vgl.: боязнивии Sr. I, 199 ('Furcht'): дшер не боязнивор (иит. Феод.), халостивыи Sr. I, 844 ('M1tle1d' u. dgl.): Еремия халостивыи (Никон. Панд.). зълобивыи Sr. I, 1001 ('Bӧваrtigke1t'): отъ съньма зълобивыихъ (Панд. Ант.), завидивыи Sr. I, 900 (Ne1d, М1вgunst): завидивыи бъсъ (Панд. Ант.), вазнивыи Sr. I, 224

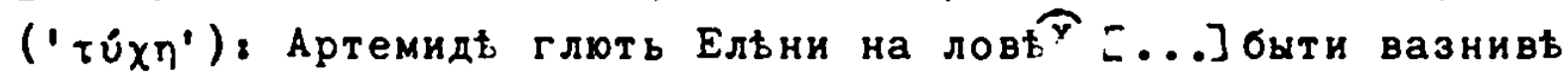
(Гр. Наз. съ толк. Ник. Ир),гладивыи Sr. I, 516 ('Hunger' im Ubertragenen Sinn: 'Uneroätlichkeit, Gier, Blutdurst'): къ влъку бо прилагаеть нравъ гладивааго а кроткааго овци (Ис. ХI.6. толк. Упыр. 101 об.), гнъвивыи Sr. I, 527 ('Zогn'), опасивыи Sr. II, 678 ('Vorsicht', 'Umsichtigke1t'): оть опасивааго пъвания - ими же не бю льзь (Панд. Ант.), охотивыи Sr. II, 838 ('Lust'), оплазивыи Sr. II, 683 ('Kuhnhe1t'. 'Verwegenhe1t'): моужь оплазивъ въпадеть въ злая (Изб. То 1073 r.). проказивыи .Sr. II, 1534 ('L1st', 'Verschlagenhe1t'): проказивъ есть дьяволь (Ио. Јьств.XIY в.), опаливыи Sr.II, 677 ('Erregbarke1t'): эробзі ипалияа муха (Прол. окт.). стръпътивыи Sr. III, 562 ('Llst', 'Hinterhältigkeit'): отъими отъ себе стртпътияа оуста и обидьливы оустьны далече [....] (Панд. Ант.) , радостивыи Sr. III, 13 ('Freude'. 'Schönhe1t'): елень бо твломъ [...] радостива(Ио. Мал. Хрон.). 
Andere Beziohungsbedeutungen sind nur in geringer zahl belegt, wie etwas пльшивыи Sr. II, 977 'mit einer Glatse behaftet', клеветивыи Sr. I, 1215 'zum Lugen, zur Verleumdung neigend'.

\section{Suffix -11v-}

Wenn man das Suffix-11v- mit -iv- vergleicht, so sieht man, daß sich das Transferendum ahnlich charakterisieren laBt, jedoch eindeutiger. Bei den gesammelten Belegen waren die Transferenda durchweg Abstrakta. Der semantische Gehalt des Suffixes labt sich in der Mehrzahl der FuIle bestimen ahnlich wie bel -iv- als 'erfullt von dem Gefuhl oder der Eigenschaft dessen, was das Transferendum bezeichnet'. VGl.: стръпътьливыи Sr. III, 563: бъ бо (Жирослав) лукавыи льстьць наречень и всихъ стропотливее и лохь пламянъ (Ип. л.) (Eigenschaft: 'List'), охотьливыи Sr. II, 838, паче же на милостыню зьло охотливъ (Переясл. л.) (Gefuhl der Lust'). боязливыи Sr. I, 159, придуть въ помысль о грвсвхъ свокхъ боязливии (Прем. Сол.) ('Gefuhl der Angst'), опьтьливыи Sr. II, 701, ... олытьливое лицемьрие ... (Панд. Ант.). ('Gefuhl der Neugier im positiven wie negativen sinne'). стпастьливыи Sr. III, 543,милостивъ и страстливъ (Пат. Син.) ('Gefül der Scham').-нier lot die Möglichkeit elner Translation $I>0$ nicht wit Sicherheit auszuschileBen.соромяхливни Sr. III, 467 ('Geruhl der Scham'). Andere Beziehungsbedeutungen sind kaum belegt, wiе смьхъливыи Sr. III, 451 'склонниы к смеху', укорьливын Sr. III, 1183 'оскорбляющй' .

§3. Sufrix -at-

Die Anzahl der Belege ist gering. In der Mehrzahl der Falle labt sich eine Fixierung der Beziohungsbedeutung vornehmen 'versehen mit dem, was das Transferendum bezelchnet'. In der Regel bezeichnet dabel das Regens ein Wesen: бородатыи Sr.I. 153. брадатыи Sr. I, 164 (ksl. Form): Ефимии брадатыи (Прол. 143). крилатыи Sr. I, 1323 в моухи крилати (Izb. 1076r.). 
Be1 устьнатни Sr. III, 1293 'пирокоротнын ' = at einer groesen Maul versehen (nicht etwa dt. 'grobnkalig' in ubertragenen Sinne) wird das Transferendum zusätzlich năher determiniert, da Ja urspringlich dem Transferendum устьна nicht die Bedeutung 'großer Mund' zugrunde liegt. Dazu könnte man auch хенатни 'bewelbt', 'mit einer Frau versehen' zuhlen (orb nona женатаго Sr. I, 857). Bel der wiederholten Translation (translation double $0>A$ > 0 fuhrt dies belm Transferendum жена zu einer Bedeutungsmodifizierung? хенатьв = мирянинъ Sr. I, 857 'Laie' (gegenuber dem unverhelrateten Mönch). Nicht eindeutig wiederzugeben iot jomatsh Sr.II. 48 Sreznevok1j: "имеющй вид ложки" (?). Eine seltene Ausnahme bildet: листвьнатыи Sr. II, 23, листвьнатымъ хьзломъ (Lärchenzwe1g), da bel der Translation von Substantiven, die Bäume bezelchnen, fast durchgängig das Suffix -ov- sowohl mit nominalem wie pronominalem Endungsmorphem gebraucht wird. DaB hier -ov- nicht als Translativ verwendet wird, durfte damit zusammenhängen, daß Substantiva auf -ica gemeinhin nicht durch -ov- transferlert werden.

\section{$\S 64$. Suff1x $-1 t$ -}

Das Suffix ist im Altrussischen nur auberordentlich wenig belegt. Der semantische wehalt labt sich nicht eindeutig f1xieren. Vergl.: тьлесистия Sr. III, 1090 'крепкий тьломъ'. Ähnlich wie bel устьнатьи wird hier das Transferendum näher determiniert, da das Substantiv røло nicht 'starker Körper' bedeutet, sondern nur 'Körper'. In elnigen Fallen lst der Lexemcharakter des Translativs völlig verblaBt, so daB Adjektive mit primärer Bedeutung entstehen: племенитыи Sr.II, 959 'nob1lis', (eigentlich: 'aus vornehmem Stamme', wobel wieder 'vornehw' nicht in Transferendum enthalten 1st), именитии Sr. I, 1039 'bedeutend' (elgentlich: 'mit einem bedeutenden Namen versehen', wobel 'bedeutend' nicht im Transferendum enthalten 1st, vgl.: bhnllch знаменитыв).

Die Suffixe -ovit-, -1st- und andere sind im Altrussischen nur ganz wenlg belegt. Daher lst es nicht möglich, sie in diesem Zusamenhang in der Konkurrenz gegenuber anderen Translativen năher abzugrenzen. 


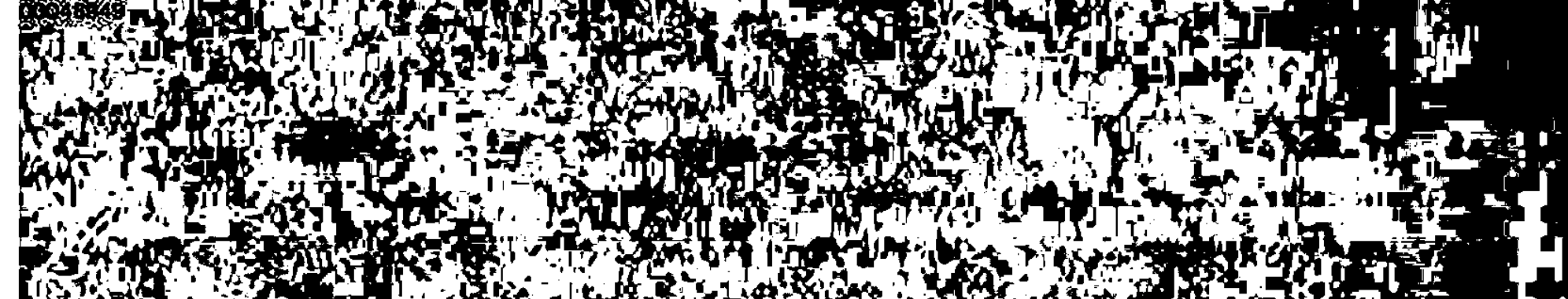

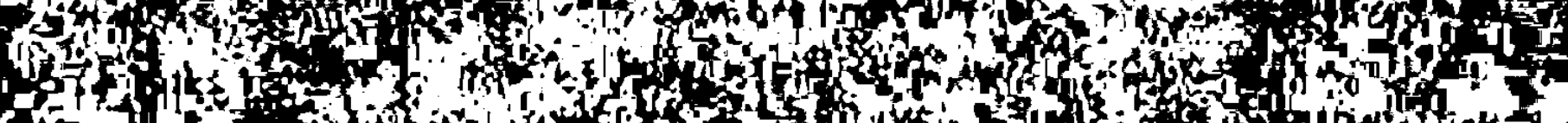
Holde

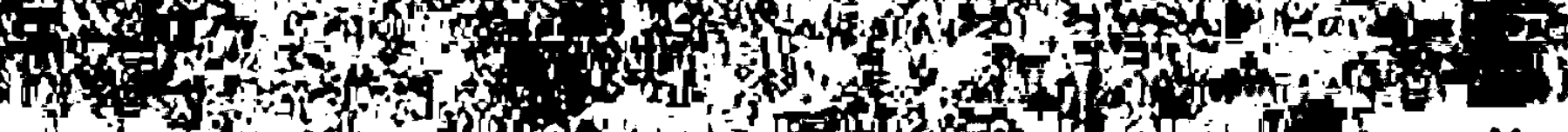
If

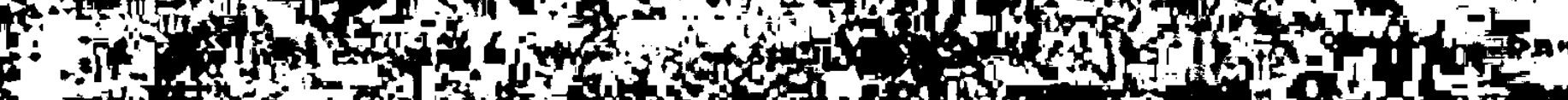

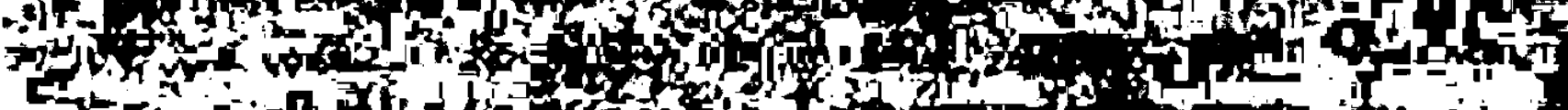

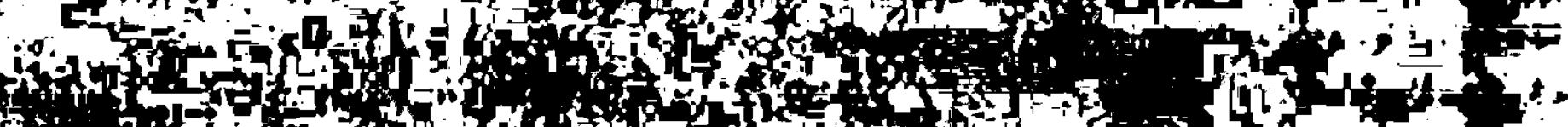

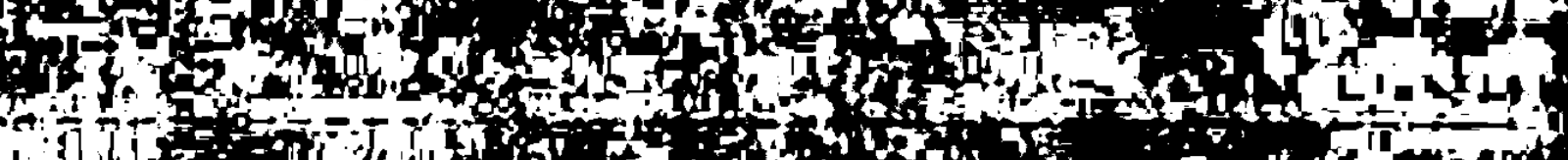
(150) detsy

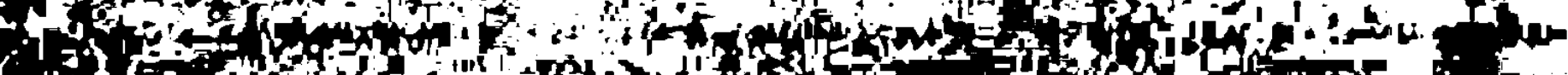

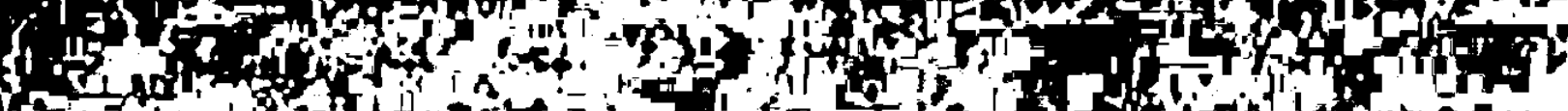

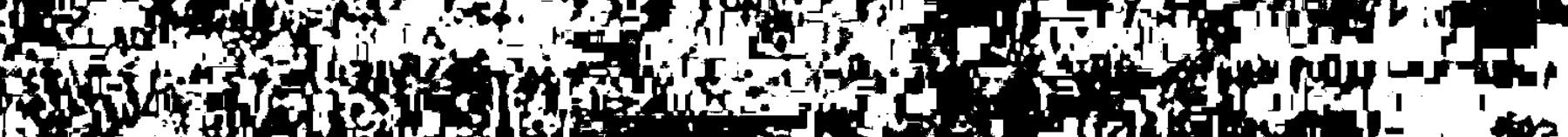

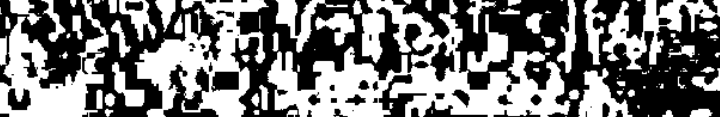
(1)

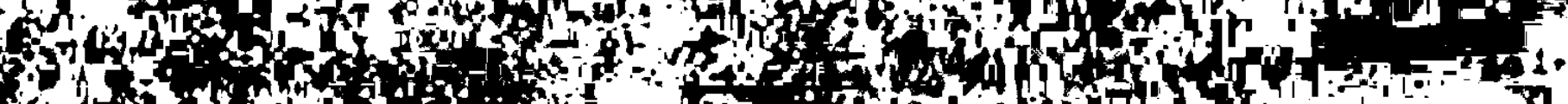

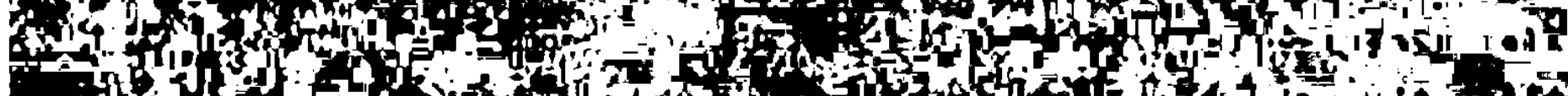

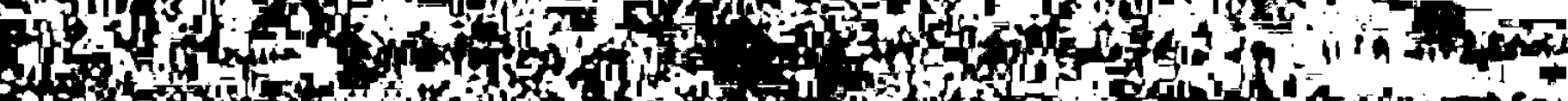
, the

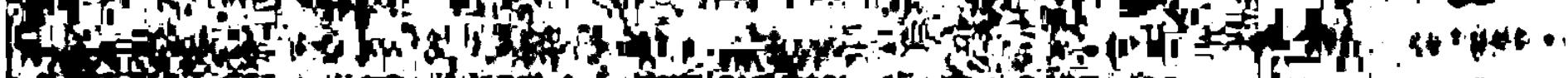

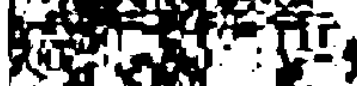

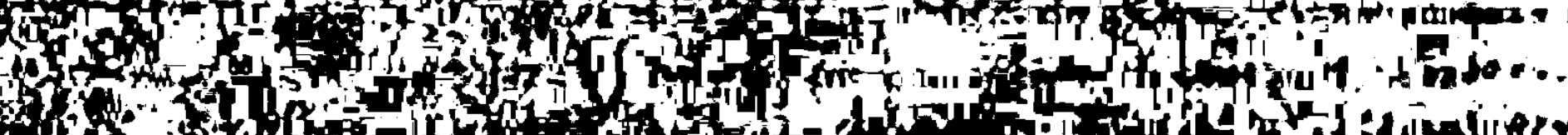

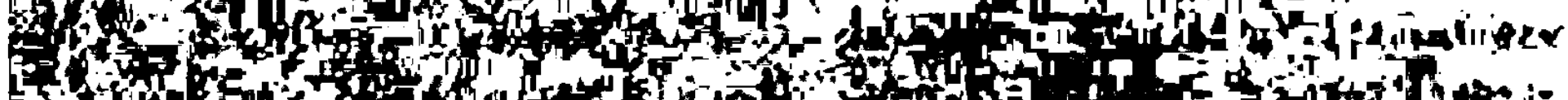

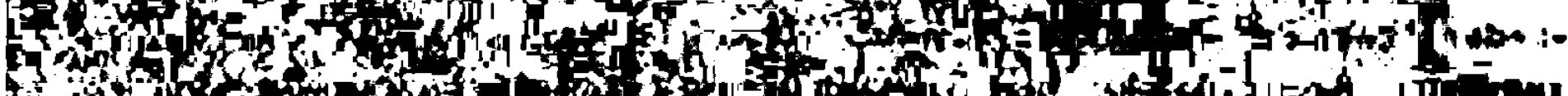

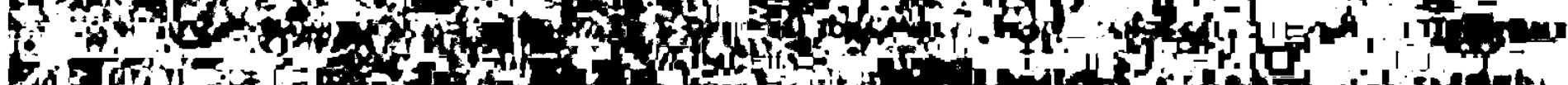

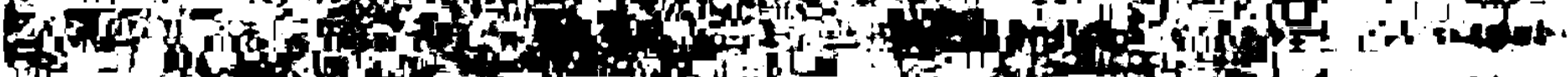

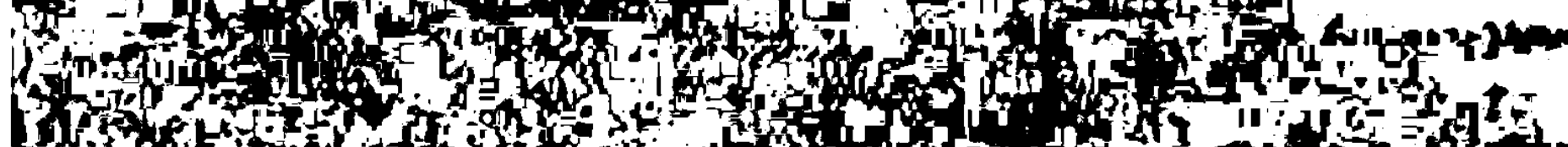
(1) 1) She 
III - Translation $0>A$ it Bedeutungswandel zur reinen Eigenschaftsbegriff

\$65. Im allgemelnen Teil dieser Arbelt hatten wir versucht, transferierte Adjektive vom Typ A $<0$ in drel groBe Gruppen zu gliedern. Wir gingen dabei von der Determinationsfunktion der Adjektive aus. Dies implizierte, daß wir die Adjektive bzw. adjektivbildenden Translative nicht vom Kontext abstrahierend untersuchten, vielmehr zumindest Determinatum (struktural: Kegens) und Determinans (strukturals subordonnb) zusammen. Die begriffich orientierte (nicht grammatische) Determination kann 1. durch Beziehung zwischen Haupt- und Nebenbegriff erfolgen, wobel a) diese belden durch Translatire rein syntaktischer Natur (= funktionale Moneme im Sinne Martinets) verbunden sein können, b) durch lexemähnliche Elemente, die allerdings nur durch Transformation sichtbar werden und 2. durch Beziehung zwischen Hauptbegriff und transferiertem Adjekt1v, wobel das Transferendum dem Venken elgentlich nicht mehr gegenwätig lst. Dies sind, wie Wissemann beobachtet hat 105, naturl1ch"Grenzfulle", wobel "der aus einem Gegenstandsbegriff entstandene Eigenschaftsbegriff einem ursprüglichen Elgenschaftsbegriff glelchkommt." Bel manchen Adjektiven besteht durchaus Doppeldeutigke1t. Erst der Kontext gibt dann naheren Aufschluß, z. B. russ. морская вода kann im Deutschen wiedergegeben werden als 'Meerwasser' oder 'Wasser des Meeres'. Mit 'Meerwasser' kann die besondere Eigenschaft des wassers gemelnt sein ("Meerwasser lst gesund"), während bel 'Wasser des Meeres' elne besondere Beziehung zwischen 'Wasser' und 'Meer' hergestellt wird ("Das wasser des Meeres glänzte"). Das Loutsche lst in diesem Falle präziser.

Bel den Adjektiven, deren Translativ alle1n syntaktische Funktion hat, libt sich die kelation graphisch folgendermaBen darstellen:

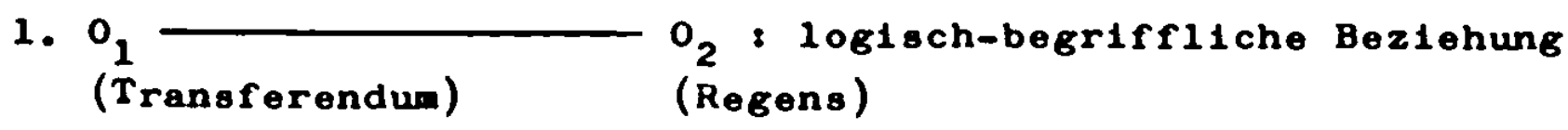

105 wissemann, a.a.0.., s. 285. 


\section{2. $\left(\mathrm{O}_{1}\right) \quad \mathrm{A}$ - $\mathrm{O}_{2}$, eyntakt.Beziehung (Transferendun) (transf.Adjekt1r) (Regens)}

Bel den transferierten Adjektiven alt primärer Bedeutung ist die logisch-begriffilche Beziehung gleich der syntaktischen Beziehung, d. $h$. der "Gegenstandsbegriff" $\left(0_{1}\right)$, der der Translation zugrunde liegt, ist nicht mehr unmittelbar gegenwartig.

Wie erwähnt, sind die Kriterien für die Einordnung der transferierten Adjektive mit primärer Bedeutung relativ flieBend. Meist kann eine Entscheidung nur unter Berucksichtigung des weiteren Kontextes vorgenommen werden. Es gibt keine Translative, die eindeutig dieser Gruppe von Adjektiven, wo sich eine Verschiebung zum Eigenschaftsbegriff vollzieht, zugeordnet werden könnte. Andererseits gibt es zahlreiche Adjektive, die man wiederum keiner Adjektivgruppe, wenigstens in threr Mehrheit zuordnen kann. Dazu gehören vor allem die am häufigsten gebrauchten Adjektive auf -bsk- und -bn-, die bisher nicht behandelt wurden und die in dem Rahmen der bisherigen Kapitel zu behandeln auch wenig Sinn hätte.

6 66. Am ehesten läBt sich elne Verschiebung zum reinen b1genschaftsbegriff bel den transferierten Adjektiven feststellen, deren Translativ allein aus dem Endungsmorphem besteht, etwa:

бользныи Sr. I, 148 'krank' (von бользнь)

сквьрныи Sr. III, 372 'schmutzig', ('schlecht'), (von cквьрнъ) золотыи Sr. I, 996 'golden' (unter der Bedingung, das eine farbbezeichnung gemeint ists von золото). другыи Sr. I, 727 'anderer' (von другъ) гобьзыи Sr. I, 530 'reich' (von roбb3b) гнусыи Sr. I, 526 'schmutzig' im abstrakten Sinne (von гнусъ)

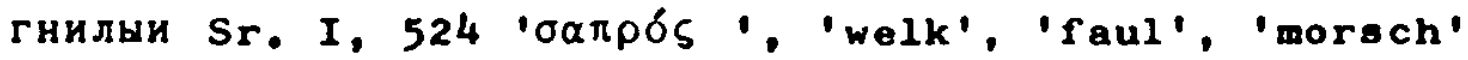
(von гнила)

Hier enthält das Transferendum bereits den Eigenschaftsbe- 
griff in sich. Durch das Translativ in Geotalt des Endungsmorphene wird lediglich die kategoriale Verschiebung arkiert. Elne Modifikation der Bedeutung des Traneferendums liegt nicht vor. Ähnlich können wir id Deutschen eagens "er hat Stolg" und "er lot stolz".

667. Schwieriger sind die suffixlosen Adjektive vom Typ высокосьрдии 'stolz', 'hochmitig' zu deuten. Eine direkte Beziehung begrifflicher Art zwischen Haupt- und Nebenbegriff kann hier nicht bestehen, da der Nebenbegriff nicht eelbstandig existiert. Es gibt kein "vysokosbrdbce", ein "vysokoe sbrdbce ergbbe ebenfalls wentg Sinn. Vermutilch wird auch

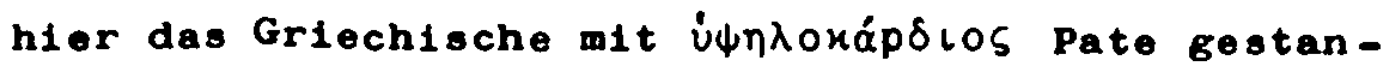
den haben. Die deutsche wörtiche Ubersetzung 'hoch-herzig' wire bedeutungsmbig falsch. Ohne Zweifel liegt hier ein Modifikationstyp vor, insofern im Begriff Buсокыи und сьрдыце nicht eo ipso der Elgenschaftsbegriff 'stolz' enthalten 1st. Diese Zusamensetzungen finden sich des öfteren.

Korposition und Translation erfolgen hier zusamen in einem Akt. Wenn man die Definition Tesnidres fü die Komposition annimat: "Dans la composition biradicale, le determinant [...] est l'objet d'une translation qui le transfère en une catbgorie susceptible d'btre subordonnt au determinb [.. ], 106 so mibte man bel Adjektiven wie златокрилыи von"doppelter Determination" sprechen, insofern das Kegens begriffilch zweifach determiniert wird. Vgl.: солнце златокрилое ( Ио. Мал. Xpoн.) Sr. I, 982. Diese Fugung stellt sich uns 1m Stemma so dar:

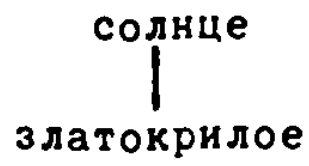

In златокрильи aber ist злато bereits objekt einer Translation:

$$
\begin{array}{r}
\text { крило } \\
\text { златое }
\end{array}
$$

Wir können Jedoch, wie berelts oben gesagt, Translation und Korposition hier nicht voneinander trennen, an sich mubte

106 Tesntere, a.a.0., s. 406. 
einem златокрильи als Transferendum ein nicht belegtes -zlatokrilo zugrundegelegt werden. Es gibt wohl ein крилатыи zu крило, nicht aber ein krilyј.Златокрили unterscheidet sich dennoch von высокосьрдыи, Insofern die begriffilche Beziehung zwischen злато, крило und солньце in der oben bezelchneten Fügung durchaus gegenwartig ist, nicht unbedingt aber zwischen высокыи, сьрдьце und einembeliebigen Regens. Die Bildung beider Adjektive ist gleich, das Transferendum existiert nicht als selbstandige lexikalische Einheit, die Adjektive können in Analogie oder als frele Blldungen entstanden sein. Высокосьрдыи Jedoch kann als Modifikationstyp gelten, златокрилыи nicht.

Das gleiche gilt fü: жестосьрдыи Sr. I, 864 'streng', 'grau-

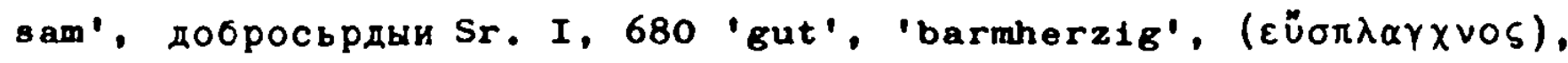
оплазосьрдыи Sr. II, 683 'grausam' иночадыи Sr. I, 1106 (bzw. единочадыи Sr. I, 815) 'eingeboren' ubersetzt das

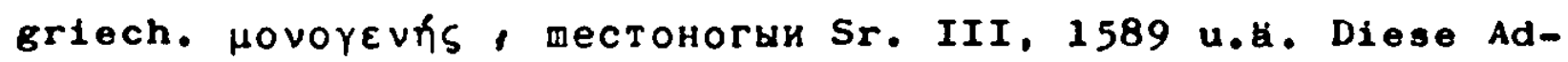
jektive sind zu златокрилыи zu stellen, d. h. der Nebenbegriff ist dem Denken durchaus gegenwärig.

§ 68. Adjektive, die mittels des Suffixes -bn-transferiert werden, und deren Transferendum ein Abstraktum auf -bstro1st, werden in der Kegel zu reinen Eigenschaftsbegriffen. Die Zahl der Transferenda, die hier in Frage kommt, ist gering. Me1st handelt es sich um das Abstraktum GoxbctBo. Es ist bezeichnend, daß im Griechischen hier ein Adjektiv steht, wahrend bel den entsprechenden altrussischen Adjektiven auf -bskoder -bj-, die von oorb abgeleitet sind, im griechischen original der Genitiv oder Dativ gebraucht wird. VGl.: дьло ти Оосж> вствено Izb. 287

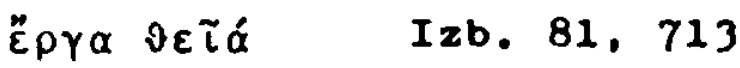

DaB es sich un ein Adjektiv mit primärer Funktion handelt, ist auch aus dem Kontext ersichtlich, wo an anderer Stelle ein solches Adjektiv gleichberechtigt neben einem priaären

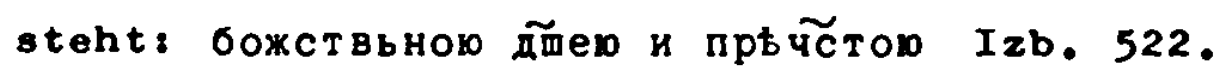


\$69. Im ubrigen kann auch ein kleiner Teil der transferierten Adjektive, bei denen in ihrer uberwiegenden Mehrheit eine Beziehungsbedeutung festgestellt werden kann, solche primkre Funktion annehmen und zum reinen Eigenschaftsbegriff werden. VE1.: багряни бархати а друзия витневы бархаты Sr. I. 266. Das Transferendum ist der Name fur eine rucht, die Adjektive bezeichnen aber eine bestimmte farbe, wobei eine nähere Determination erfolgt durch den Hinweis auf - wie hier - die Frucht, die diese Farbe trägt. Dabei ist der Grad der Netermination naturlich genauer als wenn einfach 'rot' stände. Man kann aber nicht sagen, dab eine direkte Beziehung zwischen бархаты und вишня bestunde. Vgl. ferners

Вьчистия Sr. I, 500 'aeternus'

каменистыи Sr. I, 1185 'steinig'

племенитыи Sr. II, 959 'nobilis'

именитьи Sr. I, 1039) 'bekannt'

нищавыи Sr. II, 455 'arm'

лукавыи Sr. II, 51) 'schlau'

Ebenso labt sich eine direkte Beziehung zwischen Transferendum und Regens zwischen rрькъ ( $г$ рькъ) und люди in co всьми людми гречьскими L. 47 nicht herstellen, schon gar nicht aber eine Fixierung der Beziehungsbedeutung feststellen. Es besteht keine Beziehung zwischen 'Leuten' und 'Griechen'. da diese 'Leute' ja 'Griechen' sind. Das Transferendum beinhaltet also bereits, was auch das Regens bezeichnet. Wie die historische Entwicklung zeigt, konntedas Regens auch wegfallen und das Produkt der Translation in der wiederholten Translation $A>0$ die Funktion des Regens mitubernehmen, wie etwa русьскын. 


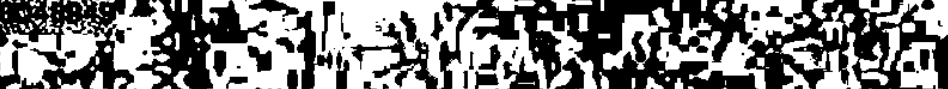

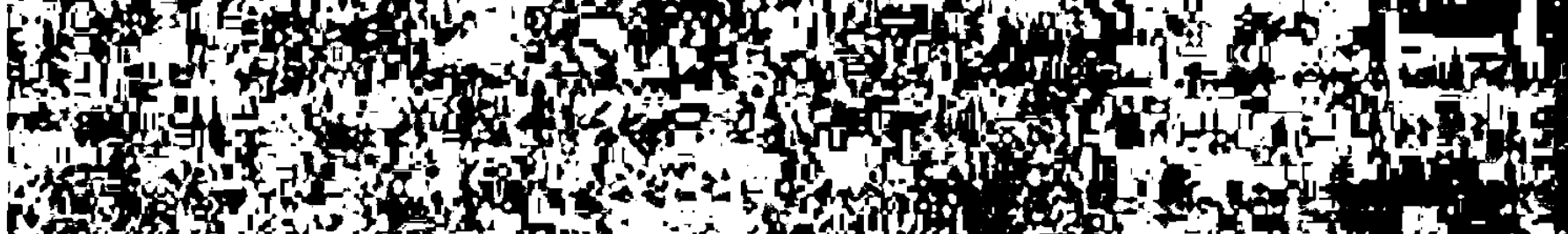

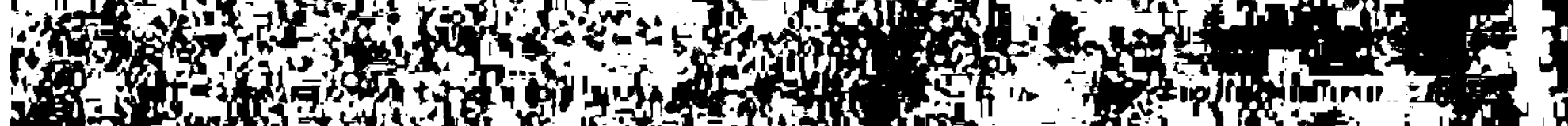

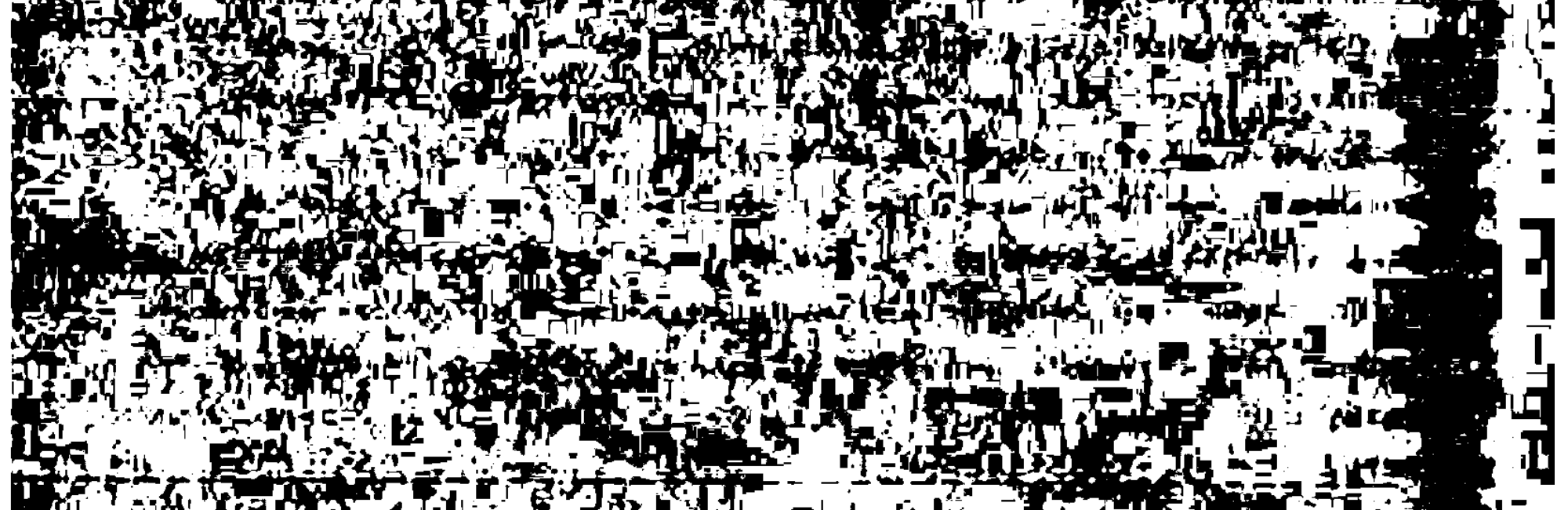

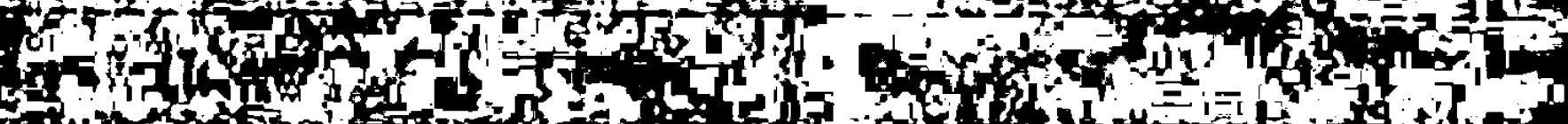

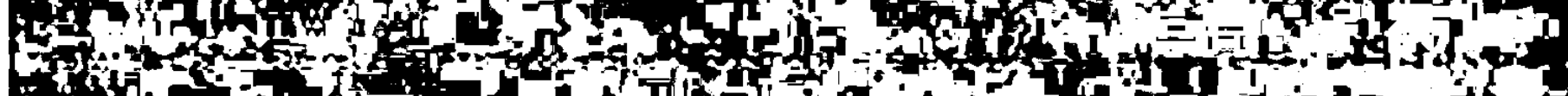
dill

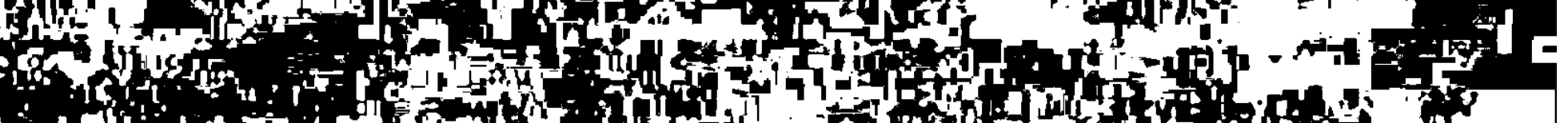

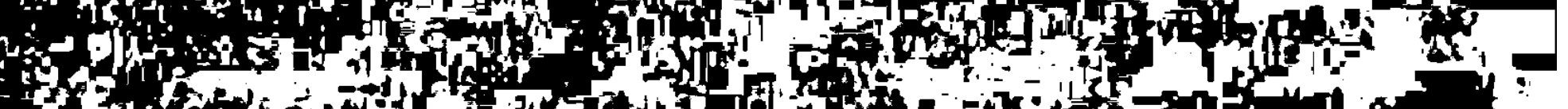
If

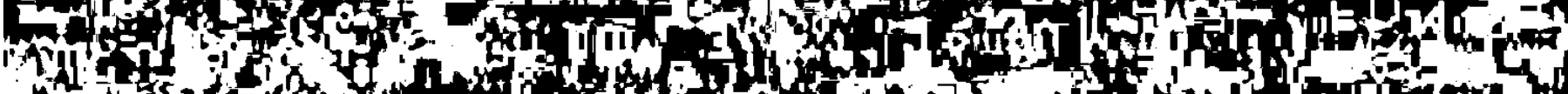
1)

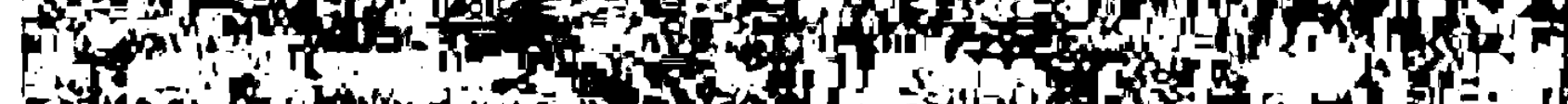
(2)

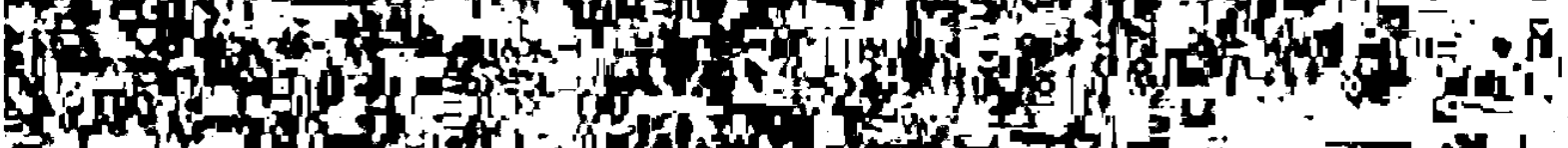

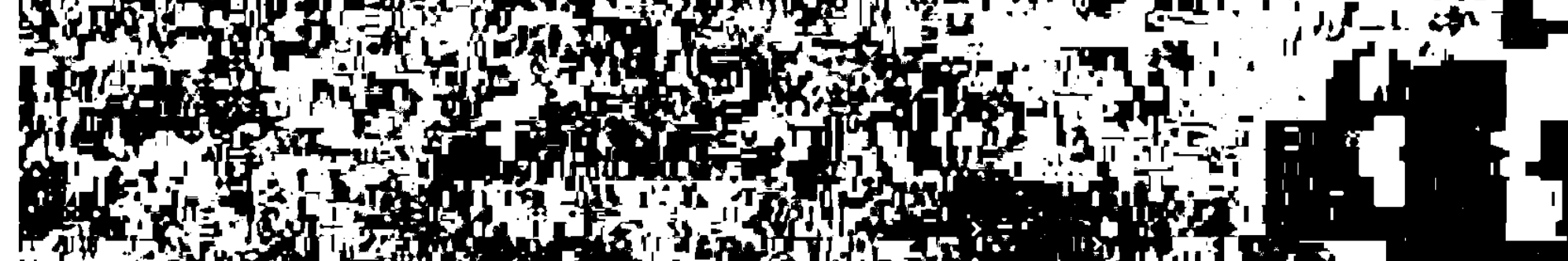
The tof

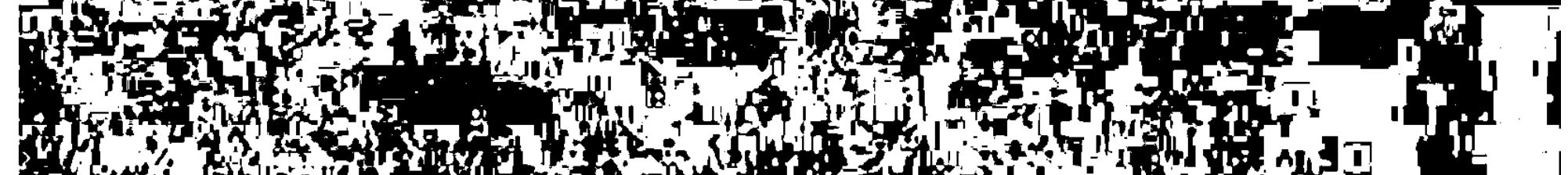

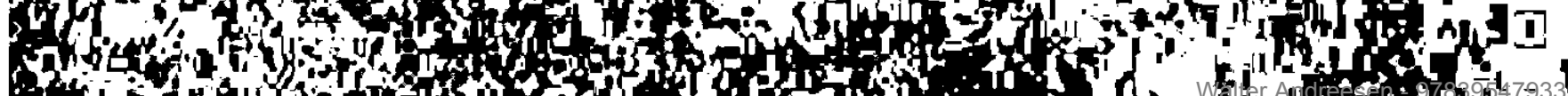
f.

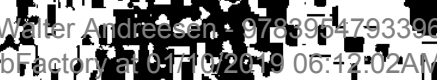


IV - Die Suffixe -bn- und -bok-

\$70. Wenn die Suffixe-bn- und -bsk- und die mit -bn- und -bskkombinierten Suffixe bisher nicht behandelt wurden, dann deshalb, well elne generelle Zuordnung, nach welchen Kriterien auch immer, hier am wentgsten möglich lat. Es glbt elnen Versuch von Reiter, d1e Konkurrenz der Funktion der Suffixe-bn- und -bsk-gegenuber -j-bzw. den Varianten von -j-, er epricht hier von suffixemen, im Altkirchenslavischen zu untersuchen. Allerdings schelnt in diesem Fall das herangezogene Material nicht sehr umfangrelch gewesen zu sein. 107 Adjekt1ve, die durch-bn-/-bsk-oder mit -bn- und -bsk-kombinierten Suffixen transferiert werden, lassen sich in jeweils elnzelnen Fälien allen drei blsher genannten Gruppen von Adjektiven zuordnen. Aus dieser Tatsache resultiert nicht zuletzt thr außerordentlich hăufiges Vorkommen.

\$71. Suffix -bsk-

Es ist bekannt, $d a B$ als Transferenda in den meisten Fallen Ethnika oder geographische Namen dienen. Es ergeben sich dabel bestimmte Gruppierungen. Das Transferendum kann bezeichnen:

a) den Angehörigen einer bestimmten Volksgruppe: до чешскаго льса L.247

b) Landschaft, Landschaftste11, Herrachaftsbereich: на горь Синаистьи L.185

море словеть Руское L.I..12

c) den Namen einer Stadt, eines Stadte11s: воеводство дерхапю Кневьскыя L.208

('Kievb ist hier bereits Substantiv, d. h. Produkt der doppelten Translation $O>A>0$ ).

Die Kiever 'Pelera' wird wie eln Ortsname behandelt: игуменъ Печерскыи L.207 (= игуменъ Печерьского монастыря).

107 Reiter, Norbert: Die Funktion der Suffixe-j-, -bsk-, -bnim Altkirchenslavischen. In: Die Welt der slaven 12 (1967), S. 363. 
Die lexikalische Breite dessen, was durch das Regens bozelchnet werden kann, lst weitaus gröBer, doch laBt sich hier eine interessante Feststellung machen. Transferendu des determinierenden und des determinierten Glieds einer syntagmatischen Fugung sind lexikalisch häufig sehr ähnlich, jedoch so, daß etwa bel a) das Regens die allgemeine Personenbezelchnung, z. В. "люди", darstellt und das Transferendum des determinierenden Adjektivs die genaue Volkszugehörigkeit der Person allgemeln formuliert. Das Kegens ist dort, wo das Transferendum des determinierenden Adjektivs ein Ethnikum bezeichnet, in der Regel, aber nicht ausnahms108, Appellativum, das Personen in sehr verallgemeinernder Form bezeichnet, oder geofraphische Bezelchnung.

672. Folgende Bezelchnungen treten in auffalligem Umfang in Fügungen, In denen Adjektive auf -bok-gebraucht werden, als Kegens besoniters hervor:

1.люди und сынове (gegenuber den determinierenden Adjekt1ven, welche elne genaue Volkszugehörlgkelt bezelchnen). Люди und сынове treten ausschlieblich innerhalb fester Fugungen auf, was für die Ubersetzung aus dem Altrussischen naturlich Konsequenzen hat: люди Русьскыя sind nicht 'ruøsieche Leute', sondern 'Kussen'. VGl.: co всьми людми

Гречьскими L. 47 ('Griechen')

люди Киевьстии L. 57 ('Kiever')

людье Нооугородьстии L. 69 ('Novgoroder')

Корсуньстии людье L. 166 ('Korsuner').

Ebenso bedeutet сьнъ in diesen Fügungen nicht etwa 'Sohn'. Bezelchnet wird lediglich der durch das Transferendum des determinierenden Adjektivs gekennzelchnete Angehörige einer Volksgruppe. Vgl.: от русьскых сыновъ L. 120, сынове рустии L. 61, рустие сынове L. 68 ('Нussen'), отрокъ съ родомъ сынъ Oугърескъ L. 134 ('Ungar').

Daß hier mit сынъ Угърескъ nichts anderes bezeichnet werden soll als 'Ungar' erhellt aus der entsprechenden Stelle der Hypatius-Chronik, wo es heiвt: [...] родомъ Угринъ нур. 120 (d. h. Угринъ = сынъ Угъреска). 
Die Folgerung, die an hieraus ziehen mus, iet, das das Transferendun des Adjektive eindeut1g die Bedeutung dee Regens rixiert. Die Bezelchnung fur den Angehorigen einer bestimeten Volkegruppe muB in Altrussischen nicht imer durch solche eyntageatischen Fugungen ausgedruckt werden, es finden sich auch Belege wies дань на Грьцых L. 65. Печеньзи L. 67 .

2. Huffig 1st ebonso das Regens кънязь wie auch царь. Vgl.: Русьскии князи L. 17, ко княземъ свьтлим Рускым L. 33. со царьма Грецкима L. 30 и. dgl., цесарь Иодьискъ L. 199. царемъ Греческмм L. 33, великаго князя Рускаго L. 46, великии князь Руския L. 48, князи Дерьвску L. 56 u. a. . Es finden sich aber auch andere Appellative, die Personen oder Personengruppen bezelchnen als Regens, wie C воини Хорватьския L. 122 oder Папекь Римьскии L. 27.

3. Regens страна, земля :

по земль Русьсть L. 17I, въ Гречьску земль L. 173.

в землю Мадьяньску L. 94 , в странь Корсуньстви L. 51 ,

- Корсуньстьи стране L. 50.

Die deutsche lbersetzung 'russisches Land' oder 'russische Lande', die melst gebraucht werden, auch nourues. 'pусская земля', 108 klingen wohl sehr poetisch. In Altrussischen aber haben diese festen Fügungen, deren tintwicklung zum Einwortlexem tendiert, gar nicht diesen poetischen Klang, der thnen zugeschrieben wird, wohl in dem Glauben, die altrussischen Texte wibten oo 1 pso poetischen Wert haben, weil tatsachlich sohr wonig an altrussischen Texten vorhanden ist, wa den Anspruch erhoben könnte, uberhaupt Dichtung gonannt zu werden. Andererselts ergibt sich die Schwierigkelt, dab -twa Русьская земля nicht den geographischen Bereich me1nen mus, der wiederun at 'KuBland' wiedergegeben wird. Sind der Staat, die politische Elnhelt oder die Bewohner gemelnt. so benutzt der altrussische Chronist in der Regel den Begriff "Русь": и полохити ряд мехю Роусь и Греки L. 32, шедшр ему Чернве рьки. въсть епархъ посла к нему. яко Русь на Црьгородь идеть L. 21. Русь stoht hier also gleichbarechtigt $\overline{108 \text { Haurig in }}$ der Ubersetzung der "Povestb" durch lichg 
neben Грекк.

4. Regens ropa:

на горь Синанстви L. 185

ко rорв Угорьстви L. 139

на гору Вамьску L. 96

горы Кневьския L. 55

Auch hier handelt es sich jeweils um feste Fügungen.

5. Regens градз, городз:

оступита Торииискни град L. 218

Корсунь град гречьскии L. 109

Im Gegensatz zu den bisher angefuhrten Fügungen sind die Verbindungen mit rородъ als Regens nicht als fest anzusehen.

\$73. Mit diesem Versuch der semantischen Bestiamung von Transferendum und Regens ist zwar die Anwendung des Suffixes -bok- zu einem prozentual hohen Anteil charakterisiert, absolute Regelhaftigkeit wird man indessen nicht registrieren können.

Als Transferenda lassen sich belsplelswelse genausogut Appellative, die Lebewesen bezelchnen (nохотью женьскою L. 79), wie etwa Abstrakta (етерьскми Sr. I, 835) wenn diese auch selten sind, nachwelsen. Charakteristisch für den Gebrauch des Suffixes -bsk- ist dessen Gebrauch in Fügungen vom Typus: Петр Переяславьскии L. 181. Transferendum ist hier jewells eine Ortsbezelchnung oder Volksbezelchnung, das Regens bezeiohnet einen Personennamen. Im Deutschen wibte dieser Typus als pripositionale Fugung wiedergegeben werden: 'Petry von Perejaslavlb'. Vgl.: съ Болеславомъ Лядьскымъ [...] съ Стефономъ Угрьскнмь [...] съ Андрихомъ Чешьскамъ L. 126

Курилъ ЯрусалимьскииL. 115

ко Рогъволоду Польску L. 75

Семионъ Болгарьски L. 42

Куриль Олександрьскии L. 115.

Beim letzten Beleg scheint es, als sel der Personenname Александрз das Transferendum, in Wirklichkeit muß man in 
Analogie zu den anderen Belegen auf die Stadt Alexandria echl1eBen.

DaB nomina auctoris auf -tels hüfig als Transferenda dienen, wobel aber das Suffix -bn- als Translativariante gelten nus, lot olne Tatsache: Ee fragt eich indesen, ob os elch lohnt, wie Zrerkorakaja ein ganzes Kapitel daruber zu schreiben 109. wenn wan eben nicht wehr fostotellen kann al diese Tatsache. Zverkorakaja hatte dabei auch bericksichtigen missen, dab zumindest das Suffix-er-/-or-als Konkurrent ebenfalls in Betracht komit ( dies erwelet sich hier auch, die nur die "Basis" der abgeleiteten Adjektire in Sinne der Wortbildung lexikalisch zu ordnen versucht und dant auch zu einer Aufgliederung der Adjektive komen möchte, wird Immer elne Unzahl ron Varianten finden, die das Unternohnen an elch fragwirdig macht.

Auffallend 1st die grobe Menge von Fremdwörtern, die als Traneferenda dienen, und die zumelst aus dem Griechischen entlehnt sind. $V_{g}$. 8

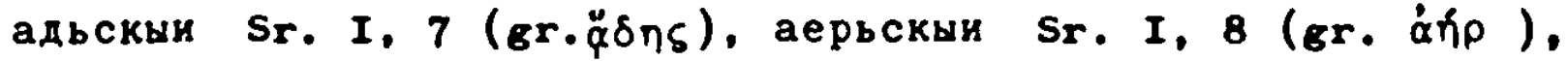

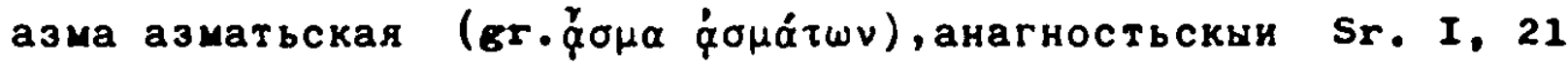

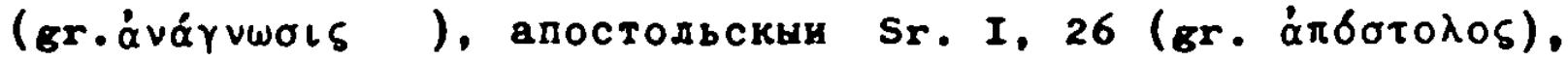

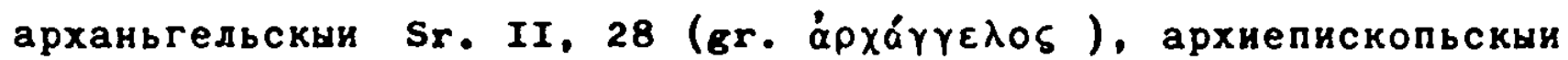

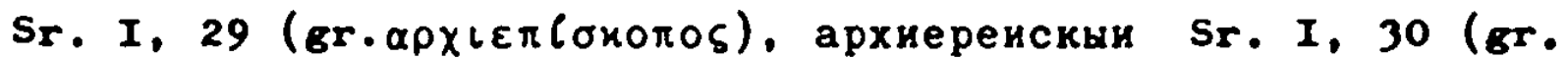

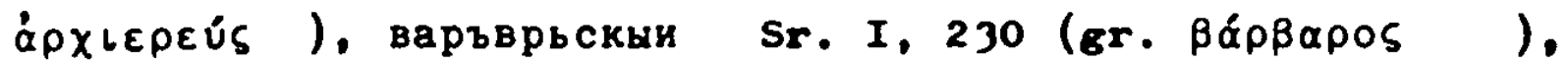

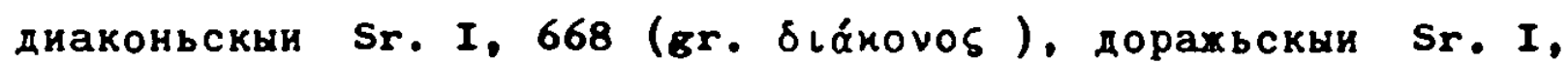
707 (mongol. doroga mongolischer Verwalter eines Bezirkes, VGl. Vasner REU 1, 364), Дьмоньскви Sr. I, 793 (gr. $\delta \alpha(\mu \omega V)$, епископьскыи Sr. I, 829 (вr. в́ліоколоs). еретичьскыи Sr. I,

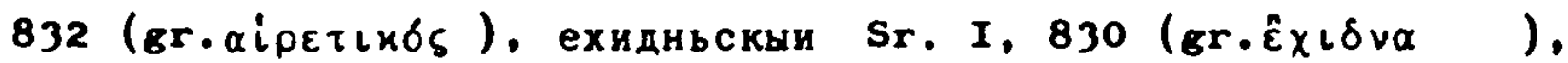
иереискыи Sr. I, 1025 (gr. ¿єрєús ), иконимьскыи Sr. I, 1088 (gr.oikovónos ), католичьскыи Sr. I, 1990 (1at.cathol1cus,

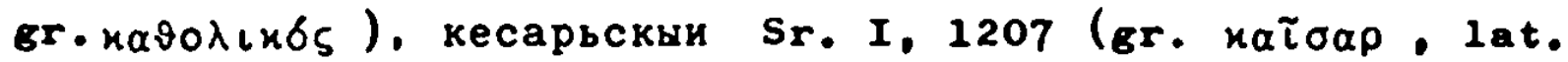

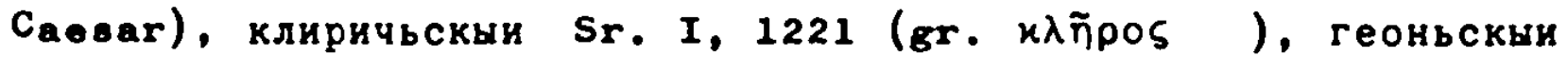

${ }^{109}$ Zrerkovekaja, N. P. P Parallel'noe obrazovanie prilagatel'nych - ouffiksani -bn- 1 -bak- $v$ drevnerusekon jazyke. Ins Issledoranija po lotor. leksikologil drevnerusek. Jazyka. Moskra 1966, S. 224 ff. 
Sr. I. 513 (gr. YદEvva < gehenna), евангельскыи Sr. I, 806

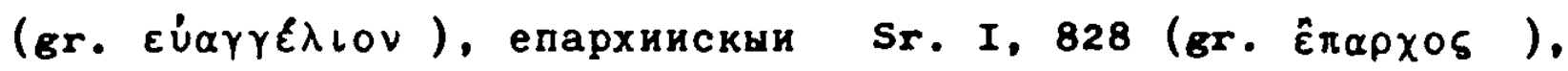

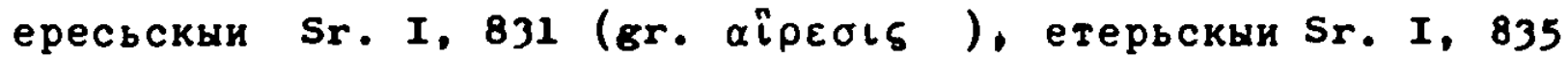

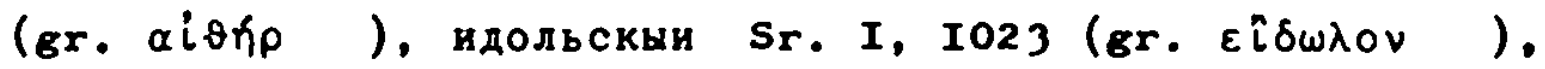
мастерьскыи Sr. II, 116 (vgl. Vasmer, REW II, 102), музьчьскыи Sr. II, 196 (gr. нойLй ), паньскыи Sr. II, 876 (rgl. Vasmer, EY II, 308), папехьскыи Sr. II, 872 (vgl. Vaseer, EW, 311), патриаршьскыи Sr. II, 889 (gr. $\pi \alpha \tau \rho\llcorner\alpha ́ \alpha \chi \circ \varsigma)$,

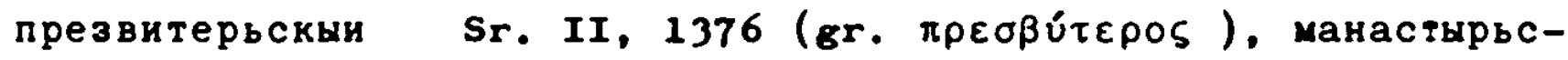

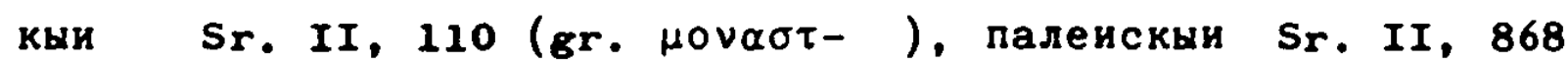
(gr. $\pi \alpha \lambda \alpha \iota \dot{\alpha})$, псалъмьскии Sr. II, 1721 (gr. $4 \alpha \lambda \mu \delta \varsigma$ ),

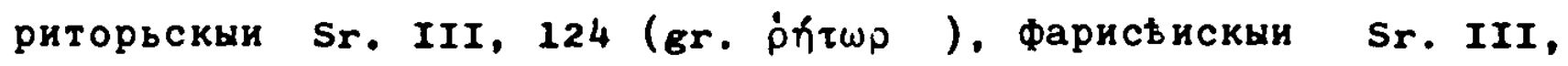

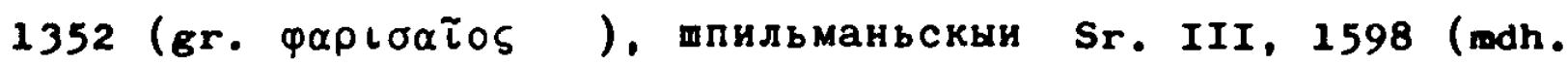
spliman, mnd. spelman, Vgl. Vasmer, REW, III, 426), сти-

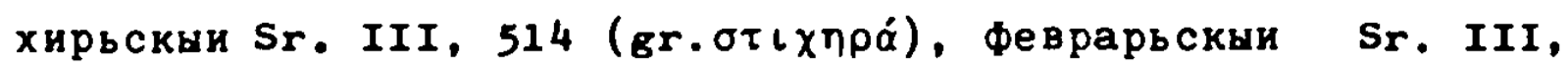
1353 (mgr. ren Transiativ spielen Entlehnungen als Transferenda eine so grobe Kolle. Dies ist ein Bewels fur die ungeheuere produktivität des Suffixes in der zeit, in der fremdes Wortmaterial in die russische Sprache, vornehmlich durch Ubersetzungen aus dem Griechischen, aufgenomen wurde und danach. Gleichzeitig darf man dies als Indiz dafur ansehen, das die Differenzierungsfunktion der groBen Zahl verschiedener Translative im Altrussischen doch nicht mehr in hohem Maße erhalten war, wenn das Suffix - bsk-, das praktisch alle Funktionen beinhalten kann, in solchem Umfang zur Translation neuer Transferenda herangezogen wird.

\section{Suffix -bn-}

Das Suffix -bn- wird ebenso häufig gebraucht wie-bsk-, wobel elne Fixierung der Bedeutung auf noch gröBere Schwierigkeiten stöbt als bel -bsk-. Die Hăfigkelt des Gebrauches bedingt letzten Endes die geringen Möglichkelten elner Flxierung der Funktion. Grundsatzlich kann man die Formulierung von Romanovakaja ubernehmen:

"Прилагательные с суффиксом -ьн-, вырахамщие отношение к чемулибо, близки по значенио к прилагательным с суффксом -ьск-. 
Однако, в отдпчне от прпдагатедьных с суффпксом -ьск-, онд как правндо, не могут обозначать отнопенвя $\mathrm{k}$ кому-днбо.[...] Кроме значенвя отновенвя $K$ чему-двбо, отв прддагатедьные могут

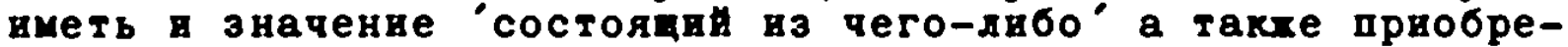
тать значения качественных прддагатедьних. Bсе прддагатедьние с суффвксом -ьн- мохно подраздедить на трп грудик:

I. Придагатедьные, обозначамщне отнотенве $\mathrm{x}$ конкретному предмету пди отвдеченному понятир, вырахенному существитедьни, от основь которого образуется придагатедьное [...]

II. Првдагатедьные, обозначарщие отнопенве ко времени в месту $[\cdots]$

III. Придагатедьные с суффиксом -ьн- со значенвем 'сдеданнын, состоящй из чего-дибо," "110

Di. Behauptung, daß Adjektive auf -bn-keine "Bexiehung zu jemanden" (kомy-дибo ) bezelchnen können, 18t - so formullort - nicht ganz zutreffend, wonn allerdings auch richtig

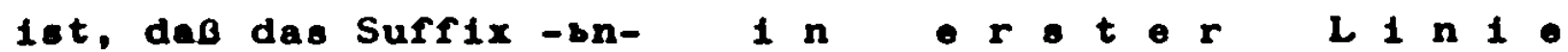

Substantive transforiert, die Unbelebtes bezelchnen, und zwar in dem MaBe, wie es bel anderen konkurrierenden Translativen kaum der Fall lot. Sonst scheint die Aussage von Ronanorskaja richtig zu sein, dennoch wird hier die ganze Schwierigkeit des Problems sichtbar, wenn man versucht, etwa den Belspiel der Akademie-Gramatik folgend, skmtliche Adjektive In eIn Gliederungsschena aufgrund ihrer "основа" zu zwangen. Denn die Charakterisierung der Bedeutung des Suffixes -bn- gilt für eine Fulle anderer Translative genausogut, to1lweise oder im ganzen. Und damit verlieren Arbelten wie die von Romanovekaja oder Zverkovekaja oder Makarova etwas von Ihrem Wert, den sie auf Grund Ihrer groben Materialfulle besitzen. was uber den Gebrauch dee Surfixes -bn- in wesentlichen ausgesagt werden kann, 14Bt sich unter $\$ 76 \mathrm{fr}$. Finden.

Einer der drei in $\$ 23$ f. beschriebenen Gruppen von Adjektiven lassen sich die Adjektive auf - sn- in ihrer Mehrheit kau zuordnen. VG1.8

a) Transiation $0>A$ mit rein syntaktischer Funktions

от древа хивотьнаго L. 89 'Baun des Lebens'

на ученье книхное L. 118 'Lernen der Bücher! (bzw. 'Hlg. Schrift')

b) Translation $0>A$ mit zusatzlicher Beziohungsbedoutungs

каменьныв Sr. I, 1183 'gomacht aus Stein'

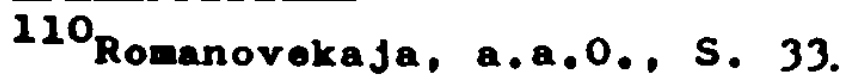


златьныи Sr. I, 984, золотоносьныв'Gold enthaltend' (sofern nicht Farbbezelchnungl)

c) Translation $0, A$, alo deren Ergebnis reine Eigenschaftebegrifre entstehen:

ручьное дъло ти Бохьствьноа не земльно Іаь. 287.

H1еr lot земльно als Adjektiv alt primarer Funktion anzusehen, de die Art des Regens näher bestimit wird. Im griechischen

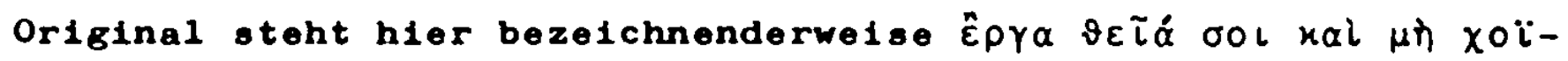

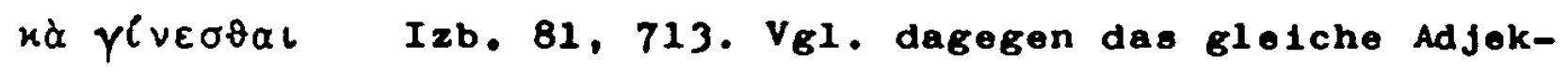
tiv in der Fugung: да ти земльнынхъ не будеть никоея хе nохоти Izb. 283. Das Griechische hat hier den Genit1v: kal $\pi \&-$

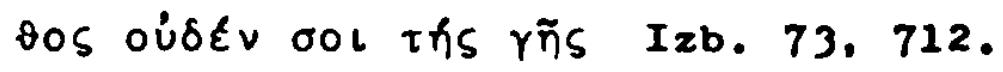

\$75. Bezelchnungen fur Tages- und Jahreszelten werden In der Regei mit dem Suffix -bn-j- + pronom. Kindungsmorphem transferiert. D1eses Zerlegen in ein "zusammengesetztes Suffix" ist nur bedingt zulassig in bezug auf die Struktur des Suffixes, da das - J- ja nicht mehr vorhanden ist. Man redet hier gomelnhin von der "weichen Variante" des Suffixes-bn-. Im Gegensatz zum Neurussischen, wo bel den bezelchneten Transferenda ganz vorwiegend diese welche Variante des Suffixes auftritt, findet sich in Altrussischen oft auch die harte Variante.

a) Jahreszeiten

весньныи Sr. I, 247, льтныи Sr. II, 80, осеньния

Sr. II, 1716 (есеньныи = ks1. Form), зимьния Sr. I, 979

b) Tageszeiten

утрьния Sr. III, 1517, заутрьния Sr. I, 956,

объдьния Sr. II, 586, вечерьния Sr. I, 251 ,

ношьныи Sr. II, 470.

Damit sind an sich samtliche Tages- und Jahreszeiten erfaßt. Insofern hat Komanovokaja nicht unrecht, wenn sie von

"прилагательные, обозначающие отношение ко времени "

spricht. Bel den Transferenda, die Monatsnamen bezelchnen, stehen die Suffixe -bn- und -bok- in Konkurrenz, vgl. z. B. августьныи Sr. I, 5, aber феврарьскыи Sr. III, 1353. Daneben stehen Zeitbegriffe allgemeiner Art, wie годьныи Sr. I.539,

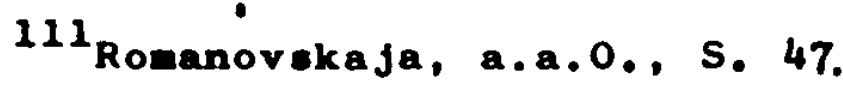


мсячьнуд Sr. II, 252, зарочьныв Sr. I, 944, срьдохрьстьныв Sx. III, 483. Benerkenowert lot das Adjekt1\% дьньдьньнии Sr. I, 771, wo elne Verdoppelung des Transforendune vorliegt. Diose For ontepricht genau den doutschen 'tagtiglich'. Typlech oind auch die Zeitadjektire rou Typ $0>E>A$, wie дьньсьнни Sг. I, 771, вьседьньныи Sг. I, 468, нсконьныи Sг. I, 1117 (искони \& нсконьныи 18t nur ale Produkt der doppelten Translation $E>\Lambda>0(\dot{\alpha} \alpha \pi \cdot \dot{\alpha} \rho \chi \tilde{n} \delta)$ belegt. $)$. 
$v$ - Translation $0>A$ bei zusammengesetzten Adjektiven

$\$$ 76. Bereits mehrfach war von den zusammengesetzten Adjektiven die Rede. In $\$ 66$ handelt es sich um Adjektive, deren Translativ allein im Endungsmorphem bestand. Tesnière geht auf diesen Typ im Russischen, der insbesondere beim Suffix auf -bn-sehr verbreitet ist, nur am Rande ein. Wir muissen hier verschiedene Typen unterscheiden, wobel die Adjektive auf - bn-zunächst als Modell dienen.

\section{\$77. Тур подънебесьныи}

Tesnière führt hier das russische Adjektiv nод-Mоск-Ов-нb̆̈ ans

"Le substantif Moskva 'Moscou' est d'abord transféré en adverbe de lieu au moyen de la préposition pod 'près de' et de 1 ' Instrumental: pod Moskvoju 'aux environs de Moscou' [...]Puis une deuxieme translation dont le marquant est le suffixe adjectival - HH transfère ensuite cette locution adverbiale en adjectif. Ce procede de derivation adjectivale, qui englobe la preposition figee, est extremement frequent en russe[... $]^{n 112}$

Man wird Tesnière hier nicht in allen Punkten folgen können. Schon die sogenannte "translation double" und "translation triple" sind problematisch genug. 113 Tesnière hat in seinem russischen Beleg nicht das Regens der adjektivischen Fügung angefuhrt, das wohl ein Substantiv sein durfte, keineswegs ein Verb. Nehmen wir an, Tesnière hat gerade jenen Beleg gewähl, weil jeder leser den $T_{1 t e l}$ des Liedes kennt, das sich "Подмгсконые вечера " nennt. Das Suffix erfullt hier keine andere Funktion als die eines Kasus, in diesem Falle des Instrumental. Ohne weiteres könnte man sinngemäß den litel des Liedes umformen in "Вечеpa под Москвор". Das wäre möglich, wenn der Tyрия подосковны im vorliegenden Fall vor allem nicht besser in den Rhythmus

112 a.a.0., s. 495.

113 Nicht immer, aber doch in der Regel, wird mit dem, was Tesnière doppelte Translation nennt, ein historischer Vorgang erfabt, d. h. das Produkt der ersten Translation ist bereits erstarrt, und als solches kann es kaun Gegenstand einer Syntax sein, die sich selbst als struktural bezeichnet. 
des betreffenden Liedes pabte. Beqepa nox MockBop aber hatte folgendes Stema: Beqpa

Regene

חод MOCKBOD

subordonnd

Под MоскBоD whire also subordonné des Substantivs beyepa und damit eindeutig Adjektiv. So ist etwa in dem Satz "On zivet $v$ Moskve" ganz eindeutig ' $v$ Moskve' als Adverb = subordonnb von 'zivet' zu bezeichnen, in "Bol'boj Teatr v Moskve osnovan ..." aber lst ' $v$ Moskve' Adjektiv = subordonnb von 'teatr'. Diese Abhangigkeitsverhaltn1sse waren bereits Gegenstand ausfuhrlicher Eörterung in $\$ 37$ r. . ПОд MосквоD kann al so Adverb wie Adjektiv sein, und der vorgang der Bildung von noдmockoвнын ist nicht so eindeutig festzulegen wie Tesnidre es tut. Im gegebenen Fall. d. h. Im zitierten Lied, im Kontext, ist noдmockовның auf das $A d j \circ k t i v$ под Москвор zurückzufuhren. Die Entscheidung daruber, ob Translation $O>E>A$ vorliegt, ist nur unter Bericksichtigung des Kontextes möglich. Wäre es sinnvoll, etwa das Adjektiv събовьныи nach dem oben angefuhrten Muster zu zerlegen? Seine Bedeutung ist identisch mit der von бохьственны, hier aber ist бoxbcrso und nicht бorb das Transferendum. Ist das Regens in der adjektivischen Fügung ein Substantiv, so wird man in der Regel besser von einem translatif dissocib zu sprechen haben. Wenn Meid hier von "unechter Komposition" spricht114, so hat er nicht ganz unrecht, insofern als etwa nод MосквоD zu nодмосковны wird,also doch von einer Art von "Zusammenruckung" gesprochen werden kann. Den Begriff "Determinativkompositum" wird man kaum gelten lassen können, denn небеснии, das ja selbstandig existiert, kann nicht durch nogb determiniert werden. Man muß die ganze syntagmatische Fügung betrachten. Vgl. z. B. къ началоыъ злобы поднебеснвмъ Sr. II, 1064. Heбо wird nicht durch подъ determiniert, sondern начало durch das Adjektiv поднебесьныи als Einheit, os wäre durchaus müglich, daß начадо подз небомъ stande. Der турия подвнебесьныи (auch подънебесьскии) ist bereits im Altrussischen relativ haufig, wenn auch, wie festzustellen ist, nicht so oft belegt, wie der in $\$ 7$

114 a.a.0., S. 39. 
beschriebene Typus, das Suffix-bn- ist hier am gebräuchlichsten:

VEl.: судохдьныи Sr. III, 601, подъризьныи Sr. II, 1067, събохьныи Sr. III, 645, подъсълньчьныи Sr. II, 1069, подънебесьныи Sr. II, 1064, безвьрьныи Sr. I, 52, безбохьныи Sr. I, 50, безбрачьныи Sr. I, 51, безвиньныи Sr. I, 51, безвластьныи Sr. I, 51, поберехьныи Sr. I, 51, задушьныи Sr. II, 984, задушьныи Sr. I, 909 (задушьныи человькъ = ein Sklave, der zum Freien gemacht wurde).

Zu den Adjektiven задушьныи und судождьныи düfte es ohnehin wohl mit Sicherheit keine Zwischenstufe E gegeben haben, da diese gar nicht vorstellbar ist.

\section{§ 78. Тур человькообразьныи}

Hier handelt es sich um wirkliche Leterminativkomposita - bei dem angefuhrten Beleg liegt das Subjektverhältnis vor -, was schon aus der Ubertragung Sreznevskijs hervorgeht: человђкообразьныи = 'имеютий образь человђка ' Sr. II, 1491 (кланатися чЛлвкообразнћи иконь его). Von einer translation double kann man hier wohl nicht sprechen, eher von einem "Doppeladjektiv", wobei in einem nicht belegten गчеловькообразъ nach Tesnière natürlich das erste Glied das bestimmende wäre, человъкъ wäre das Transferendum, der Bindevokal -o- das Translativ. Ein aus образъ transferiertes образьныи ist bei

Sreznevskij nicht angefuhrt. Komposition und Translation erfolgen hier also in einem Zuge, eine solche Interpretation ist in diesem Falle besser, als von freien Blldungen zu sprechen. Diese Bildungen konnten und können jederzeit erfolgen, wobel sie keineswegs erstarren ( $f 1 g \ell$ ) muBten.

Besonders häufig sind die Adjektive dieses Typs mit -образьныи als zweitem Glied. Vgl.: человькообразьныи Sr. III, 1491, огнеобразьнии Sr. II, 1602 (vgl. auch огнезрачьныи Sr. II, 602), златообразьнии Sr. I, 982, звьрообразьныи Sr. I, 966, aber auch: дђтьскоумьныи Sr. II, 797. дьломырьныи Sr, I, 789, братоненавистьныи Sr. I, 170, богомирьныи Sr. I, 132. Die Bildungen auf -образьныи und -зрачьныи Iießen sich auch 
mt anderen Traneferenda komponierea, die Besiehmeobedentune der dadurch ontetehonden Adjekt1re lust eich rizieren. 2wischen Haupt- und Nobonbogriff real1siert elch die Berlehungsbedeutung 'dem ubnl1ch eolend, was dae Traneformdun I (= I. Glied der Kompoeition) bezelchnet: VGl.8 Myx Bsbpooбразьнъ (Муч. Кир. Уд.) Sr. I, 966, радунсл престоде огнезрачнии (Мин. Мар.) Sr. II, 602. Di॰ Beziehungebedontung 1kBt elch hier eindeutig auf Grund des semantiechen Gehaltes des Traneferendune II (= 2. Glled der Kompoeition) firieren.

679. Elne besondere Gruppe der aur S.116 gekennzelchneten Adjektive bilden jene von Typ qудотворьнни . Ee eleht zunischet so aus, als lage hier Tranelation I / A ror, wobel es sich un Doterminativkonpoita alt Objektrerhuitnie handele. al 00 -tพa чудотворити > чудотворьнын.

In der Tat gibt $\bullet$ Belege, die elne Tranelation I J A durch dae Translativ -bn- als e1ne Moglichke1t zulaseen, wie etwa багроносьныи (1at. purpuran gestans), Sr. I, 38, агноносьния Sr. I, 5. Ee kann olch auch um frele Bildungen in Analogie su anderen handeln, deren Traneforendur eindeutig ein Substantir 1st, wonngleich man in der Falle багроносьнни doch rur Translation I > pludieren wirde, da das Griechioche hier elcher ein Partisip hatte. Glelchgultig, ob es elch un die Tranelation I > A oder 0 ) A handelt - ontecheiden wuB wan auf Grund dos Einselbelege -, bel den zusamengesetzten Adjektiven dieses Typs steht das orste Glied imer in elner Objektverhultnis zun zwoiten Glieds epecoначальның Sr. I, 831 , чудотворьнын Sr. II, 1540, духоносьныв Sr. I, 748, агноносьныи Sr. I, 15, аероходьныи Sr. I, 7. багроносьныи Sr. I, 38, дьтогубьнын Sr. I, 796.

\section{0. Тур дъдгодушьныи}

H1er handelt es of un Deterninativkomposta, wobel jedoch das erste Glied prinäres Adjektiv 18t. Schumann 115 fuhrt fur einige dieser Konpostionen den Begrifr "Lehngliedzueatz" ๑1ns

115 a.a.0.. s. 3 . 


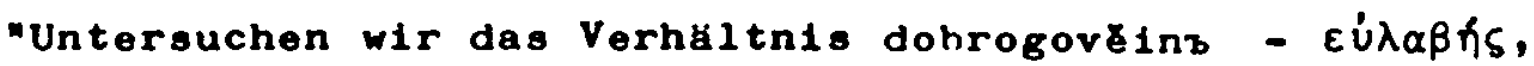
so ergibt sich, daß wir hier keine regelrechte Lehnubersetzung vor uns haben, dobro entspricht zwar einer $\varepsilon \dot{U}-$, aber govilnb ubersetzt nicht etwa den zweiten Teil des

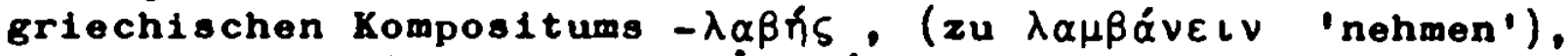
sondern gibt allein schon $\varepsilon \dot{u} \lambda \alpha \beta \hat{r} S^{\prime}$ 'fromm, ehrfürchtia' wieder. dobrogovinb enthalt also eine genaue Ubersetzung von $\varepsilon \dot{u} \lambda \alpha \beta \hat{f} \zeta$ - deshalb kann hier auch nicht etwa von Lehnubertragung gesprochen werden - und zugleich eine zusätzliche Ubersetzung eines der Glieder des griechischen Kompositums. Das griechische Wort wird im Altbulgarischen gewissermaben anderthalbmal wiedergegebens

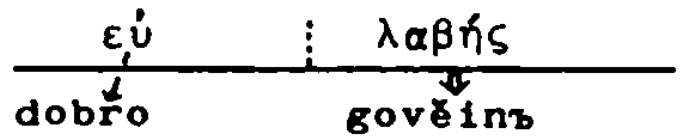

Ich möchte für diese Bildungsart den Terminus "Lehngliedzusatz" vorschlagen." 116

Dies mag in bezug auf das Adjektiv доброговьинъ richtig beobachtet sein. Indessen wird wan sich fragen mussen, ob eine solche Analyse auch für ein Adjektiv, wie длъготрьпя

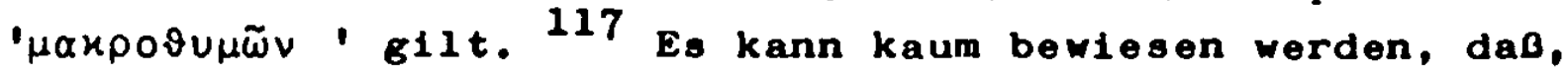
wie Schumann meint, трьля bereits die gesamte Bedeutungsbreite von $\mu \alpha \mu p o \vartheta u \mu \tilde{\omega} v$ wiedergibt. Lis gibt ja im Ar. wie im Aksl. eine sehr grobe Fulle von solchen Kompositionen auf добро- oder дълго-. In sehr vielen Fällen шіе доброличвныи 'єن்

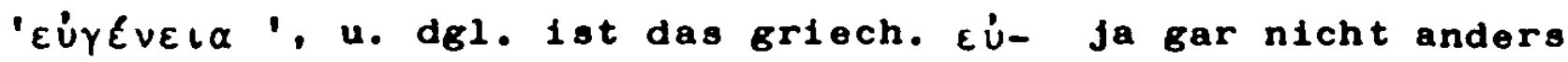
wiederzugeben. Be1 добпогласьньи ' $\alpha \alpha \lambda \lambda \ell \varphi \omega \vee \zeta^{\prime}$ liegt sogar eine strukturel1 ganz entsprechende Lehnübersetzung vor, und das

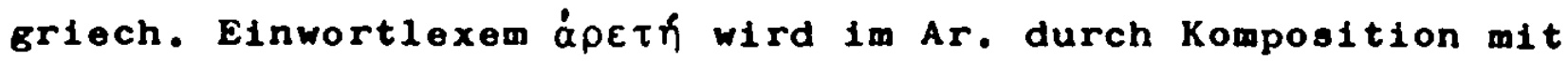
добро- wiedergegebens добродьтелие, добродьяние. Die Form auf -o- sollte nicht täuschen, es handelt sich nicht etwa um Adverbien, da das zweite Glied in der Kegel nicht verbaler Herkunft (also $I>0$ ) ist: дъдгодушьния Sr. I, 755 , драгокаменьньи Sr. I, 710, мъногострастьньи Sr. II, 209, великогласьньи Sr. I, 234, вельмьсльныи Sr. I, 241, великольпотьныи Sr. I, 235, великодьньньи Sr. I, 234, высокомысльныи Sr. I, 451, високолетьньи Sr. I, 451, високоумьнми Sr. I, 452, вьшепамятьныи Sr. I, 458, доброплодьния Sr. I, 678, доброличьныи Sr. I, 677, доброродьныи Sr. I, 679, доброуставьныи Sr. I, 680, добрьвъгодьнии Sr. I, 684. 116 Schumann, a.a.0.., s. 3 . 117 ebenda. 
Strukturell unterschelden sich Adjekt1ve wie ocyordacbныи Sr. II, 728, пьрвообразьныи Sr. II, 1764 (Zahlwort ale erstes Glied) oder cerorодьнкн Sr. III, 320, вьсьмврьныв Sr. I. 474, вьседьньния Sr. I, 468, nicht von dea bieher aufgezuhlten, da Tesnière Numeralia (adjectifs attributifs de quantitb) und Denonstrativa (adjectifs de rapport circonstanciels) zu den Adjektiven zkhlt.

\section{$\S 81$. Тур неправьдьния}

Adjektive, die durch das Suffix -bn-transferiert worden sind, können mit der Negationspartikel ne- versehen werden: etwa небурьния Sr. II, 359, неправьдынын Sr. II, 413.D1ese Neglerung lst grundsätzlich uberhaupt nicht möglich bel AdJektiven, deren Translativ nur syntaktische Funktion hat. In der Regel lst die Möglichkeit einer Neglerung ein sicheres Zeichen dafur, daß die transferierten Adjektive primbren glelchkommen. Wenn das Translativ rein syntaktische Bedeutung hat, so lst elne Negierung ja ganz unmöglich, da zwlochen dem Regens und dem Transferendum elne Beztehung begriffilcher Natur vorliegt, die semantisch nicht fixierbar ist. Bei den Suffixen mit fixierbarer Beziehungsbedeutung whre inmerhin eine Negierung denkbar wie etwa крилатыи - некрилатьи. Bel den primären Adjektiven bzw. don transforierten mit primärer Bedeutung lst die Negierung eo 1 pso am verstandilchsten, da diese ja Zustand, Seinsweise, Art u. dgl. charakterisieren sollen, etwa правьдьнви 'gerecht' - нenpaвbдвныи 'ungerecht'. 


\section{Y f}


VI - Granmatische Fixierung des Transferendume

\$ 82. Radorslav Vexerka geht in selnem Aufsatz "Ko konkurenci adnominklniho genetivu a adjektiva $v$ starosloringting auf die Frage e1n, warum der adnominale - nicht erweiterte - Genitiv in Altkirchenslavischen häufiger im Plural auftrete als im Singular. 118 Allerdings fuhrte or auf den folgenden Selten mehr Belege im Singular als im Plural auf, so daß man an der Glaubwirdigke1t der Argumentation doch etwas zweifeln muB. Daß der adnominale Genitiv im Altkirchenslarlschen häufiger auftritt als im Altrussischen hatten wir bereits in $\$ 32$ gesagt. Vezerka argumentiert so: Die in erster Linie mit dem Genitiv konkurrierenden Suffixe -ov-, -ev-, -in-, "ryjadrujl pfivlasthorkel jedinci,majl individualisujlcl, singulárovf vfznam." 119 Reiter sioht die Suffixe-in-, -ov-, -j-, -bjals Vartanten des glelchen "Surfixems" an. 120 Die Beobachtungen Vexerkas sind nicht unrichtig. Denken wir doch daran, dab die Adjektive aur -ov- und -in- belopielsweise in der Mehrzahl einzelne Personennamen als Transferendum haben. bbenso sind die - allerdings wenig belegten - Abstrakta als Transferenda, die durch das Suffix-in- In Adjektive transferlert werden, naturlich nur im Singular denkbarıнеприязнинз . момонинъ, зиминъ, друхьбинъ . Man muß dazu sagen, daß selbstrerständich die genannten Suffixe nur in Verbindung mit dem nominalen Endungsmorphem gemeint sein können, eine Tatsache, die im Aufsatz Reiters nicht recht zum Ausdruck kommt.

Selbst bel Belegen, wie человbк а виденье обезьанино Sr.II, 500, wo man zweifeln könnte, ob das Transferendum hier im

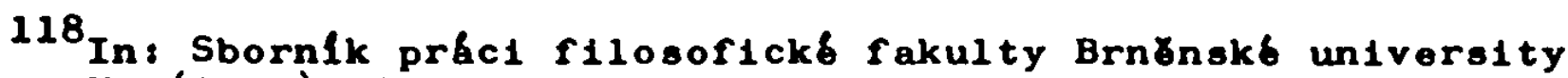
VI $(1957)$, s. 30 .

119 ebenda.

120a.a.0.. S. 364. DaB Vezerka in-J-ein "Mittelding" zwischen -ov - und -bsk- sehe, durfte diesem wohl unterstellt sein. 
Singular oder Plural gemeint ist, zeigt die Entwicklung, die vom Suffix zum Genitiv fuhrt, daB der Singular gemeint ist. Im Neuruselschen wirde hier der Genitiv Singular stehen, was aber, und darauf geht Reiter in seinem Aufsatzein, nicht besagt, daB ein ganz bestimmtes Individium gemeint sel (Individualis), sondern der Singular steht hier fur die ganze Gattung schlechthin, nicht fur das Individium. Allerdings mus man nicht die Ansicht Reiters teilen: "Während das in den Plural Gesetzte immer auf die Gattung fuhrt, gibt das in den Singular Gesetzte kelne elndeutige Auskunft." 121 Erstens können als Transferenda Personennamen auftreten, und wir haben gesehen, dab es ganz bestimmte Translative sind, die hier eine vorherrschende Kolle splelen. In diesem Fall meint das Transferendum elndeutig den Singular. Zweitens fuhrt das in den Plural Gesetzte nicht immer auf die Gattung, sondern es kann aus dem Kontext durchaus ersichtlich sein, daB eine Reihe einzelner Individuen gemeint ist. Die Vetermination 1st also praziser. Jedenfalls fuhrt eine vom Kontext losgelöste Betrachtungswelse nicht zur Lösung des problems. Kommen wir auf den Belegs а видинье обезьянино (s.0.) zuruck. Diese Figung kann im Deutschen wiedergegeben werden durch 'in Gestalt eines Afren'. 'in Gestalt von Affen'. Das Translativ hat die Funktion eines General1s, das Transferendum meint 'Affe im allgemeinen, schlechthin'. Innerhalb eines anderen Kontextes kónnte genausogut der Individualis gemeint sein.

Vexerka geht auch auf das Problem der sogenannten pluralbedeutung des Suffixes -bsk- ein und ubt dabei kritik an Vaillant. Er glbt Belege aus dem Altkirchenslavischen an, die sowohl die pluralische wie auch singularische Funktion dieses Suffixes beweisen sollen.

Plural:

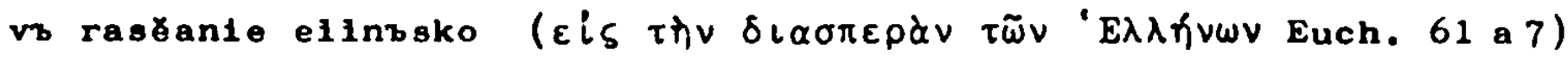
Vorausgesetzt, daB hier ühnliche Verhaltnisse vorliegen wie im Altrussischen, ist allerdings doch sehr fraglich, ob etwa

121 a.a.0., s. 368 . 
елиньскъ nicht mehr beinhaltet als '... der Griechen'. Singular:

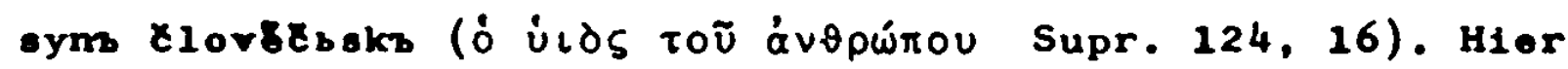
kann man enderer Ansicht sein. Man sollte nicht nur die griechische Vorlage berticksichtigen, wo eben der Genitiv Singular steht. Gemelnt lst 'der Menschen Sohn, Sohn des Menschen'. Ides Menschen schlechthin'. Das Translativ hat hier sicher die Funktion eines Generalis.

Reiter ubt heftige Kritik an der von Vezerka gebuberten Ansicht, daß das Suffix-j-pluralische Funktion haben könne: "Da bel -ov-, -in- ausnahmslos 'singularische Funktion'zu beobachten se1, sah sich Vezerka veranlaBt, -j- eine Sonderstellung einzuraumen und thm eine wentger prägnante Funktion zuzuweisen als sie-ov-, -in-häten." 122 Reiter bringt dann den Beleg aus Euch. Sin. 4 b, 1: 'bogb ... pride na zemljq. obrazb raba priemb, vo podobbl citi byrb'. "Diese stellung soll nach Veterka die 'pluralische' Funktion demonstrieren, die-j- u. a. [?] haben könne. Vezerka erwartet hier anscheinend $x \tilde{i} \mathbf{r}$, da doch Gott in 'allgemein menschlicher Gestalt erscheinen mubte. Well nicht-bsk-, sondern-j-verwendet wird, der Sinngehalt aber festzustehen scheint, folge daraus die pluralische Funktion des-j-." 123 Reiter meint, wenn ausgedruckt werden soll, daB Gott als Mensch eine ind1viduelle Gestalt in Christus gehabt habe, so bliebe keine andere Wahl, als sich des-j-zu bedienen, "und dann hat das Suffix kelneswegs die 'pluralische' Funktion, die ihr Veterka unterschiebt [?], sondern stimmt dieses Beispiel mit anderen uberein, wo die Funktion des-j-deutlicher zum Ausdruck komnt." 124 In dem vorliegenden Fall wird man in den Suffixen -j- und-bok- nur Varianten sehen können, wenn die il folgenden angefuhrten Belege auch aus dem Altrussischen stammen.

122 a.a.0., s. 375 .

$123_{\text {a.a.0... s. } 376 .}$

124 a.a.0., s. 376. 
Vgl, etwa:

пришьдз къ чЛ̈вкъ, въсхотьдз ев и образъ чйвчь прияти ( Мин. I096 г. ) ядущии плоти человыча въ хльба мвсто (Псков. I. I.)

Sr.II. 1494)

Velerka lst der Wahrheit sicherlich naher als Reiter, wenn man auch nicht von einer pluralischen Funktion des Suffixes sprechen solite, sondern eher von elner genralisierenden Funktion, da 'Mensch im allgemeinen', 'Mensch schlechthin' gemeint lst. Es wäre elne Fehlinterpretation der slavischen Blbel-Übersetzung, wenn in den oben angefuhrten Belegen nicht gemeint sein sollte, dab Christus in der einfachen Gestalt eines Menschen oder der Menschen schlechthin erschienen wäre. Label splelt zunächst kelne Rolle, daB der Begriff 'Menschensohn' älter ist als das NT, Ja vermutlich älter als die biblische Uberlieferung: "Am nächsten liegt es, an die im Orient verbreitete Vorstellung von "Urmenschen" zu denken bzw. an thre iranische Ausprägung in den Gestalten des Gayomart und Saobyant. Vabel ist jedoch zu beachten, daB einer der wesentlichsten Züge dieser Vorstellung, die urbildliche und kosmologische Bedeutunf des Urmenschen, gerade dem at.-jud. M. enschensohn fremd 1st." 125 Bemerkenswert lst sogar, daB, wie aus der von Galling herausgegebenen Enzyklopädie hervorgeht, nach hebraischem wie aramälschem Sprachgebrauch mit 'Menschensohn' das Einzelwesen Mensch gemeint sein kann: "Bel Ez. Ist M. häufig Anrede Gottes an den propheten, welche die menschliche Niedrigkeit betonen soll." 126

\$ 83. Wenn Kelter die Suffixe-in-, -ov-, - J- und -bj-als Varianten eines Suffixems wertet, so ubersieht er, dab etwa -ov- und -in- sowohl mit pronominalem wie mit nominalem Endungsmorphem auftreten und die bunktion dann varilert. Veferka ist in dieser Hinsicht korrekter. Zumindest für das Altrussische - und im Altkirchenslavischen werden die Vinge nicht an-

125 Aus: Die Religion in Gesch. U. Gegenwart. Hersg.v. Kurt Galling, Tübingen 1960, S. $874 \mathrm{f}$.

126 ebenda. 
ders liegen - sind die Suffixe-1n-, -ov-, - j- und - bj- nur sehr bedingt als Varianten zu betrachten. Das lust sich schon anhand der Adjokt1ve veranschaulichen, deren Transferendum einen Baumnamen bezeichnet und deren Translativ das Suffix -ov- + nom. Endungsmorphem ist. Aворовъ Sr. I, 111 zunindest ist schon im Aksl. belegt. Vgl.: cльмена едова Sr. I, 824 'Balken aus Tanne (Flchte) (das Transferendum bezelchnet hier das Material, also eigentlich 'Tannenholz') schlechthin', ebenso вьрьбовьмь гьздомь Sr. I, 460 'Weldenzwe18', на кровати тисовъ Sr. III, 960 'Bett aus Ébenholz' (d. h. die Materie lst gemeint.). Vgl. Ferner: листь липовь кору березову

кору липову

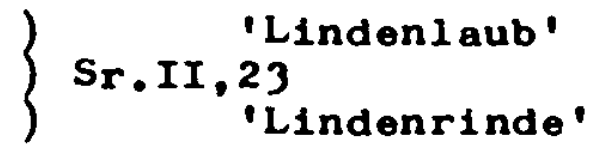

на березовоу пень

кору березову

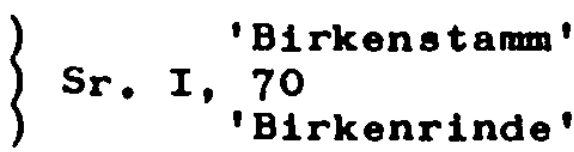

Березово поле Sr. I, 70 'B1rkenfeld' (É1genname). Niemals wird hier der Individualis ausgedruckt. 127 Bezeichnend ist, daß solche Fugungen, die keine Individualisierende Beziehung ausdrucken, auBerordentlich huufig als feste fugungen ("Wortgruppenlexeme") auftreten. Dies ist sehr selten der Fall bei Suffixen, die gerade im allgemeinen keine genaralisierende Beziehung ausdrucken, wie-ov-, -in-, - j-, -bj- + nom. kindungsmorphem. Dies hatten wir ja bereitg gesehen. Diese Regel labt sich jedoch nicht, wie Reiter es tut, verabsolutieren. Denn gerade hier, wo ganz feste fügungen auftreten und gar kein Indiviudual1s gemeint sein kann, wie am Be1spiel der Baumnamen exemplifiziert, tritt z. B. -ov- + nom. Endungsmorphem auf. Ls ist nicht unbekannt, und das mag eine Erklarung in diesem spezifischen Falle sein, daB in der Mythologie Baume als belebt angesehen wurden. Das widersprache

127 zu den Begriffen "Individualis", "Generalis" vgl. Royen, G.: Die nom. Klassifikationssysteme in den Sprachen der Erde, Wien 1929, S. 636, wo das Bretonische angeruhrt wird, das weit mehr Numeri unterscheidet als $z$. B. das Deutsche, bret. ed koll.plur. 'Korn', edenn sing. 'Getre1. dekorn' : ed-ou 'versch.Getreidearten': edenn-ou 'eine bestimete Anzahl Getreldekörner'. 
also nicht Grundsätzlich der Anschauung, daB alttels des Suffixes -ov- ursprunglich nur Substantive transferiert murden, die Belebtes bezeichnen. Fur das Altrussische gilt dies jedenfall. nicht mehr. Wir finden ubrigens das Suffix -ov- + pronos. Endungamorphem bel der Translation von Baunamen naturlich auch. wenn auch bel weltem nicht so häufig wie mit nom. Endungsmorphem: дубовуг кору Sr. I, 739 ('Eichenrinde'), на черьмховъи кустъ Sr.III, 1500 ('Faulbaumzwe1g'), дьбрь тисовая Sr. III ('Elbenschlucht', d. h. 'Schlucht, wo Eiben wachsen', hier Eigenname). -ov-/-ov-yj- sind hier als Translative Varianten. Generell werden jedenfalls Baumamen durch das Suffix -ovtransferlert. Nur drei Ausnahmen sind bekannt: B абланньмb овоши (яблоня) 'Äpfel' Sr. I, 3, олшаны вьтви (vоп ольха) 'Erlenzwelge' Sr. II, 664, листвьнатым хизломъ (neuruss. лиственница) 'Lärchenzweig' Sr. II, 23. In Jedem der drel Ausnahmefaile 11 egt jeweils ein anderes Suffix vor. Lautliche Schwierigkelten wird man hier kaum geltend machen können, da im Neurussischen beispielsweise ein олховын existiert. Sehr bemerkenswert ist die Tatsache, daB Feminina auf -a liberhaupt durch das Suffix-ov-transferiert werden, etwas, was man sonst nicht zu bemerken prlegt. Vondrak schreibt ganz eindeutig' "Von den u-st. haben sich diese Bildungen dann auch auf die ost. erstreckt, we wir es sonst auch in anderen Sprachen finden. Im Slavischen haben sie aber speziell die Geltung poss. Adjektive ubbernommen, also den Gen.sg. vertreten, wenn es sich um die Benennung elnes lebenden Wesens handelt. Von a- und 1Stämmen werden derartige Adjektive nicht mit -ovo-, sondern mit -ino- gebildet." 128 Wir hatten dagegen gesehen, das als Transferenda auch a-Stäme wiе липа, береза, сосна vorkommen. Miklosich druckt sich - 1875 / - wesentlich vorsichtiger aus: "An benennungen lebender wesen gefugt bildet es adj. possessiva, sonst bezeichnen die dadurch gebildeten adj. die materle, aus der etwas gemacht lst [... $]^{n} 129$ Es ist 1mmerhin erstaunlich, daB gerade Baumamen hier eine Ausnahme bilden. Elne Lrklärung kann man, wie berelts erwähnt, möglicherwelse in der Mythologie suchen. Reiter schreibt im"Wörterbuch der Mythologie", daB mit $S_{1 c h e r h e l t}$ angenommen werden düre, daB die slavische Heligion elne den Bedurfnissen des Ackerbauern 128 vondrak, a.a.0., S. 253. 129 Miklosich, Stammb1ldungslehre. 
angemessene Naturreligion war: "Ls wird berichtet, daB Quellen,[...] Gewasser, heilige haine und Bäume [...] angebetet murden, ob man diese aber personifiziert oder als Sitz eines Gottes angesehen hat, laBt sich trotz zahlrelcher zeugnisse mit Sicherheit nicht ausmachen [.. . ]" 130 Nimmt man Bkume als den Sitz von lottheiten an, so libt sich die Translation durch -ov- + nom. Endungsmorphem viellelcht inhaltich verdeutlichen, grammatisch kann man die Translation von a-Stämen durch das Suffix -ov- nur als absolute Ausnahme betrachten.

Im Deutschen wird dort, wo die individualisierende Tendenz in der Beziehung zwischen Regens und Transferendum des determinierenden Adjektivs nicht vorhanden 1st, mit Vorliebe ein Determinativ-Kompositum bevorzugt. Dies gilt nahezu in der Regel für Fugungen mit Adjektiven, die durch das Suffix -ov+ pronom. Bndungsmorphem transferiert werden. $V_{G} l_{\text {. }}$ тьрговая пошлина Sr. III, 1053 'Marktabgabe' медовая чаша Sr. II, 122 'Kupfertasse' лаина илова Sr. I, 1091 'Z1egelste1n' туча дохдевая Sr. I, 754 'Kegenwolke' мировая грамота Sr. II, 145 'Friedensurkunde' u. a. Dort, wo ein solches Translativ in der Funktion eines Genera11 s vorliegt, können wir die Fügung Adjektiv + Substantiv im Deutschen in der Kegel als Kompositum wiedergeben, d. h. die Wortgruppe ist der Komposition gleichwertig. Die Folgerung, die man daraus ziehen mus, ist die, daß das determinierende Glied der Determinativ-Komposita die glelche Funktion ausuben kann wie ein determinierendes Adjektiv innerhalb einer syntagmatischen figung. Dies meint auch Wissemann, wenn er sagts "In paкетоносец 'Kaketenträger' ist das syntaktische Verhailtnis der belden Glieder umgekehrt [...]Nun ist pakera in ein Adjektiv transferiert. Translativ ist der Kompositionsvokal." 131 Damit sind wir bel den gleichen Erkenntnissen angelangt, wie

\footnotetext{
130 Norbert Reiter: Mythologie der Slaven. In Wb. d. Mythologie, hersg. v. H. W. Haussig, Stuttgart 1965 fr.. 1. Abt., 6. Lieferung, S. 168.

131 a.a.0., S. 281 .
} 
wir sie im allgemeinen Teil dieser Arbeit unter dem Kapitel "Wortbildung und Syntax" dargelegt haben. Ls ist verstandlich, daB in solchen Figungen ar ehesten das Regens schwinden konnte und wir dann den Typus $0>A>0$ vorfinden. Vgl.: горница столовая Sr. III, 516, столовая 'Speisezimier', заутрьная (Regens: cryzoa) Sr. I, 956 'Morgengottesdienst'. Ein anschaultches Belspiel sind hier die Bezelchnungen für zollähnliche Abgaben. Grundsatzlich können Adjektive wie unter Kapitel II und III beschrieben, Gegenstand der translation double $O>A>0$ sein. Bel den Adjektiven auf -ov- + pronom. Endungsmorphem ist jedoch die Tatsache interessant, daB diese Translation $O>A>0$ in der Mehrzahl aller gefundenen Belege bei solchen Zollbezelchnungen erfolgt. Als Regens kommen hier Bezelchnungen fur Abgaben wie оброкъ, пошлина, дань, мыто in Frage. Vgl.: оброкъ медовин oder медовое Sr. II, 121 'der Kupferne', становое (von станъ) Sr. III, 491,'Liegegeld', шестовое Sr. II, 1588 = "пошлина, которая бралась съ шестовъ, употреблявшихся на речнихъ судахъ"(Ср.), роговое Sr. III, 129 "пошлина с водоходныхъ судовъ" cropoxeвое Sr. III, 522 'сторожевая повинность' (нier ist keine Abgabepflicht gemeint, sondern eine Dienstleistung.), судовое Sr. III, 601 ( а судовых пошлин не имати ) 'Schifrsgeld', търговая потлина Sr. III, 1053 (търговое) 'Marktzins'.

\$ 84. Kehren wir noch einmal zu der These Keiters zurick: "Während das in den plural Gesetzte immer auf die Gattung funrt, gibt das in den Singular Gesetzte keine eindeutige Auskunft." 132 Be1 Belegen wie coзданиа миру L. 37 oder цьлованью креста L. 167 zeigt das Transferendum des transferierten Adjektivs, dab hier nicht die Gattune gemeint sein kann. Andererseits gibt der Dativ Plural bel творец каноном Pat. 126 eindeutig daruber Auskunft, daß es sich um eine ganz bestimmte $2 a h 1$ von Einzelindividuen handelt, während ich bel конець хитир Раt.56 nicht weib, ob es sich um 'das Ende allen Lebens schlechthin' oder um das 'Lebensende' eines bestimmten Menschen handelt. Ich muв хитие als neues Regens in einem weiteren noeud untersuchen, um Klarheit zu bekomen. Was die Tendenz im Gebrauch an-

132 a.a.0., S. 281 . 
belangt, o hat Relter nicht unrecht, wenn er die Suffixe -or-, -In-, -j-, - -j- als Varianten elnes Suffixese wertet, nur kann man diese Tatsache wahrscheinlich nicht absolut formelhaft fassen. Dagegen sprechen Belege wie etwa die oben angefuhrten Adjekt1ve, die sich ron Baumbezelchnungen ableiten. Auch andere Translative als -or- lassen sich anfuhren, die durchaus in Konkurrenz zu -bsk- stehen können, d. h. den Generalis ausdrucken Suffix $-j-8$

но азъ есмь роду княга L. 23 (von allgemein furstlichem Geschlecht, nicht dem eines bestimmten Fursten)

дворь княгь L. 55 ('Furstenhof', nicht der Hof eines bestimten Fursten, häufig in der Laur.Hs.)

выры бохмичв L. 84 (von allgemein mohammedantschem Glauben, nicht dem eines best. Mohammedaners)

не украшени ризъ бдудничи ('Hurenkleldung', nicht die einer best. Person) Sr. I, 117

Suffix $\rightarrow J-:$

рыбии хвостъ L. 165 ('Plschschwanz', nicht der eines bestimaten Fisches)

Suffix $-1 n-8$

чедовъкъ а виденье обезьанино Sr. II, 500 (In 'Gestalt eines Affen', nicht der eines bestianten Affen).

Diese nur beispielhaft angefihrten Belege sprechen gegen die Behauptung Reltersi "Wenn signalisiert werden sol1, daB es in der Beziehung eines y zu einem kxemplar der Gattung $x$ Momente glbt, die nicht identisch sind mit Momenten der Beziehung, die zwischen demselben $y$ und einem anderen Exemplar der Gattung $x$ bestände, so wird Suffix-j-verwendet" - j-verstanden als Suffixem der oben genannten Suffixel und: "Der Plural ist eln Distributivus, - bsk- kann ohne Zusatz die Distribution nicht anzelgen. Der Distributivus steht in Opposition zum Generalis, -bsk- steht in Opposition zu-j-, das den General1s gerade nicht anze1gt." 133

Was fur das Altkirchenslavische ausgesagt wird, nuB nicht unbedingt fur das Altrussische gelten, jedenfalls d a B os

133 a.a.0., s. 370 . 
nicht für das Altrussische gilt, scheint in Anbetracht der oben angeruhrten Belege einleuchtend zu sein. Formeln lassen sich also kaum aufstellen. Dies besagt nicht, dab die Suffixe-j-, -ov-, -bj-, -1n-, und als Translative sind hier Kasus und Präpositionen etwa in gleichea Maße zu berúcksicht1gen, b1s zu elnem gewissen Grade glelche Zuge in threr Funktion aufweisen, denke man nur daran, daß Personennamen und Appellativa, die Personen bezelchnen, als Transferenda be1 den genannten Translativen eine ubergeordnete Rolle spielen. Die Beziehung zwischen dem Transferendum des determinierenden Adjekt1vs und dem Kegens = Determinatum entspráche in diesen Fälien also dem Individualis. Dies gilt für die Mehrhe1t der unter Kapitel I näher bezelchneten transferierten Adjektive. Bei durch andere Translative, etwa durch die Suffixe-bok-, -bn- transferierten Adjektiven ist die Tendenz, das Translativ in der Funktion elnes Kasus Generalis zu gebrauchen, wesentlich stärker. Vgl. etwa: мудрости Бохьа но она человьчески L. 62. Die Welsheit des persönlichen Gottes (Suffix-bj-) wird hier der allgemein menschlichen gegenubergestellt (Suffix-bsk-): женьская прелесть L. 80: Gemeint ist nicht die 'List' oder verfuhrerische Schönheit einer bestimmten Frau, sondern der Frauen schlechthin, wie der Kontext zeigt: зло бо есть женьская прелесть якоже рече Соломанъ покаявся о женах L. 80. Bekanntlich verkörpert die Frau in der altrussischen Literatur sehr häuflg das Böse, wenn nрьльсть - das Regens im angefuhrten Beleg - eine Bedeutungsentwicklung von 'List', 'Betrug' u. dgl, zu 'schönhe1t' durcheemacht hat, so deshalb, well 'Schönhelt' und 'Verfuhrung' im negativen (= antichristilchen) Sinn als identische, zumindest potentielle Elgenschaften der Frau angesehen werden. Schon anhand dieser Belege mag deutlich geworden sein, dab naturlich Translativen wie den Suffixen -ov-, -in-, -J-, -bjim allgemelnen eine individualisierende Funktion, -bsk- und -bn- eine mehr, aber nicht ausschlieblich generalisierende Funktion zukommt. Dies mag auch in etwa das sein, was Reiter letztlich meinte. Diese Beobachtungen beim Gebrauch von bestimbten Translativen auf einen formelhaften Nenner bringen zu wollen, ist Indessen ein problematisches Unterfangen. 
VII - Semantische Fixierung des Transferenduns

$\$$ 85. Reiter weist in seinem Aufsatz darauf hin, daB aksl. мирз in der Bedeutung 'Frieden' mittele des Surfixes -bnabgeleitet wird, in der Bedeutung 'Welt' Jedoch durch $-3.8 k-.134$ Obwohl gerade dies fur миръ zumindest im Altrussischon nicht zutrifft,ist doch erkannt, daß durch die Verwendung eines bestimmten Translative, wenn es in Konkurrenz zu anderen steht, die Bedeutung des Transferendums fixiert werden kann. Diese grundsutzliche Möglichkeit sieht auch Zverkovskaja, wenn die Problematik auch nur sehr unklar in ihrem bereits erwänten Aufsatz zum Ausdruck kommt. Wissemann verwendet in seinem Aufsatz die Terminologie Tesnières und spricht von "Fixierung der Bedeutung des Transferendums durch das Translativ." 135 Dieses Verfahren lot allein schon deshalb in Betracht zu ziehen, da es in vielen Füllen, in denen ein Transferendum durch mehrere Translative transferiert wird, gar nicht möglich 1st, eine andere Differenzierung durchzufihren. Es lst insbesondere fur die aktive Sprachbeherrschung des modernen Russisch, d. $h$. das Erlernen dieser Sprache als Fremdsprache von Wichtigkeit, zu wissen, ob eine semantische Differenzierung zum Ausdruck gebracht wird, wenn etwa seмля durch-bn-oder-(j)an-transferiert wird. Von Interesse sind hier alle Signifikate, die mehr als einen Signifikanten haben, d. h. die Signifikanten fallen in den Bereich der Polysemie. Indessen lst es naturlich nicht möglich, im Altrussischen auf diese Art in allen Fällen, wo ein Transferendum durch mehrere Translative transferlert wird, eine Fixierung des Transferendums festzustellen.

Untersucht wurde ein an Umfang begrenztes Material - die Materialy Sreznevskijs - das naturlich jederzeit durch Sichtung der gesamten altrussischen Texte erweltert werden könnte. Indessen bieten sich hier naturlich zunächst die "Materialy" an, da die zu vergleichenden Adjektive unmittelbar in alphabetischer Reihenfolge angeordnet und genugend Textstelien zitiert
134 a.a.0., s. 398 .
139 a.a.0.. S. 298 . 
sind, um Aufschlusse zu geben. Es geht hier weniger um Vollstandigkeit als vielmehr darum, exemplarisch die Möglichkeit einer semantischen Fixierung des Transferendums zu erkunden und damit indirekt zu einer $D_{i f f e r e n z i e r u n g}$ der konkurrierenden Translative, wenigstens in binzelfälien, zu kommen. In der Tat lst dies bel einer nicht geringen Anzahl von Belegen durchfuhrbar. Es gibt naturlich Fälle, in denen nur durch das Regens ersichtlich wird, um welches Transferendum es sich bei dem dazugehörenden Adjektiv handelt: etwa вьчия könnte theoretisch von Btkb 'Ewigkeit', Bbko 'Augenlid' und Bbye 'altr. Volksversammlung' abgeleitet sein. In der Tat dient hier als Transferendum вьче : а вьчеи колоколь отлокили Sr. I, 500, was nicht verwunderlich ist, wenn man - wie bereits erlautert in Betracht zieht, daß als Transferenda der durch Suffix -bjgebildeten Adjektive vornehmlich Bezelchnungen für Lebewesen oder Gruppen von Lebewesen dienen. Gewibheit allerdings gibt das Adjektiv allein nicht. Bel вьчьныи wieder konkurrieren die

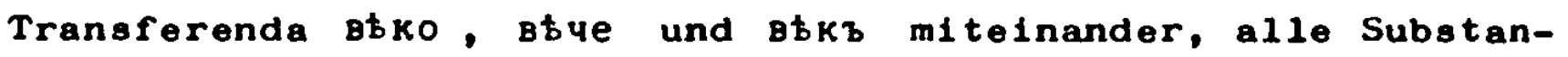
tive sind als Transferenda dieses Adjektivs belegt: bursa мукы Sr. I, 501 'ewige vualen', вьчныа pясны Sr. I, 501 'AuGenwimpern', диака въчного Sr. I, 502 'diakonus consili1'. Zum dritten konkurrieren die Adjektive въчьньи und въчистьи miteinander, beide leiten sich ab von $\mathrm{Bt} \mathrm{Kb}$. Und hier scheint jeweils wentgstens eine Bedeutungsnuancierung vorzuliegen, soweit eg die semantische Fixierung des Transferendums angeht. Vergleichen wir zwei Belege miteinander: Bъчныр мукы Sr. I, 501 'ewige Qualen' und на богомоле вечистое Sr. I, 500 'evige Furbitte' (eigentlich: "immerwahrendes Beten zu Gott"). Das Transferendum Btkz bezelchnet im ersten Beleg tatsächlich 'Ewigkeit'. Богомолье вьчистое ist ein feststehender Begriff. Wenn ein Laie der Kirche materielle Giter uberlieb oder eine Kirche bauen lieB, so geschah diese Tat, damit man den Stifter in die Gebete der Mönche etwa oder der rriester einschlieben sollte. Diese Gebete waren nicht 'ewig' im Sinne einer fortdauernden Furbitte ohne UnterlaB, sondern wurden von Zeit zu Zeit vollzogen, solinge die betreffende Kirche oder das Kloster existierte. 
Wlssemann hatte festgestellt, daß am Transferendum sersi verschiedene Bedeutungen flxiert werden können, und swar durch земнов 1. Erdkörper als Ganzes, 2. Landoberfiache in Gegensatz zu Meer und Luftraum, 3. die irde als Diesseits in Gegensatz zum Uberirdischen, durch земляно die Bedentang des Stoffes und durch земедьны dle Bedeutung 'Grund und Boden als Objekt des Besitzes und der Bewirtschaftung'. 136 In Altrussischen existieren die Adjektive земьныи Sr. I, 971, земльскии Sr. I, 972, земляныи Sr. III (Anhang), 117 vom Transferendum земля und земьныи Sr. I, 975, земьскии Sr. I, 976 von земя. Землянисты und землисты sind jedenfalls in den "Materialy" nicht belegt. Eine relativ eindeutige Fixierung der Bedeutung des Transferendums wie im modernen Russischen libt sich nicht feststellen. Fur земляныи bringt Sreznevskij nur einen Beleg im Anhang seiner Materialy, und gerade aus diesem Beleg ist ersichtilch, daß gerade ganz im Gegensatz zum modernen Kussischen nicht земля als Stoff gemeint ist, Sreznevskif uberträgt земляньи mit "относящинся къ вотчину и дьлная земляная", der Beleg: грамота на его вотчину и льлная земляная . Alle anderen Adjektive vereinigen, wie man bei Sreznevskij leicht nachprifen kann, verschiedenste Bedeutungen, der einzige erwähnenswerte Beleg wäre viellelcht die feste Fügung: земьскыи бояре Sr. I, 976.

\$86. Bei den folgenden transferierten Adjektiven ermöglicht die Differenzierung beim Gebrauch unterschiedilcher Translative in Gestalt von Suffixen eine Fixierung der Bedeutung des Transferendums. Es geht dabel oftmals allerdings nur um feinste Bedeutungsnuancierungen. Der Oppositionscharakter der Translative wird durch den innerhalb des Kontextes zu bestimmenden Bedeutungsgehalt des Transferendums fixiert. In den $\$ \$ 32-38$, in denen der Genitiv oder Dativ als Konkurrent gegenuber Suffixen bei der Translation $0>A$ behandelt wurde, hatten wir dieses Verfahren ja im Prinzip bereits angewandt. Wir sahen dort, daß bel der Mehrzahl aller Belege, wo der nicht erweiterte Genitiv gebraucht wurde, der Kasus beispielsweise stehen muste, da das konkurrierende suffixal transferierte Adjektiv 136 a.a.0.. S. 296. 
sinngembi etwas anderes ergeben wirde, vgl. dazu $\$ 32$ fr. Das Altrussische unterscheidet hier also durch die wahl des Translativs polysemantische Worter. Dies aber, und dies mu in aller Klarheit gesagt werden, ist keinesfalls die Regel - In diesem Falle wäre diese Arbeit ein leichtes gewesen -, vielmehr sind es vornehmlich die am häufigsten gebrauchten suffixalen Translative, die in Ihrer Masse keine solche Lifferenzierung bewirken. Dennoch läbt sich bel elner ganzen Anzahl von suffixal transferierten Adjektiven eine sixierung des Transferendums durch das gegebene Translativ feststellen. Die folgenden Adjektive sind alphabetisch geordnet. Die bei der behandlung des Genitivs und Dativs - vgl. $\$ 32$ ff.-herangezogenen Belege aus der Laurentius-Chronik werden hier nicht wlederholt.

1. гладивыи / гладьныи ьzw. голодьныи Sr. I, 516 f.: гладьныи бzw. голодьныи sind transferiert aus einem Substantiv, das schlechthin 'Hunger' bezeichnet. Веl гладивын kann das Objekt, worauf sich 'Hunger' oder 'Gier' richten, im Transferendum miteingeschlossen sein, also etwa 'blutgier', so dab dann Sreznevskij als eine der Bedeutungen von гладивын ganz richtig angibt als "кровохаднын": къ влъку бо прилагаеть нравъ гладивааго, а кроткааго овци ( Ис. ХI, 6. толк. Упыр.)

2. Гнусивын / гнусьньи/ гнусыи Sr. I, 526 Dem Adjektiv гнусивын liegt als Transferendum das Substantiv rнусb in der Bedeutung von 'Schmutz im konkreten Sinne' zugrunde (griech.jur $\alpha \rho \delta \varsigma$ ), während rнyç bel dem ohne Suffix gebildeten гнусыи mehr 'Schmutz' Im abstrakten Sinne' meint, vgl.: Словеса ихъ гнуса оставло [...] Sr. I, 526. Ähnlich bezelchnet das Transferendum von гнусьныи 'Schamlosigkeit', 'Ekelhaftigkeit' u. dgl.

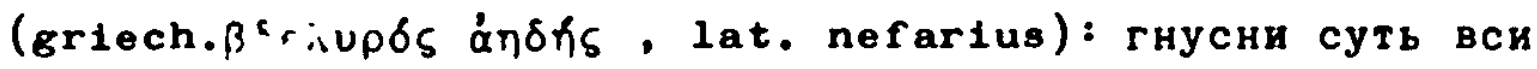
грьси (Упыр. 223), / да останешися гнусьных и грьшьныих дьлъ [...] (Пат. Син. XI в.)

3. жалостивыи / халостьныи Sr. I, $844 \mathrm{f}$. Durch die Translation халостивыи wird am Transferendum die Bedeutung 'Mitleid'. 'Finigkeit zum Mitleid' fixiert 
(Sreznevakij: cострадательнын) \& Немвлостивии и негалостивыв , поити имъ во тму кромышир (Грам. Алекс. митр. IЗ56 г.), durch zалостьныи die Bedeutung 'Kummer' oder eigentlich, wenn man die beiden bei Sreznevskif angefuhrten Belege näher betrachtet, bezeichnet das Transferendun das objekt oder den Ausdruck des Mitle1dss Жалостьныв [...] гласы ( vоврбs ), (Гр. Наз.) /халостьно видвние (Новг. І.д.). 4. мирьныи / мирьскыи /мировьи/мировьныи Sr. II. 151 Мирьнын шіе мирьскии fixieren am Transferendum мирз eетоhl die Bedeutung 'Welt' wie 'Frieden'.Vgl. dazu die Belege bel Sr., die in $\$ 34$ bereits angefuhrt wurden. Мировыи Sr. II, 1451 st nur 1nnerhalb der festen Fugungen мировая грамота, мировая запись 'Frledensvertrag' belegt. Das Translativ -ov- fixiert hier am Transferendum nur die Bedeutung 'Frieden'. Für -ov-bn- fürt Sreznevskij nur einen Beleg an: чировьная благыни [...] (Гр. Наз. XI в.) Sr. II, 145. Auf Grund elnes einzelnen Beleges laBt sich naturlich wenig sagen. Jedenfalls gibt Sreznerskif fur мировьныи кеine andere Ubersetzung an als мирсков.

5. мсячь / мьсячьныи Sr. II. 252

Durch Suffix -j- wird mbяLb ausschlieblich in der Bedeutung 'Mond' transferierts и боудеть свьтъ mbячь [...] (Kc. XXX, 26 Ynkp.) . Als Erklärung hatten wir bereits bel der Behandlung des Suffixes - j-angefuhrt, daB hier

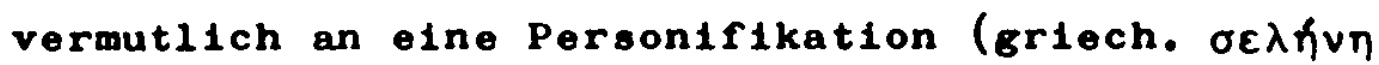
'Mond'. glelchzeltig Name fü dle Mondgöttin) zu denken 1st, da durch - j- nahezu ausschl1eBlich Transferenda, die Personennamen bezelchnen, transferlert werden. -bn- transferiert mbcaцb in der bedeutung 'Monat' wle 'Mond'. Translation double $O>A>0$ lst hier möglich, das so entstandene Substantiv mсячвныв bezeichnet dann a) лунатик 'Mondsuchtiger': б бъсны, и Яныя , зды недоугъ имша [...] ( МФ.ІУ, 24, ЕВ.1307 г.), b) in der neutralen Form мьсячьное

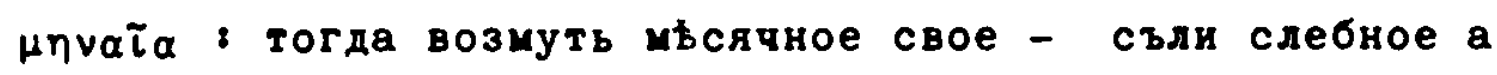
гостье щсячное (Дог. Игор. 945 г.).

6. огневыи /огньныи Sr. II, 602,605

Das Suffix -ev- fixiert am Transferendum orbhb die Bedeutung 'Fieber' (Bedeutungsverengung von 'Hitze', 'Feuer'): гоячка: приде огнь велии, спрьче огневая бользнь 
(Никон. д.). -sn- fixiert die Bedeutung 'Feuer' sowie in spezieller Bedeutung 'Höllenfeuer': повиньн есть геоньны огьнви (Панд. Ант.).

7. петровъ / петровьскыи Sr. II, 921 -ov- traneferiert lediglich den Personennamen Петpъ, während Sreznevskij neтровьскии wiedergibt als "относящияся къ Петрову дно": [...] и за Рохественое, и за Петровское ( Уст. гр. Вас. Дм. I392 г.).

8. печерьныи / печерьскьи Sr. II, 927

-bn- transferiert neqepa zu einem Adjektiv, wenn es die Bedeutung 'Höhle' im allgemeinen Sinne trägt. -bsk- als Translativ verengt die Bedeutung des Transferendums: neqepa ist hier nur die Kiever Печера oder Печерьскыи монастырь \& и бисть манастирь славьнъ, се же и донннь есть, Печерьскыи наричемъ (Нест. Кит. Феод.)

9. плитьныи /плитяныи Sr. II, 965

Das Transferendum плита bezeichnet bel плитьныи das zu fertigende Produkt: таково бо плитное дыло скончаваaся

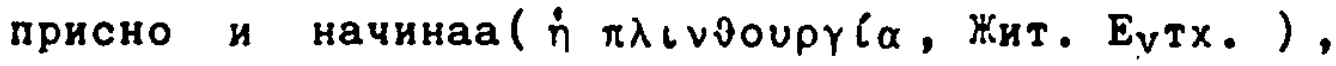
bei плитяныи das fertige Produkt, das aus плита besteht: [..] залохи стъну плитяну (Псков. I. л.)

10. Пльтьныи /плътьскыи /плътяныи Sr. II, 973 f.

Bel allen drei Adjektiven kann das Transferendum Bezeichnung für 'Körper' sein: a)Надъяся плотнои силь (Ип. Л.), b) [...] претькающеся о плотьское смотрыние (Посл. Акинд.). c) Помышляеси о плотяныхъ, а не о доховыхъ [...] ( Симон. Посл. Пат. Печ.). Das Suffix-bn-fixiert diese Bedeutung allein. Bel durch - bok- transferierten Adjektiven ist das Spektrum der Bedeutungsnuancen des Transferendums breiter. Es kann bezeichnen a) 'Körper', 'Fleisch', b) 'Erde'. Vgl. die Beleges a) Ни отз кръви, ни отъ похоти плътьскыа [...] ( Остр. ев.),

ь) рави, послушаите плътьскыхъ гия своихъ (Панд. Ант.). Bei пльтяни fixiert das Translativ die Bedeutungen 'Fleisch', 'Körper'\& на похоти плотяныа (Илар. Зак. Благ.),

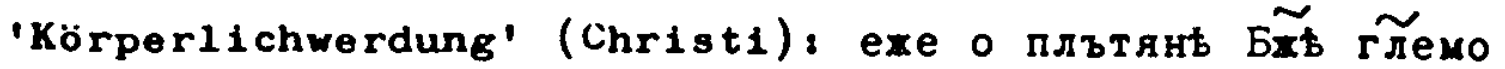
( Ио. екз бог.) sоwie 'Körperlichkeit' gegenüber dem Gel- 
stigon': Помишдяешв о пдотянихв, а не о дховнихз $(A>0)$ ( Пат. Печ.) .

11. прохазивии /проказьнии Sr. II, 1534 f. -sn- Fixiert an Transferendum lediglich die Bedeutung 'das Böse', 'Bosheit': от прохазннхв (A>0) избаввль ны есть (OXT. XIIIB.), während -iv- auBerden an npoxaza die Bedeutung 'Krankheit' fixiert: Удрьгаяmе ге нуди, ти яко и ныкако недуга проказива (Гр. Наз.).

12. СКвьрнивви /сквьрныи /сквьрньныи Sr. III, 371 f. vie bereits ofters beobachtet, fixiert naturlich das Suffix -sn- mehrere Bedeutungen am Transferendum, hier bel сквьрнъ \& 'Schmutz', 'Sunde', 'Lastex', рукама сквьрньнама прияти [...] (Сбор. 1076 г.) ('beschmutzt'), нъ сквьрьно творя [...] (Уст. крм. Апл) ('unsitt11ch'), [...] скверненая его дута [...] (Жит. Андр..0p.) ('lasterhaft').

Das suffixlos gebildete Adjektir bedeutet 'unrein' in Sinne der alttestamentlichen Vorschriften, soweit man nach dew Beleg in den "Materialy" urteilen kann he aдите скверна (Лук.Кнд.). Wenn Sreznevakij fux сквьрныи und сквьрнивьна1s eine der Bedeutungen нечистн angibt, fur сквьрнивыи Jedoch скверны, мерзкин, so lst dies insofern inkonsequent, als das Transferendum ckBbpнb in dieser Falle die ganz konkrete Bedeutung 'Schmutz' hat, Jedenfalls sofern man nach dem bel Sreznevskij angefuhrten Beleg urteilen kann: Обьметь и облобызаеть опешренур и гнусивур и скврьнивуо нашу вко (Панд. Ант.)

13. стодовыи /стольньи Sr. III, 516, 519

-ov- fixiert hier am Transferendum столъdie Bedeutung 'Tisch'. 'Speise': cосуды столовье 'Tafelgeschirr'. горница столовая бълая 'Speisezimmer' Sx. III, 516. -bnfixiert die Bedeutung 'престодз ': стодьныи кънязь = "великий князь, занимахшй старший престодъ", стольнии городъ = "столица, мъстопребьвание великаго князя, стольнаго князя Sr. III, 519.

14. стръпътивни /стръпътливии /стръпътьнии Sr. III, 562 Die Suffixe-iv- wie-1iv- fixieren am Transferendum cтръпьть die gleiche Bedeutung: 'Verlogenheit', 'Verschlagenheit's отъими отъ cебе стръпътива уста [...] 
(Панд. Ант.), бъ бо [...] лукавыи лъстьць наречень и всихъ стропотливее и лохь пламянъ (Ип. л.).

-bn- fixiert wieder mehrere Bedeutungen wie 'Mühe', 'Stren6e', 'Unebenheit': Оубояхъ хе ся начати, стръпътьное словидьвъ [...] (Конст. Болг. поуч.), яко стръпътьна есть вельми ненаказанымъ и не првбоудеть въ неи ( Сбор. I076 г.).

15. язичьныи /язычьскыи Sr. III, 1649

язычьскии fixiert am Transferendum die Bedeutung 'Heide', 'Fremder'. Vgl. dazu Vasmer: "[...] jezylbm Adj. zu Jezykb

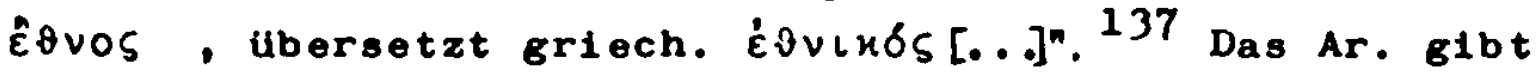
auch das griechische Original in diesem Sinne wieder. Vgl.: имется десять мухь от всих племенъ язычьскыих (Захар. Упыр.)

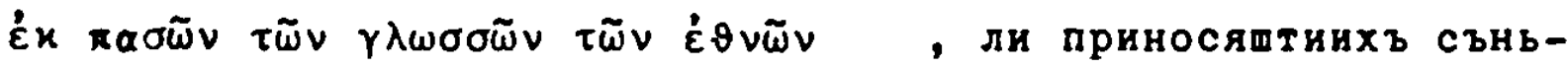

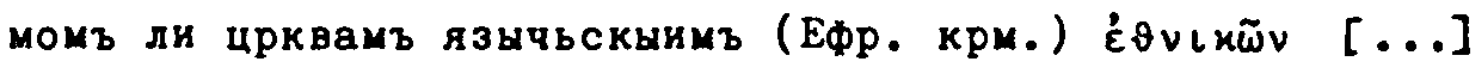

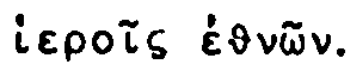

Dies ist die einzige Bedeutung, die das Transferendum trägt.Язычьныи wird in der gleichen Bedeutung gebraucht, jedoch fixiert es auch am Transferendum die Bedeutung 'Zunge', was bel язычьскыи nicht der Fall ist: nocjent ze оусть есть языкъ [...] язычная хе та плоть рьтка есть (lал.хІу। 16. владычьнь /владычьния /владычинъ Sr. I, 268

In $\$ 51$ wurde bereits darauf hingewiesen, dab das Suffix -bn-j- + nom. Endungsmorphem das Substantiv владыка dann transferiert, wenn es sich bedeutungsmabig an rocnorb anlehnt, dagegen erfolgt die Translation durch -bn-j- + pronom. Endungsmorphem, -bsk- oder -in-, wenn dle Bedeutung 'dominicus' o. dgl. vorliegt. Vgl.s ha образъ Влччн (Пов. вр.л.), аbег въ съмотрения владичьняго (Іанд. Ант.), владычьскы воля (Гр. Наз.ХІ. В.), vg1. auch духовныи судъ владычинъ (Зап. о Рхевск дан. П.1047 г.)

\$ 87. Es konnte anhand der angefuhrten Belege wenigstens exemplarisch gezeigt werden, dab durch einzelne adjektivbildende Translative eine Fixierung des semantischen Gehaltes des Transferendums ermöglicht wird, wenn mehrere Translative miteinander konkurrieren und das Transferendum mehrdeutig ist. Gerade hierbel hat sich sehr deutlich gezelgt, daB zwischen zwei oder mehreren konkurrierenden suffixalen Translativen kein einfaches 
Oppositionsverhältnis ron der Art "Translativ a 8 Translatir b" besteht. Wir hatten gesehen, daß-j-beispielsweise ubcaub in der Bedeutung 'Mond' transferiert, -nn- aber in der Bedeutung 'Mond' wie 'Monat'. Die Konkurrenz labt sich 1m rorliegenden Fall also so schematisieren:

Transferendur: Bedeutung 'Mond' Transforendum: Bedeutung 'Monat'

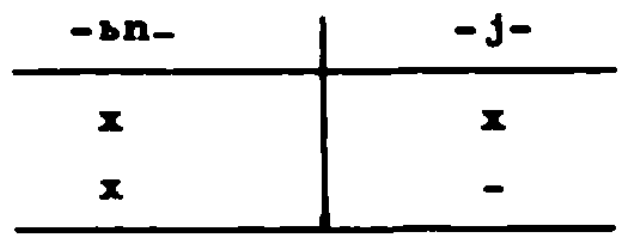

-J-steht also nicht in Opposition zu -sn-, sondern allenfalls zu "Nicht -j-", und dies im gegebenen Falle in bezug auf die Bedeutung eines möglichen zu transferierenden Substantivs. Noch schwieriger lst die Konkurrenz der suffixalen Translative beim Transferendum пльть darstellbar, sowohl-sn- wie-bokund - ( $j$ )an- transferieren das Adjektiv in der Bedeutung 'Körper', erst bei anderen Bedeutungen lst elne gewisse Differenzierung feststellbar. Diese Tatbestände ließen eine beschrelbende Darstellung am geeignetesten erscheinen. 
Fy

art

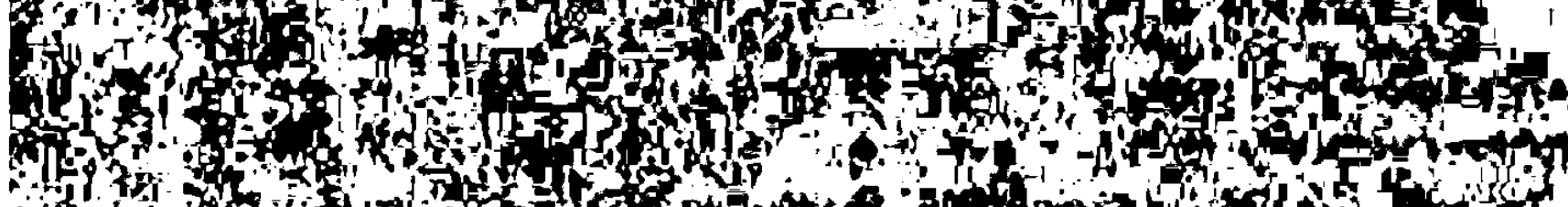

$\therefore$ inte -

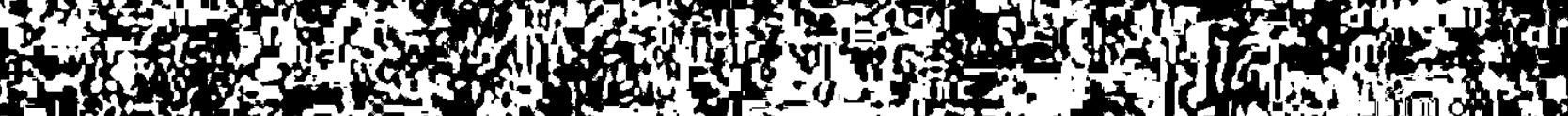

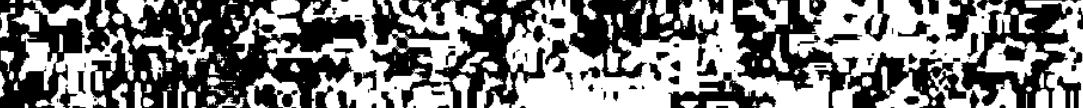

- $=2$ :

(n) 1 3)

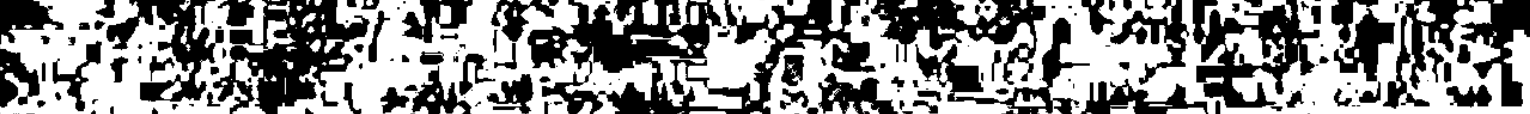
2.

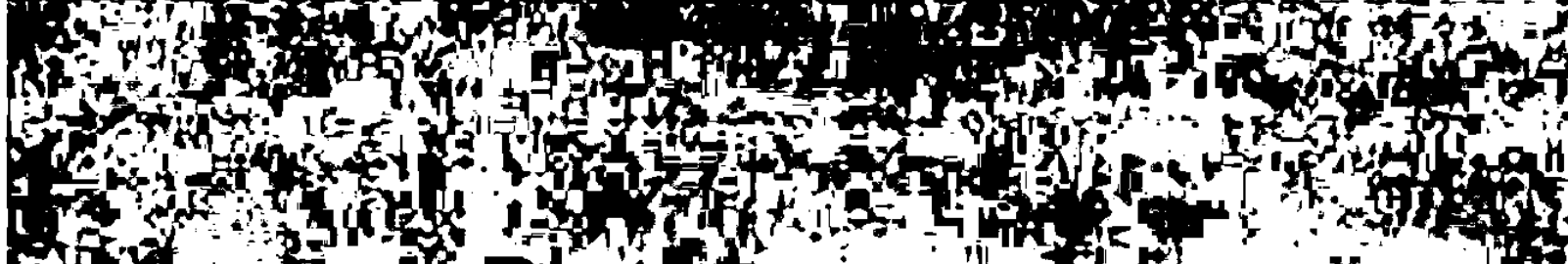
and 4.

if

intistis.

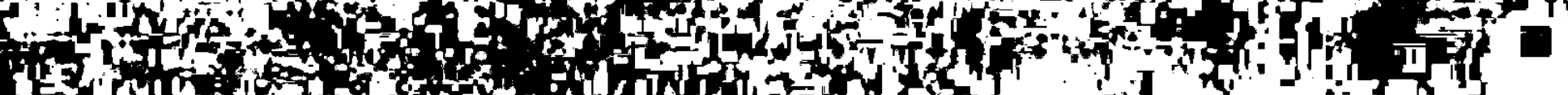
H.

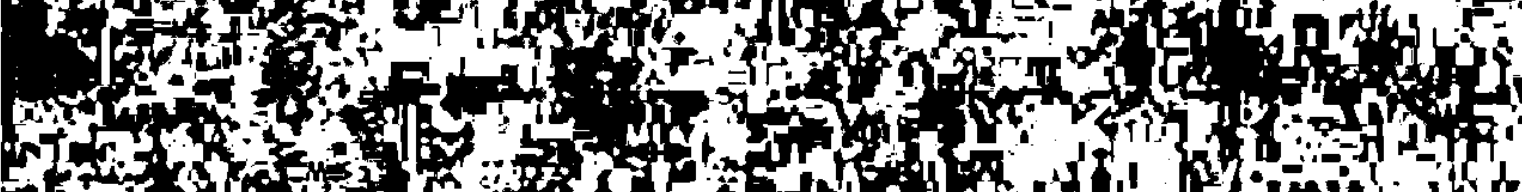

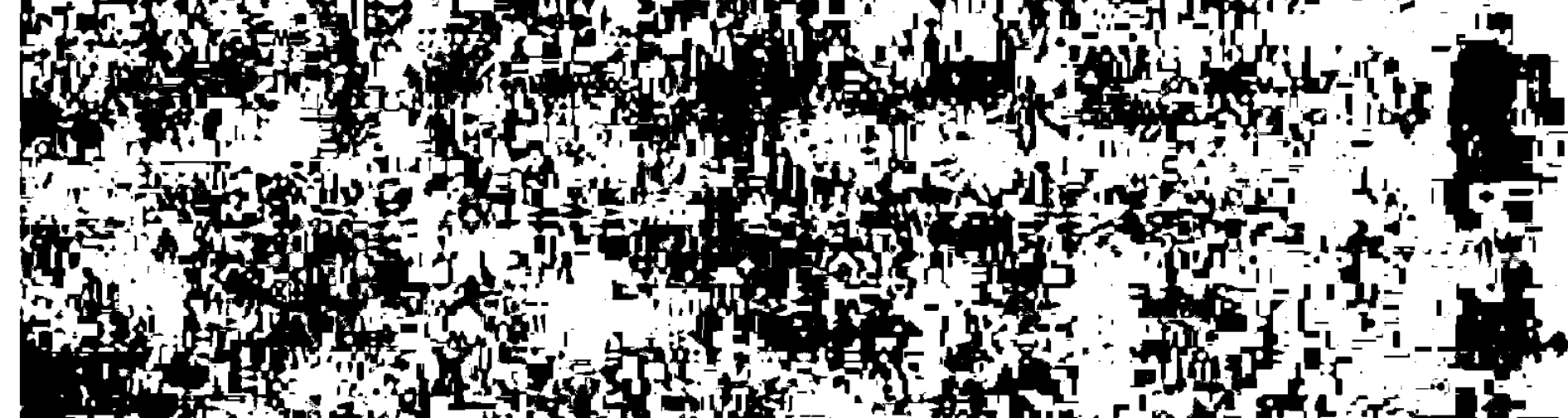
(2)

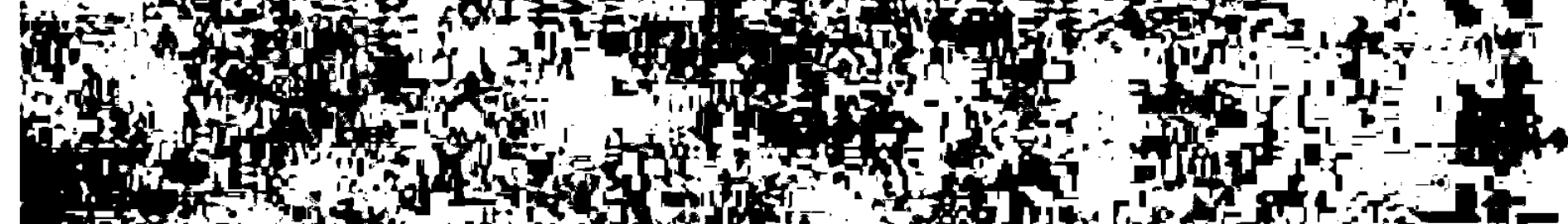

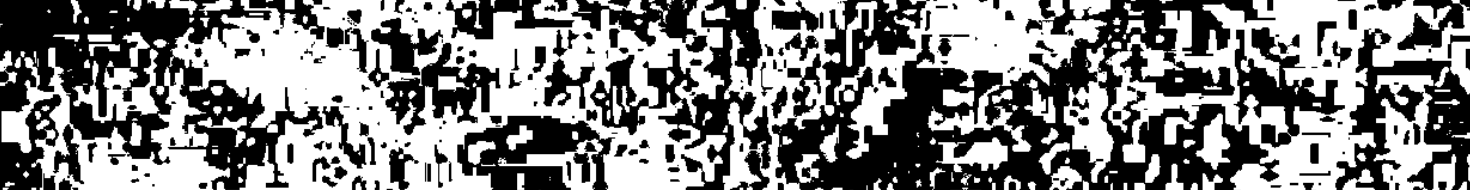

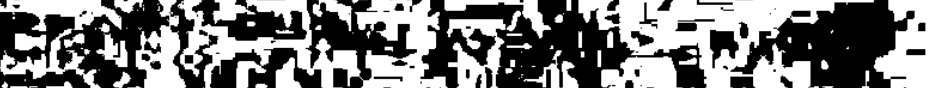

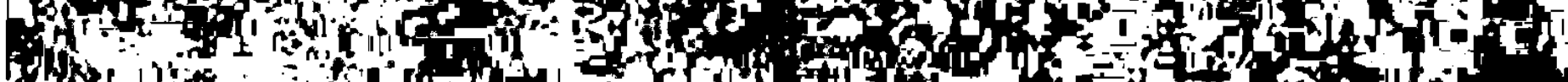

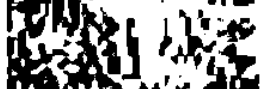
6.

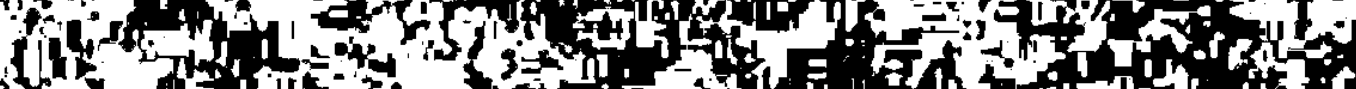

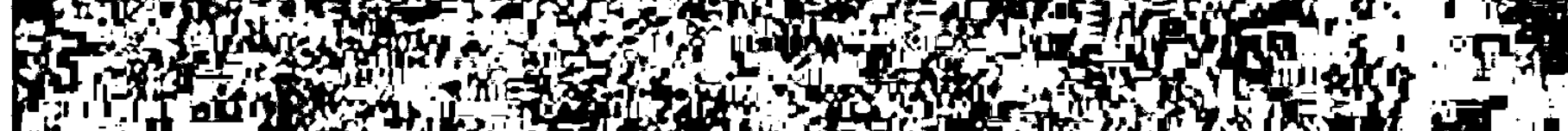

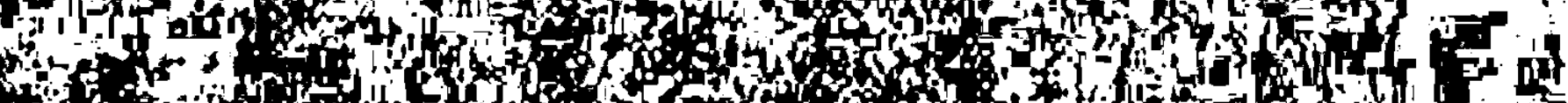

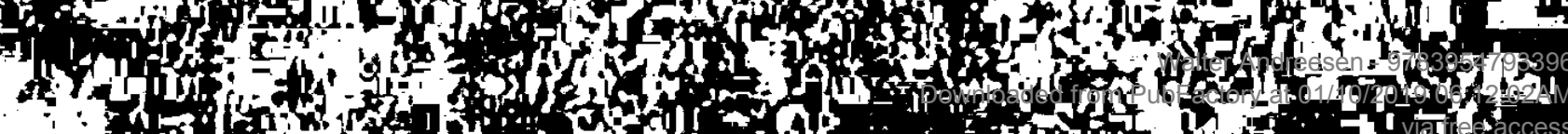

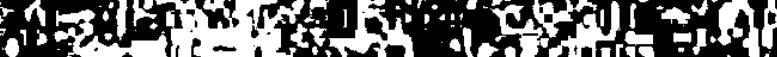


An den Beginn der vorliegenden Arbeit wurde ein relativ breit ausgearbeiteter "Algemeiner Teil" gestellt. Dies lat kein Zufall, vielmehr zwang uns die Materie dazu. Also nicht die Kenntnis der Translationelehre Teanières lieB uns nach geeigneten Forschungsobjekten im Altrussischen euchen 138, sondera das unbefriedigende Ergebnis, wollte man das Thema "Konkurrenz zwischen possessivem Genitiv und Possessivadjektiven" zur alleinigen Thematik elner Untersuchung machen, fuhrte uns mit Notwendigkeit zu einer Theorie wie derjenigen Tesnières, womit das Thema glelchzeitig elnen weiter umfasenden Rahmen bekam. Dies bedingte allerdings auch den Verzicht auf detallliertes kingehen auf manche binzelprobleme, wollte man den roten Faden, der durch das sehr breite Thema "Translation o > A" gegeben war, nicht verlieren.

Ferner zwang die Lösung von den bisherigen Adjekt1vbezelchnungen im Russischen - nicht einmal Kiparsky konnte sich von solchen Bezeichnungen wie "Possessivadjektive" trennen - und der Versuch elner Neugliederung, auch hier nicht Detailfragen, sondern generelle Fragen in den Vordergrund zu stellen, wobei allerdings nicht gesagt werden soll, daß etwa Detallprobleme nlcht des öfteren brgieblgke1t zeigten. So konnte etwa gezelgt werden, daß weder Genitiv noch Dativ noch Komposition ( $\$ 32-38$, 8 30-55) gegenuber der suffixalen Translation echte Konkurrenten sind, ferner, daß häufig bei mehreren konkurrierenden Translativen durch die Wahl elnes Translative der semantische Gehalt des Transferendums fixiert werden kann ( 8 83-85), das die Wahl des nominalen bzw. pronominalen Endungsmorphems offensichtilch auch ein Faktor bei der suffixalen Translation sein kann (\$ 80-82), daB bel manchen suffixalen Able1tungen durch translation double die entstandenen Translationsprodukte hohen Ähnlichkeitscharakter haben ( 8 80-82) u. dgl.

138Den zitierten Aufsatz H. Wissemanns uber adjektivbildende Translative lernte ich erst relativ spat kennen. 
Gewisse Translative - etwa die am häufigsten gebrauchten Suffixe-bn-, -bsk- widerstrebten andererseits einer generelien Kategorisierung, so daß Einzelbeobachtungen hier in den Vordergrund ruckten und die bei diesen Adjektiven beobachtete Prafigierung gesondert behandelt wurde (\$ 68-79). BewuBt wurden die Adjektive nicht isoliert untersucht, sondern in threr Funktion als Determinanten innerhalb syntagmatischer Fugungen, was des öfteren zu der Erkenntnis fürte, daB die Wahl des Translativs bisweilen nicht ganz unabhängig ist vom Regens dieser Fügung (vgl. $\S 23-30, \S 38-39, \S 70-73, \S 82-84)$. Die von uns vorgeschlagene Kategorisierung der Adjekt1ve (vgl. B I, II, III) war so uberhaupt nur möglich.

Der Nutzen einer solchen Arbeit ergibt sich nicht nur aus der Lösung einiger Probleme, sondern insbesondere aus dem Ausfindigmachen neuer Aufgaben, die zu lösen wert waren. Dies gilt etwa für die Probleme der Beziehungen zwischen Wortbildung, Syntax und Morphologie, wobei Ansatzpunkte bel Tesnière und Martinet hier dargelegt wurden, beachtenswert sind insbesondere auch die zitierten Aufsätze von M. Dokulil. Die Kolle des Gebrauchs pronominaler oder nominaler Endungsmorpheme bei der Bildung von Adjektiven in Altrussischen könnte man durchaus in einem eigenen Aufsatz untersuchen. Ferner die Translation $O$ ) A (insbesondere die suffixale) bei bitlehnungen im Kussischen, präfigierte Adjektive, Adjektivkomposita, die stilistische Funktion von Adjektiven. SchlieBlich ware es wert, eine größere Untersuchung iber die kolle translativbildender Suffixe bei der semantischen Fixierung substantivischer Transferenda zu unternehmen. Fur das Altrussische hat te dies mehr exemplarischen wert. Gerade aber bei der Erlernung der modernen russischen Sprache zeigt sich sehr oft Unsicherheit bei der Wahl zwischen mehreren konkurrierenden Translativen, belspielsweise etia bel solchen Adjektiven, wie mirnyj, mirskij, mirovyj, mir-a, mir-u, $v$ mire u. dgl. Mit der genaueren, auch stilistischen Fixierung des semantischen Gehaltes der Transferenda in solchen Fallen wäre auch eine didaktische Aufgabe gelöst. 


\section{Literaturverzeichnie}

Quelien

Ipat'evskaja 18topis'. Polnoe sobranie russkich letopisej, Bd. II, Moskva 1962.

Izbornik 1076 goda. A N. Institut russkogo jazyka. Moskva 1965.

Lavrent'evskaja litopis'. Polnoe sobranie russkich letopieej. Bd. I, Moskva 1962.

Das Paterikon des Klever Höhlenklosters. Nach der Ausgabe von D. Abramovid neu herausgegeben von Dmitrif Tschizewskif. München 1964.

Povest' vremennych let. rodgotorka teksta D. S. Llchareva. Moskva, Leningrad 1950.

wörterbuicher

Berneker, E.: Slavischeo etymologisches Wörterbuch. Heidelberg 1908 - 1914.

Dal', Vladimir: Tolkovyj slovar' zivogo velikorusskogo jazyka. Bd. I - IV. Sanktpeterburg, Moskva 1913.

Machek, Václav: Etymologický slovnlk jazyka Zeského a slovenského. Praha 1957 ( 21968$)$.

Miklosich, Franz: Lexicon palaeosloventco-graeco-latinum. wien 1862 .

Pawlowaky, I. Ja.: Russisch-deutsches wörterbuch. R1ga 1911. 
Slovarb sovremennogo russkogo literaturnogo Jazyka.

17 Bde. Moskva, Leningrad 1950-1965.

Sreznevakif, I.I.: Materlaly dlja slovarja drevne-russkogo jazyka. Bd. I-III, Sanktpeterburg 1893-1903.

Vasmer, Max: Russisches etymologisches Wörterbuch.

Bd. I-III, HeIdelberg 1953-1958.

\section{Allgemelne Literatur und Grammatiken}

Admon1, A.: Strof nemeckogo jazyka. Moskva, Leningrad 1966.

BorkovskiJ, V. I.: Sintaksis drevnerusskich gramot. Moskva 1958.

Borkovskij-Kuznecov: Istorileskaja grammatika russkogo Jazyka. Moskva 1963.

Brugmann, K. und Delbruck, B.: GrundriB der vergleichenden Grammatik der indogermantschen Sprachen. Strabburg $1909 \mathrm{fr}$.

Buslaev, F. I.: Istortleskaja grammatika russkogo jazyka. Moskva 1959.

Coseriu, E.: Einführung in die strukturelle Linguistik. Vorlesung gehalten im us $1967 /$ I 968 a.d.Universität Tübingen.

Coseriu, E.: Einfihrung in die transformationelle Grammatik. Vorlesung gehalten Im SS I968 a.d.Universität Tübingen.

Dokul11, Milor: Zum wechselseitigen Verhältnis zwischen Wortbildung und Syntax. In: Travaux linguistiques de Prague 1, 1964, S. 215. 
Dokul11, M1lod, Zur Frage der Stelle der Wortbildung io Sprachsystem. In: Slovo a slovesnost XXIX, 1, 1968, S. 9.

Doroszewsk1, Witold: Zarys ogblnej klasyfikacjt znaczentowej sufiksbw w Jezykach skowiahskich. In: Sbornlk pracl I. s jezdu slavjanskfych filologú v Praze 1929, S. 505.

Doroszewski. Witold: Syntaktyczne podstawy szowotw6rstwa. In: Z polskich studiow slawistycznych. Seria 2. Jqzykoznawstwo. 1963, S. 65.

Gunther, E. und K.: Die Haupttypen der nominalen und verbalen Wortbildung im Russischen. In: 28. F. Slawistik 5 $(1960)$, S. 446 .

Grammatika russkogo jazyka I-III. AN SSSR. Moskva I960.

Hirt, H.: Indogermanische Grammatik I-VII. Heidelberg $1927-1937$.

Horecky, Jan: Sbmantická klasifikfcla zlozenfch slov. In: Studie ze slovanske jazykovłdy. J'raha 1958, S. 285.

Isacenko, A. V.: 0 vzajomnf́ch vzt'ahoch medzi morfologiou a derivfaciou. In: Jazykovedny Xasop1s VII, 1, 1953. S. 35.

Isatenko, A. V.: Die russische Sprache der Gegenwart. Teil I, Formenlehre, Halle 1962.

Issledovanija po sintaksisu staroslavjanskogo jazyka. Praga 1963.

Jelitte, Herbert: Probleme und Aufgaben einer strukturalist1schen Darstellung der altkirchenslavischen Deklination. In: Slovo 15-16, 1965, S. 298. 
Kiparoky, Valentin: Russische historische Grammatik I-II, Heldelberg I963 u. 1967.

Krugleveka, L.: Zur Geschichte des Gebraubhs des Genitive und Adjektivs in der russischen Literatursprache. Pinneberg 1947.

Kuznecov, P. S.: Oterki po istoriteskoj morfologit russkogo Jazyka. Moskva 1959.

Lomtev, T. P. o oterki po istorileskomu sintaksisu russkogo jazyka. Moskva 1956.

Makarova, S. Ja.: Vyrazenie prinadleznosti v russkom jazyke XI-XVII vv., Moskva 1952.

Marchand, Hans: Lxpanston, Transpostition and Vertration. In: La linguistique 1 (1967), S. 13.

Martinet, Andre: Grundzige der Allgemeinen Sprachwissenschart. Vom Verfasser autorisierte Ubersetzung aus dem Franzosischen. Stuttgart 1963.

Martinet, André A Functional View of Language. Oxford 1963.

Martinet, Andrb: La linguistique synchronique. Parts 1965.

Me1d, Wolfgang: Wortbildungslehre. Germanische Sprachwissenschaft. Herauggegeben von Hans Krahe. Bd. III, Berlin 1967.

Melllet, Andrb: Etudes sur l'itymologie et le vocabulatre du vieux slave. Parts 1902.

Me1llet. Andre und Vaillant, A.: Le slave commun. Parts 1934.

Miklosich, Franz: Vergletchende Grammatik der slavischen Sprachen. I-IV. Wien 1852 fr. 
Reformatok1f, A. A.: Vredenis $v$ jazykoznanie. Moskva I960.

Sprintak, Ja. A.: Oterk russkogo lotoribeskogo sintaksisa. Kiev 1960.

Schumann, Kurt: Die griechischen Lehnbildungen und Lehnbedeutungen im Altbulgarischen. Berlin 1958 .

Sachmator, A. A. S Sintaksis russkogo jazyka. Leningrad ${ }^{2} 1941$. Photowechan. Nachdruck The Hague 1963.

Sachmatov, A. A.: Istoriteskaja morfologija russkogo jazyka. Moskva 1957 .

Sansk1f, N. M.: Oterk1 po russkomu slovoobrazovan1ju 1 lokeikologil. Moskva 1959.

Tochernych, P. J.: H1storieche Grammatik der russischen Sprache. Halle 1957.

Vachek, Josef: K problemat1ce Eeskfch posesivnlch adjekt1v. In: Stud1e a práce lingulstickb I, 1954, S. 171.

Vaillant, A.: Grammaire comparbe des langues slaves I-III Lyon, Par18, 1950-1958.

Vezerka, Radoslavi Ke konkurenci adnominflniho genetivu a adjektivu. In: Sbornik praci filosofickb fakulty Brntnokb university VI (1957). Rada jazykovðdinh A 5, S. 25.

Vidnes, M.: 0 nekotorych izmenenijach $v$ pozicil vyrazentja prinadleznosti $v$ russkom jazyke XVIII-XIX vv. In: Voprosy jazykoznan1 ja 5 (1958). S. 99.

Hackernagel, J.: Genitiv und Adjekt1v. In: Mblanges de lingulstique offerts d F. de Saussure. Paris 1908. 
Widnäs, Maria: 0 vyrazenil prinadleznosti pritjazatel'nym prilagatel'nya 1 roditel'nym padezom prinadieznosti $v$ russkow jazyke XVIII-XIX vv. In: Scando-Slavica 4 (1958), S. 166 .

Hisemann, Heinz: Zur Problematik der Suffixbedeutung adjektivbildender Translative im Russischen. In: Slavistische Studien zum VI. Internationalon SlavistenkongreB in Prag 1968. Munchen 1968, S. 280.

Zimek, Rudolf: K chlpáf posesivnosti. In: Rusko-reské studie, 1960, S. 131 .

Zvenkov, G.: K postanovke problemy suffiksal'noj variantnosti. In: Kirgizskif Gosudarstvennyj Universitet. UEenye zapiski filologiteskogo rakulteta. Slavjanskij sbornik II (1963), S. 38 .

\section{Zu Adjektiven}

a) suffixal gebildete Adjektive

Brodowaka-Honowaka, Maria: Słowotwbrstwo przymiotnikbw w jęyku staro-cerklewno-slowlahskim. Krakbw, Wroclaw, Warszawa I960.

Bukatevil, N. I.: Glavnej8ie suffiksy prilagatel'nych $v$ drevnerusskom literaturnom jazyke. In: Trudy Odesskogo Gosudarstrennogo Universiteta. Seria fil. nauk 9 (1959). S. 157 .

Danilenko, V. P.: Obrazovanie katestrennych prilagatel'nych ot osnor imen sureestritel' nych pri pomozel suffiksor -at-, - Eat- 1 -ast-. In: Trudy instituta jazykoznanija 3 (1954). S. 120 .

Relter, Norbert: Die tunktion der Suffixe-j-, -bsk-, -bn1m Altkirchenslavischen. In: Die Welt der Slaven 12 (1967), s. 363 . 
Romanovakaja, V. D. Obrazoranie otnostel'nych prilagatol'nych r drovnerusakom jazyke. In: Trudy Instituta Jasykosnanija AN SSSR $3(1954)$, S. 32 .

Kudner, A. G.: Vnutrennie zakonomernost1 upotroblenije 1monnych 1 mostolmennych prilagatel'nych $\checkmark$ drevnerueskom jazyks. In: Slavia 26 (1957). S. 192.

Schnolder, Leszek\& Slowotwbretwo przymiotnikbw odrzeczomikowych * Jøzyku staroruok1m, Krak6w 1965.

Zemekaja, E. A. \& Ob osnornych proceoeach sloroobrasovanija prilagatel'nych $v$ ruookom literaturnom jazyko XIX $v$. In: Voprosy jazykoznani ja 2 (1962), S. 46 .

Zverkovakaja, N. P. \& Prilagatel'nye ouffikeant -or- 1 -ovbn- v drevnerusekom jazyke. Ins Iotorideakaja gramatika 1 loksikologija russkogo jazyka. Moskva 1962. S. 171 .

Zverkovokaja, N. P.: Parallel'noe obrazovanie prilagatel'nych - suffiksaml -bn- 1 -bsk- v drernerusakom jazyke. In: Isslodovanifa po latoriceskoj lekeikologil drevnerusekogo jazyka. Mookva 1964, S. 272.

Zverkovokaja, N. P. Parallel'nye prilagatel'nye ouffiksaml -ov- 1 -bn-. In: Lekeikologija 1 elovoobrazovanto drovnerusskogo Jazyka. Moskva 1966, S. 224.

Zwolihok1, P. \& Funkcja strukturalna oufiks 6 w -jb-, -ja-, -jo-. In: Biuletyn polokiego towarzystwa jqzykoznawczego 24 (1966), S. 197 .

b) nicht ouffixal gebildete Adjektive

Cooko, E. V.: Nojtralizacija padeknych protirostavlenij $v$ razvit11 bietemy oklonentja ataroslavjanskogo jazyka. In: Slvajanskoe jazykoznanie. Doklady sovetskoj 
delegacil. V. Mezdunarodny s-ezd slavistov. Moskva 1963. S. 273.

Dickenmann, Ernst: Die Nominalkomposition im Kussischen, Diss. Berlin 1933.

Guldenstubbe, 0 . $v_{\text {.: }}$ Gebrauch der Kasus im Altrussischen

In: Arch. F. s1. Philologie 38, 1923, S. 150, " $"$ 39, 1925, S. 235.

Jakobson, Romans Beitrag zur allgemeinen Kasuslehre. Ins Etudes dedibes au quatrième congrès de linguistique. Travaux du Cercle Linguistique de Prague 6 (1936). S. 240 .

Keller, Georg Siegmund: Das Asyndeton in den baltoslavischen Sprachen. Heidelberg 1922.

Makarova, S. Ja.: Roditel'nyj padez prinadleznosti $v$ russkom jazyke XI-XVII vv. In: Trudy instituta Jazykoznanija 3, 1954, S. 7 .

Mincova, A.: Za proizchoda na datelnija padez $v$ genitivna funkcija $v$ bolgarski ezik. Ins Slavistiten sbornik. Po slukaj $v$. mezdunaroden kongres na slavistite $v$ Sofija, 1963. S. 105.

Mrázek, R.: Datel'nyj padez $v$ staroslavjanskom jazyke. In: Issledovanija po sintaksisu staroslavjanskogo jazyka. Praga 1963. S. 225.

Tomson, A. I.: K voprosu o vozniknovenil rod.-vin. padeza v slavjanskich jazykach. In: Izvestija otdelenija russk. Jazyka 1 slovesnosti Imp. Akad. Nauk 13, 2 (1908), S. 281.

Veterka, Hadoslav: Genitiv data $v$ staroslovendting. In: Slavia 26 (1957), S. 31. 
VeEerka, Radoslavi Sintaksi bespredloznogo roditel'nogo padeza $v$ staroslarjanakom jazyke. In: Isoledoranija po sintaksiou staroslavjanskogo jazyka. Praga 1963, s. 183.

Esycrlacho

Gisot:=1blict: sk

Munchion 